\title{
Constraints on the pressure-temperature path for Belt-Purcell Supergroup metapelites from Snow Peak, northern Idaho
}

\author{
Sarah Elizabeth Johnson
}

Follow this and additional works at: https://researchrepository.wvu.edu/etd

\section{Recommended Citation}

Johnson, Sarah Elizabeth, "Constraints on the pressure-temperature path for Belt-Purcell Supergroup metapelites from Snow Peak, northern Idaho" (2015). Graduate Theses, Dissertations, and Problem Reports. 5895.

https://researchrepository.wvu.edu/etd/5895

This Thesis is protected by copyright and/or related rights. It has been brought to you by the The Research Repository @WVU with permission from the rights-holder(s). You are free to use this Thesis in any way that is permitted by the copyright and related rights legislation that applies to your use. For other uses you must obtain permission from the rights-holder(s) directly, unless additional rights are indicated by a Creative Commons license in the record and/ or on the work itself. This Thesis has been accepted for inclusion in WVU Graduate Theses, Dissertations, and Problem Reports collection by an authorized administrator of The Research Repository @ WVU. For more information, please contact researchrepository@mail.wvu.edu. 
Aquaponic Production of Lettuce (Lactuca sativa L.) Using Effluent from a Cold Water FlowThrough Aquaculture System

\title{
Gaylynn Elise Johnson
}

Thesis submitted to the Davis College of Agriculture, Natural Resources, and Design at West Virginia University in partial fulfillment of the requirements for the degree of:

\author{
Master of Science in Horticulture \\ Nicole Waterland, Ph.D., Chair \\ Sven Verlinden, Ph.D. \\ Kenneth Semmens, Ph.D. \\ Division of Plant and Soil Sciences \\ Morgantown, West Virginia \\ 2014
}

Keywords: aquaponics, aquaculture, lettuce, quality, profitability, trout

Copyright, 2014 - Gaylynn Elise Johnson 


\begin{abstract}
Aquaponic Production of Lettuce (Lactuca sativa L.) Using Effluent from a Cold Water FlowThrough Aquaculture System
\end{abstract}

Gaylynn Elise Johnson

Aquaponics is the integration of aquaculture (the rearing of fish) and hydroponics (the conventional method of soilless farming). Effluent produced from the production of fish can be utilized as a source of nutrients by plants for growth in a hydroponic subsystem. Lettuce (Lactuca sativa) is an economically important vegetable crop that can be grown aquaponically. However, the suitability of lettuce for production in cold water flow-through systems (FTSs) is poorly described. The purpose of this study was to evaluate the growth, market rating, and nutrient uptake of lettuce grown in a cold water FTS. Three objectives were established to examine lettuce production and nutrient uptake in this system: (1) evaluate various lettuce types and cultivars for performance; (2) compare two harvesting methods, cut-and-come-again (CC) and once-and-done (OD), for lettuce yield and market quality; and (3) assess year-round lettuce production in a pilot scale setting for lettuce yield, nutrient removal, and economic viability.

To achieve the first objective, 28 lettuce cultivars were grown for ten weeks in aquaponic, hydroponic, and spring water conditions and lettuce productivity was compared. Productivity was calculated by grams of harvestable fresh weight divided by the number of growing weeks until harvest $\left(\mathrm{g} \cdot \mathrm{wk}^{-1}\right)$. Twenty cultivars, $71 \%$ of cultivars, showed no difference in productivity between the hydroponic and aquaponic treatment; Only one cultivar, 'Speckled Amish', had higher productivity in the aquaponic treatment compared to the hydroponic treatment. Productivity in the eight of the cultivars was greater in the hydroponic treatment compared to those same cultivars grown in the aquaponic treatment. Maturity of lettuces grown in the spring water control, which had little nutrient to sustain continual growth, was the only rating description with observed differences. Maturity ratings in the spring control were immature.

While lettuce types and cultivars were evaluated in objective one, two harvesting methods, CC and OD, were evaluated in objective two. With the OD strategy, all plants in the system are sown and harvested at the same time. After harvest, a successive crop is sown to complete a new growing cycle. With the CC strategy, all plants in the system are sown, but cut above the meristem at harvest to allow for continued growth. A successive crop is sown when the crop no longer continues to produce. There was no difference in productivity between the harvesting methods during the first two harvests. CC productivity declined significantly after that period. Productivity in the CC treatment was better when growing time was incorporated into the final harvest.

In addition to evaluation of lettuce types and cultivars and harvest strategies for lettuce production in FTS, seasonal effect on lettuce production and nutrient removal was investigated 
in objective three. Production was maintained year-round and highest yields was obtained during the spring and summer months. Higher light levels were favored for lettuce production during spring and summer. Optimal light intensity for lettuce production is between 400 to 600 $\mu$ moles $\mathrm{m}^{-2} \mathrm{~s}^{-1}$. It was intriguing to see how year-round production of lettuce impacted removal of excessive nitrogen $(\mathrm{N})$ and phosphorus $(\mathrm{P})$ perhaps owing to significantly low nutrient concentrations in the influent of the FTS. Removal of $\mathrm{N}$ and $\mathrm{P}$ from the FTS was insignificant. Removal rates for $\mathrm{N}$ ranged between -0.004 to $0.03 \mathrm{mg} \cdot \mathrm{L}^{-1}$, while the highest removal rate for $P$ was $0.0009 \mathrm{mg} \cdot \mathrm{L}^{-1}$. The FTS was found to profitable only when high yields and weekly harvesting were achieved. Low harvest amounts during the winter rendered year-round production unprofitable. Higher yields were needed in during months with higher light intensity to supplement that low yields during the winter. 


\section{Acknowledgements}

First and foremost, I would like thank God, who has blessed me with many opportunities and gives me the strength to proceed when there is doubt. To my parents, Tiffani and Garland Johnson, whose love and support have made it possible for me to achieve my goals. Thank you to the USDA for funding and to Dr. Barton Baker for assistantship extension.

Thank you to Dr. Nicole Waterland for extending an invitation to visit West Virginia University and encouraging me to begin my research in aquaponics. I would like to thank my committee members, Dr. Sven Verlinden and Dr. Kenneth Semmens, for their patience, assistance in structuring the proposal and seminars, and providing feedback in their respective areas of horticulture and aquaponics, respectively. Thank you to Matt Ferrell for maintaining the facilities and helping with harvest and planting on my farm days. Thank you to Dr. Karen Buzby for analyzing water samples. Thank you to the staff of Reymann Memorial Farm, headed by Jerry Yates, for the cookouts, laughter, and support. The latter experiments could not have been possible without the help of Gene Jacobs, who constructed and maintained equipment, and for his enthusiasm for aquaponics.

I wish to send my thanks to Dr. Kenneth Ryan for helping me with statistical analysis within hours of sending an email. Thank you to Crop King and researcher, Dr. Natalie Bumgarner for answering countless amounts of questions about hydroponics. I would like to send another special thank you to Dr. Constinia Charbonnette, who has mentored and uplifted me throughout these years. Lastly, to my colleagues, friends, and the staff of entire college, thank you for the encouragement, laughter, and support. 


\section{Table of Contents}

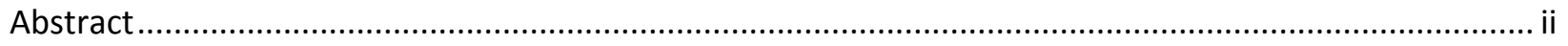

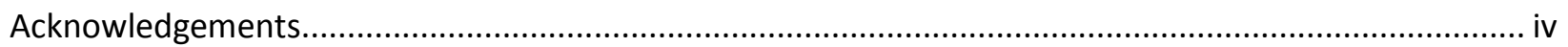

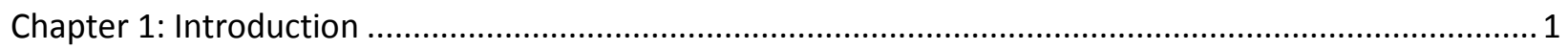

Chapter 2: Literature Review ......................................................................................................

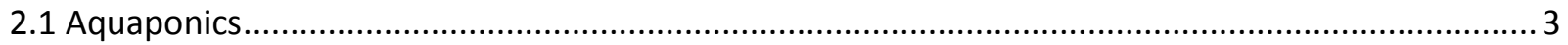

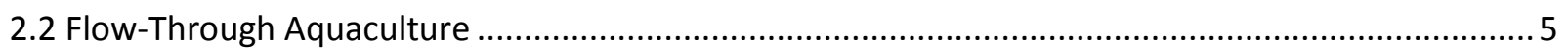

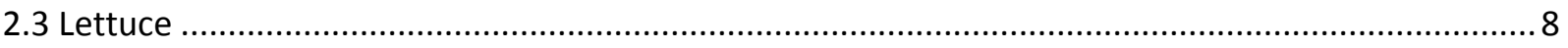

Chapter 3: Evaluating various lettuce types and cultivars for performance in a flow-through system ......11

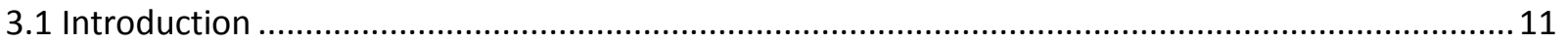

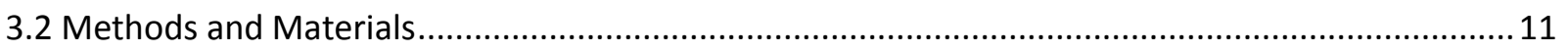

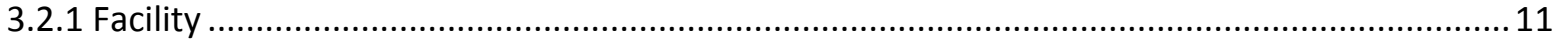

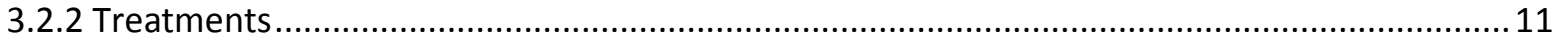

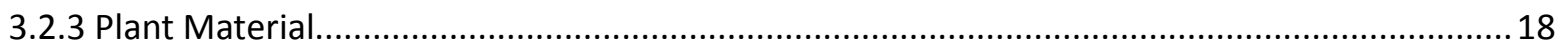

3.2.4 Stand Establishment and Productivity ............................................................................ 19

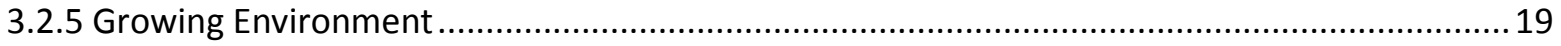

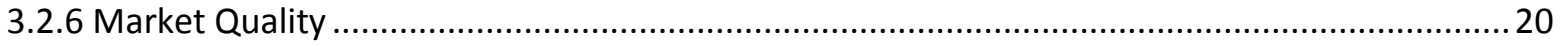

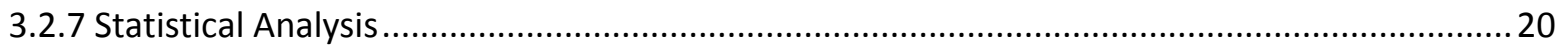

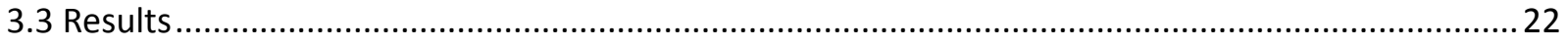

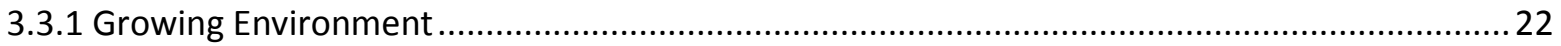

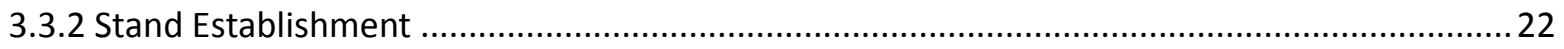

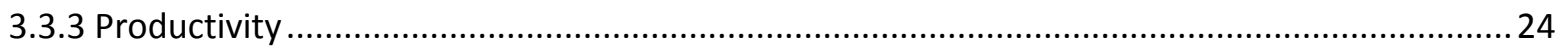

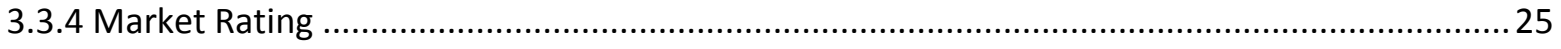

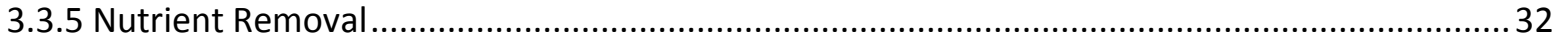

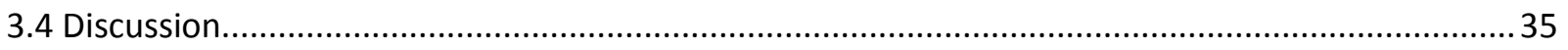

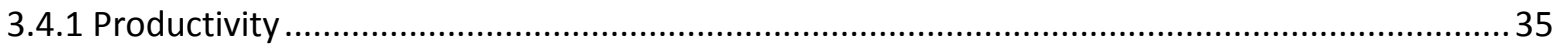

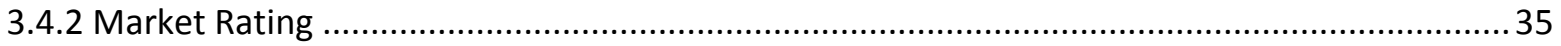

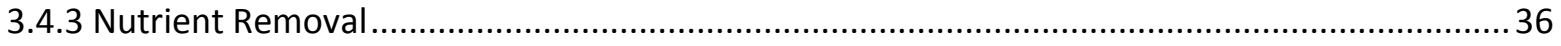

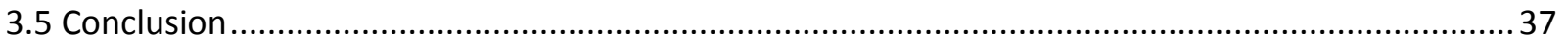




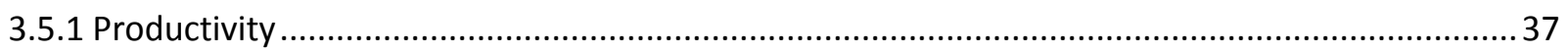

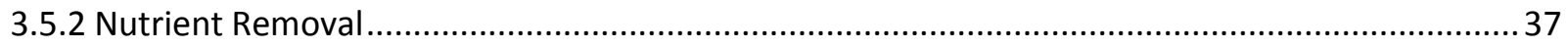

Chapter 4: Comparing two methods of harvesting lettuce for productivity, nutrient removal, and market

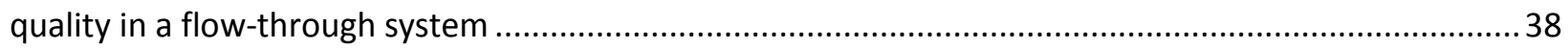

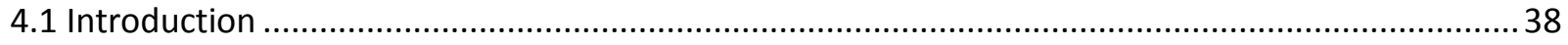

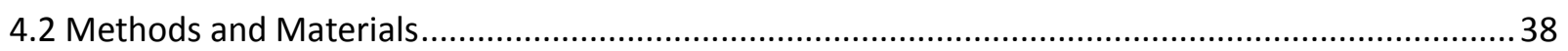

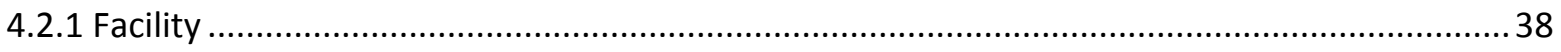

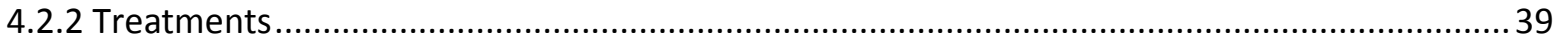

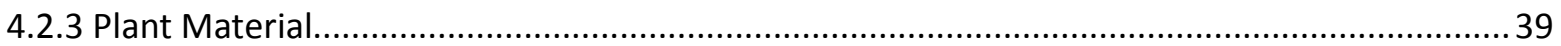

4.2.4 Stand Establishment and Harvesting Methods.................................................................. 41

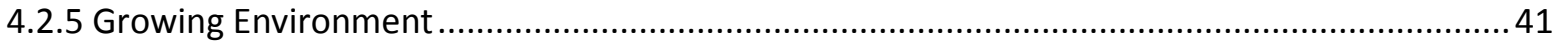

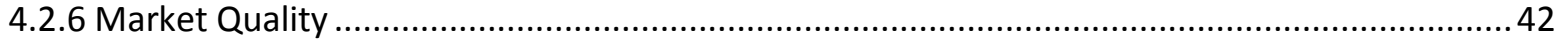

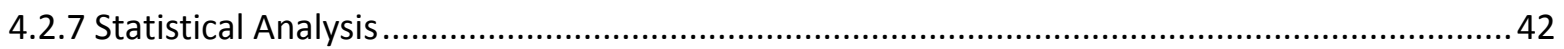

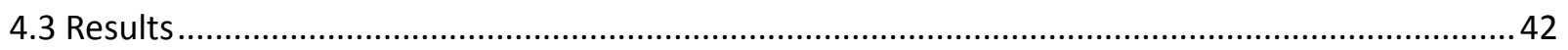

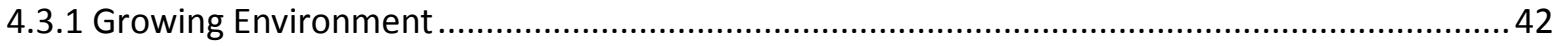

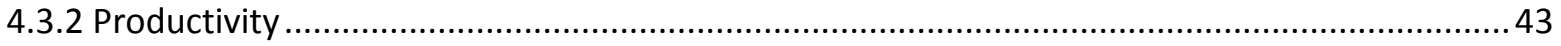

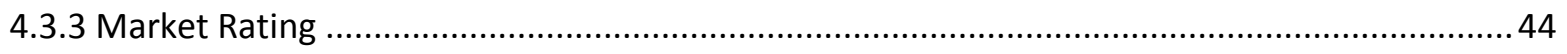

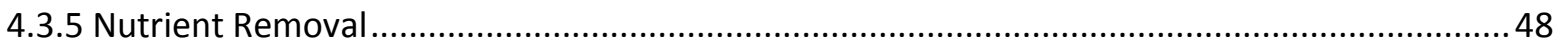

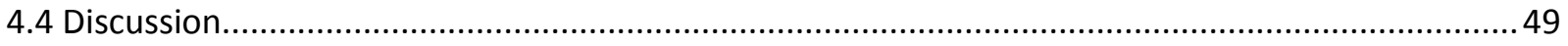

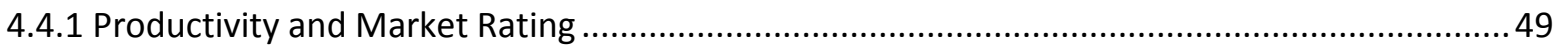

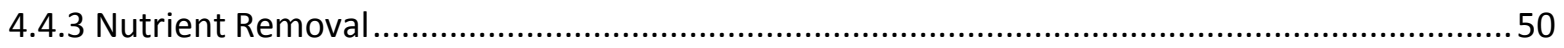

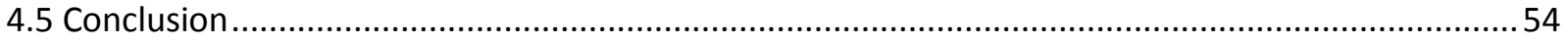

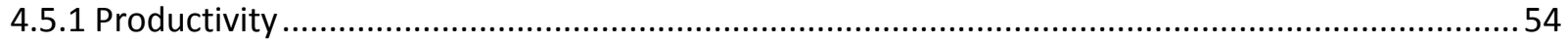

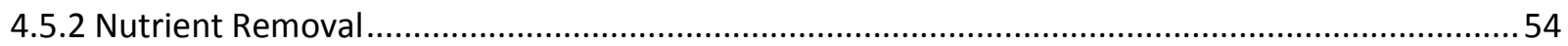

Chapter 5 Evaluating Year-Round Lettuce Production in a Pilot Scale Setting for Yield and Economic

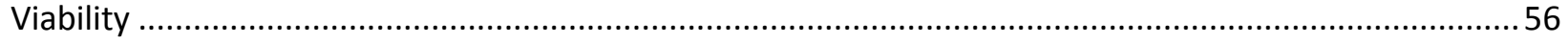

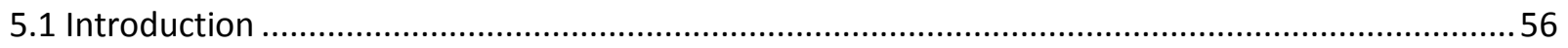

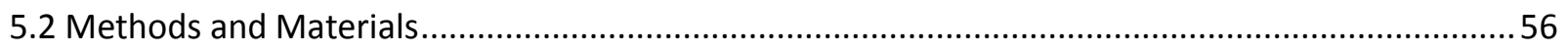

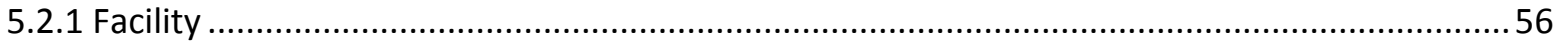

5.2.2 Plant Material, Stand Establishment, and Harvesting .......................................................5 57

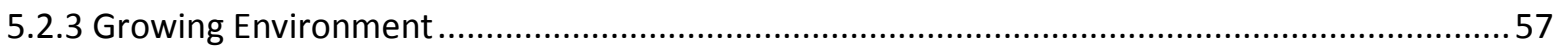

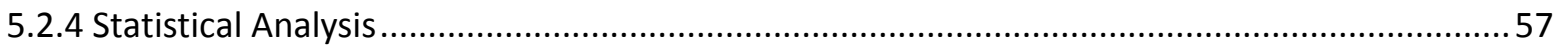




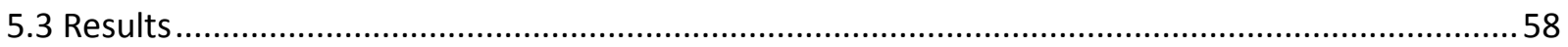

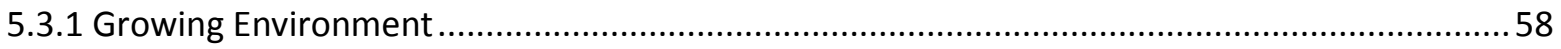

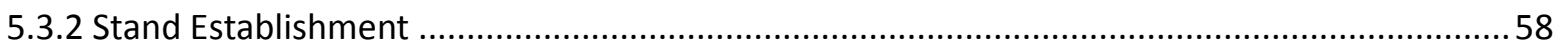

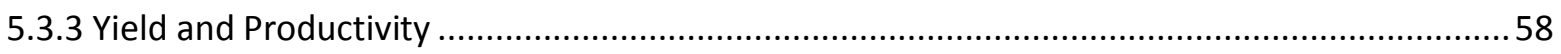

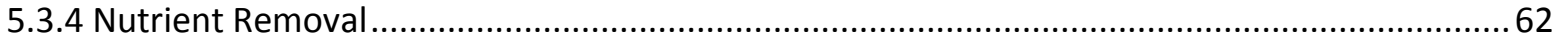

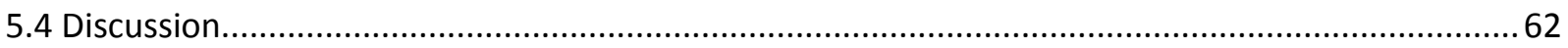

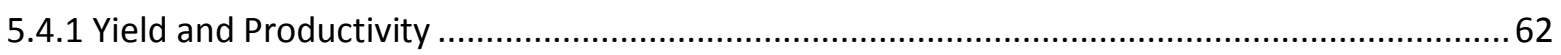

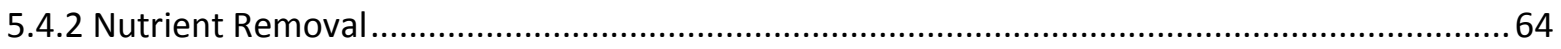

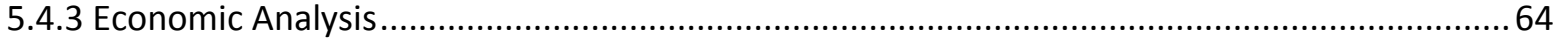

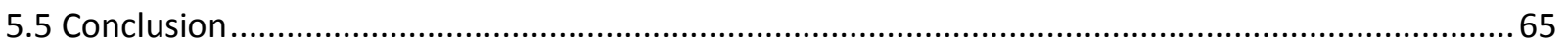

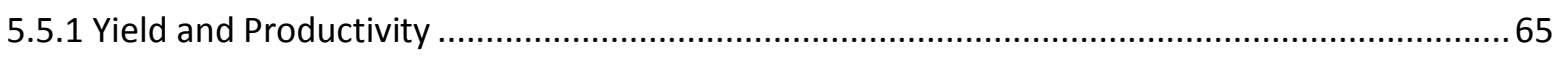

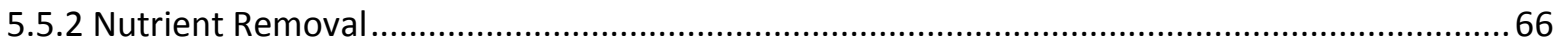

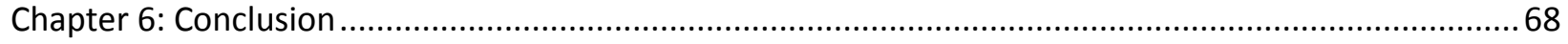

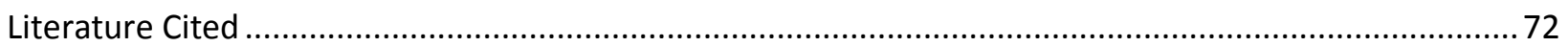




\section{Chapter 1: Introduction}

Aquaponics, a combination of fish farming and soilless plant farming, is growing in popularity and gaining attention as an important and potentially more sustainable method of food production (Love et al., 2014). In an aquaponics system, effluent containing nutrients generated through the feeding and growing fish is passed through the rooting zone of plants (Rakocy, 2007; Buzby and Lin, 2014). Plants use the nutrients to support growth and represent an additional commodity for the farmer. Warm water, recirculating aquaponic systems (RAqS) have been well documented (Blidariu et al., 2013; Diver, 2006; Graber and Junge, 2009; Martins et al., 2010; Rakocy et al., 2006; Rakocy 2007; Tyson et al., 2008; Tyson et al., 2011). The cold water FTS at Reymann Memorial Farm (RMF), located in Wardensville, WV, does not fit this pattern. The spring feeding the system supplies approximately, 400 gallons per minute (gpm) or $1.51 \mathrm{~m}^{3} \cdot \mathrm{min}^{-1}$, and diluted nutrient concentrations, $<1 \mathrm{mg} \cdot \mathrm{L}^{-1}$. By comparison, flow rate can be 10-100 times lower and nutrient concentrations 10-100 times higher in RAQS (Blidariu et al., 2013). Plant roots have reduced contact time with lower nutrient concentrations in a FTS compared to a RAQS. Average water velocity in Rakocy et al., (1997) was $43 \mathrm{gpm}\left(0.16 \mathrm{~m}^{3} \cdot \mathrm{min}^{-}\right.$ ${ }^{1}$ ), while total ammonia-nitrogen (TAN) values averaged $1.47 \mathrm{mg} \cdot \mathrm{L}^{-1}$, approximately five times higher than TAN concentrations in the FTS at RMF. Nitrate-nitrogen concentrations of $11 \mathrm{mg} \cdot \mathrm{L}^{-1}$ (Lennard and Leonard, 2004) and 22 and $26.7 \mathrm{mg} \cdot \mathrm{L}^{-1}$ (Rakocy et al, 2003) have been reported.

In a FTS, the predominant strategy is to remove settable solids from the effluent rather than suspended solids or soluble nutrients (IDEQ, 1998). These soluble nutrients, although diluted, are discharged into lakes, rivers, or streams, and contribute to eutrophication of the aquatic environment. Aquaponic production may be a way to help producers remove soluble 
nutrients from the effluent while producing a second cash crop. However, long-term plant yield and nutrient removal capabilities of a FTS at both a small and pilot scale are poorly described. The latest census shows that $68 \%$ aquaculture facilities in West Virginia are using FTS (USDANASS, 2014). Sales from West Virginia's 19 aquaculture facilities increased 45\%, from $\$ 1.15$ million in 2005 (USDA-NASS, 2007) to \$1.6 million (USDA-NASS, 2014) in 2012. An abundance of water resources, topography, and close proximity to eastern markets, give West Virginia (WV) a unique opportunity for growth (Viadero, 2005). Results from this line of research may assist current aquaculture operations in determining if the addition of an aquaponic component would benefit their operation. 


\section{Chapter 2: Literature Review}

\subsection{Aquaponics}

Aquaponics is the mutually beneficial integration of aquaculture and hydroponics to simultaneously produce animal and plant products (Love et al., 2014). Hydroponics is a plant culture technique, which enables plant growth in a nutrient solution with the mechanical support of inert substrate (Blidariu and Grozea, 2011). Aquaculture is the husbandry of aquatic plants and animals and includes recirculating aquaculture systems where fish are reared in a controlled environment (Timmons and Ebeling, 2010). Nutrients, by-products that can be used to produce plant crops, are released into the water as fish digest feed and excrete ammonia $\left(\mathrm{NH}_{3}\right)$ through their gills and feces; $\mathrm{NH}_{3}$ also enters the system from the decomposition of organic matter. Plants have the capacity to remove nutrients from wastewater and convert them to metabolic products which could be toxic to the fish (Rakocy, 2010). Conventional hydroponics uses chemical fertilizers as the nutrient source for plant growth, while aquaponic production utilizes fish waste, in a potentially economical and sustainable system for the agriculture sector (Blidariu and Grozea, 2011)

Many economically important vegetables and flowering plants can utilize the ammonia released from fish production for their growth (Rana et al., 2011). However, the most commonly grown plants are leafy greens such as lettuce and herbs (Oziel and Oziel, 2013). Lettuce and herbs make excellent crops because of high market prices and short production cycles (Rakocy et al., 2006). These crops also have low to medium nutritional requirements and are well adapted to aquaponic systems (Blidariu and Grozea, 2011). The production of fruiting crops is more difficult than leafy crops because the nutrient demands of the plant change 
during different stages of plant growth (Roosta and Hamidpour, 2011). Once the plant starts setting fruit, it required more calcium, magnesium, and potassium (Roosta and Hamidpour, 2011). Foliar application (Roosta and Hamidpour, 2011) of these nutrients or stocking the system with more fish to increase nutrient concentration in the effluent (Blidariu and Grozea, 2011) are needed to produce a fruiting crop.

Aquaponics applies methods developed by the hydroponics industry (Love et al., 2014). Hydroponics is a system of cultivating plants in water, in the absence of soil, where nutrients required for plant growth are provided through the water by means separation of a nutrient solution (Guadagnin et al., 2005). Plants are grown in a controlled environment where nutrient solution supply, electrical conductivity $(\mathrm{EC}), \mathrm{pH}$, and temperature are monitored and regulated by the grower (Vallance et al., 2011). The most common hydroponic systems employ an ebband-flow media beds, nutrient film technique (NFT), or a floating raft hydroponic system (Adler et al., 2006; Tyson et al., 2011). In an ebb-and-flow, or media bed system, the nutrient solution is pumped from a reservoir into the growing medium, flooding it with solution for a short period, which flows out of the rooting medium back into the reservoir (Jones Jr., 2005). The media provides support for the plant (Adediran, 2005). Expanded clay, gravel, peat, perlite, rockwool, sand, volcanic rock, and vermiculite are examples of such media used in systems (Jones, 2005). The NFT method uses a thin film of water typically flowing down a narrow channel, with the plant roots partially submerged in the water film (Lennard and Leonard, 2006). In a raft system, plants are set in small holes and supported by a raft floating on a nutrient solution with the plant roots extending into the solution (Jones, 2005). 
There is debate about the best approach for raising crops in aquaponic systems because published comparison of crop production methods are rare (Love et al., 2014). However, two studies, published by Lennard and Leonard $(2004,2006)$, suggests that the choice of production system affects both crop production and nutrient removal. Lennard and Leonard (2004) found that lettuce yields to be higher in aquaponic systems with constant flow (e.g. FTS) because plant roots were completely inundated and in constant contact with the nutrient effluent. The higher contact time of roots in the nutrient effluent provides more opportunities for the plant to assimilate nitrate. Lennard and Leonard (2006) found lettuce yields significantly higher in gravel beds compared to floating raft and NFT systems. However, lettuce yields in the floating raft system were significantly higher than the NFT system. Nitrate uptake was significantly higher in the floating raft and gravel bed systems and was related to the complete inundation of the plant roots in the nutrient effluent. The NFT system was $20 \%$ less efficient. However, removal of phosphate was significantly lower in the floating raft system suggesting complete inundation of roots in the nutrient effluent had no relation of phosphate removal. The study suggests that plant productivity, and thus phosphate removal, is dependent by the nutrient(s) present in the lowest supply. Phosphate uptake may be increased by supplying the nutrients that are in the shortest supply for sustained plant growth.

\subsection{Flow-Through Aquaculture}

Aquaculture is the practice of rearing, growing, or producing aquatic plants and animals in water in managed water systems (Meade, 1989) Flow-through systems (FTSs) involve the continual flow of high water volumes through a tank (either circular or rectangular) or a raceway (a long, narrow tank) (Adler et al., 2000; Snow et al., 2012); these systems are most 
commonly used production system for salmonids such as rainbow trout (Oncorhynchus mykiss) (Snow et al., 2012). Clean water is typically directed in a single pass through the production unit (Blidariu and Grozea, 2011) and the wastewater is discharged directly into receiving bodies of water (Viadero et al., 2005). Nutrients are diluted and make mechanical treatment of particulate matter the primary focus of wastewater treatment. Biological treatment in combination with mechanical treatments has been suggested as a way to reduce both soluble and particulate effluent nutrient fractions (Sindilariu et al., 2007). Plants have been used to as a wastewater treatment in wetlands (Blidariu and Grozea, 2011). Plant production associated with FTS may be a way to treat soluble nutrients.

The aquaculture facility at Reymann Memorial Farm operates as a cold water FTS producing trout (Fig. 1). Spring water was collected as surface run-off and flowed by gravity through trout raceways before being pumped into the aquaponic greenhouse. The water first flowed into a head-box within the building containing trout raceways. The head-box did not contain any fish and delivered the flow to the raceways in parallel. Each raceway was $30 \mathrm{ft}$ by 3 $\mathrm{ft}$, with water $3 \mathrm{ft}$ deep supplied with a flow of about $175 \mathrm{gpm}$. Water flowed in parallel in each stream through a series of four raceways where Rainbow Trout (Oncorhynchus mykiss) were housed and fed. Each of the eight raceways had a quiescent zone form which fish were excluded and solid waste would settle. Periodically, accrued solid waste would be removed from these quiescent zones. From the tail box, the effluent is pumped into the high tunnels $(\mathrm{HT})$, where lettuce production occurs. The lettuce uses the soluble nutrients in the effluent, which is then discharged into a retention pond for further settling of particulate matter. 


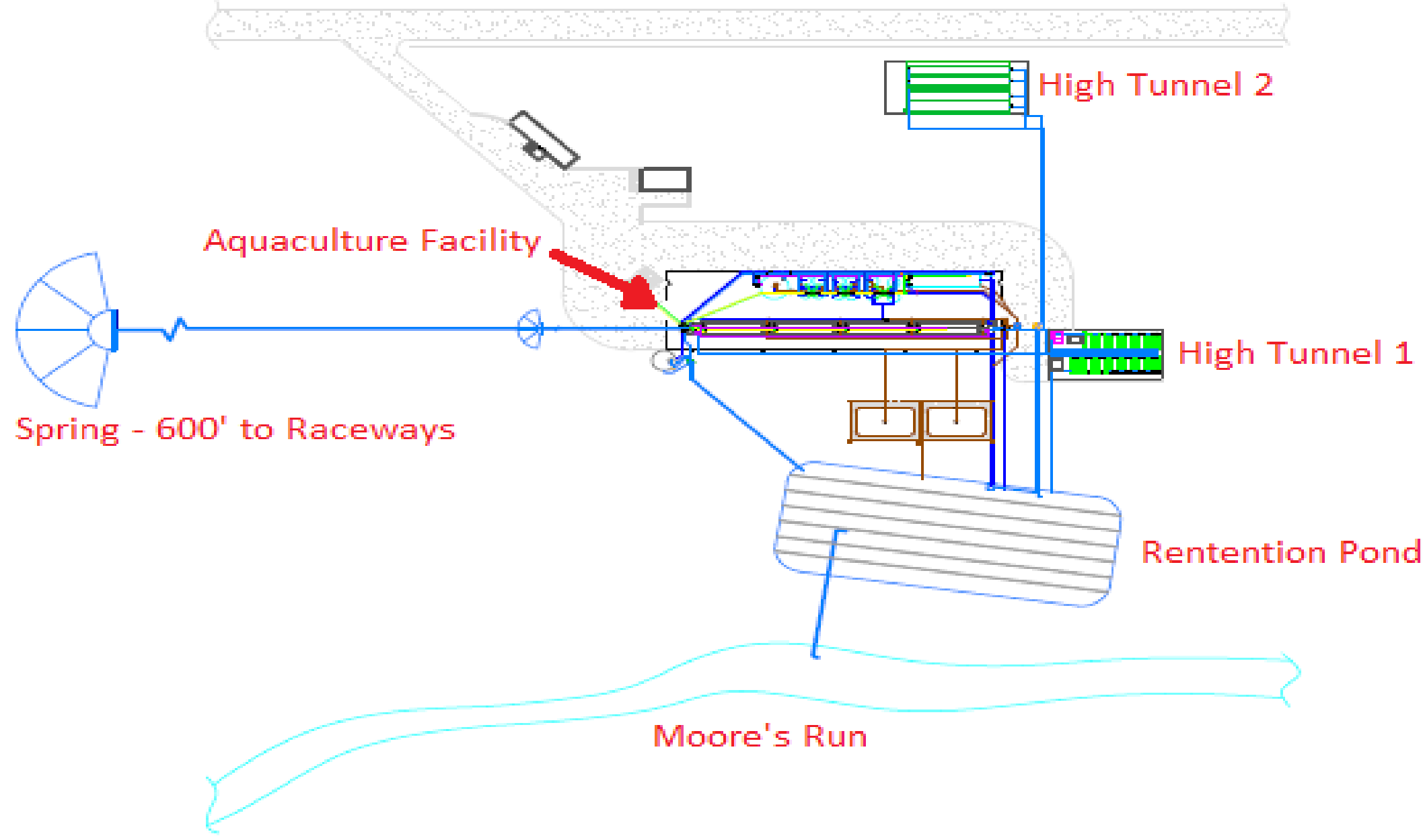

Figure 1. A diagram of the WVU Reymann Memorial Farm's aquaponic facility in Wardensville, WV. Spring water was gravity fed into the aquaculture building from a spring located $600 \mathrm{ft}$ away. Effluent from the aquaculture building was pumped into two high tunnels (HT) for aquaponic production of lettuce (Lactuca sativa). Cultivar trials (Objective 1) and harvesting evaluation (Objective 2) were assessed in HT1, while pilot scale production was conducted in HT2. The effluent water was released into a retention pond for the settlement of additional solid and soluble waste before discharge into Moore's Run Creek. 


\subsection{Lettuce}

Lettuce is one of the most important salad crops worldwide (Lee et al., 2012) and is the most widely consumed vegetable in the U.S. with a wholesale value of \$1.7 billion (Wu et al., 2011). It is a cool season crop with an optimal temperature range between 13 to $16^{\circ} \mathrm{C}$, but it can tolerate temperatures as low as $-2^{\circ} \mathrm{C}$ (Borrelli et al., 2013). As a cool season crop, lettuce has the potential for production in flow-through systems (FTSs). It is grown as a leafy vegetable and is usually consumed raw (Caliskan et al., 2014), commonly found in salad mixtures and sandwiches (Mou, 2008).

The cultivation of lettuce is preformed through traditional, organic, and hydroponic systems (Gomes Neto et al., 2012). Current USDA statistics do not separate lands, greenhouses, and high tunnels designated for traditional, organic, or hydroponic lettuce production. The traditional method is characterized by the cultivation of lettuce in the soil with the use of fertilizers and pesticides (Gomes Neto et al., 2012). Organic agriculture has emerged as an alternative to highly mechanized agriculture and avoids the use of synthetic pesticides, agrochemicals, fertilizers, and growth regulators (Gomes Neto et al., 2012). The United States is the largest producer of lettuce as a salad crop, producing $22 \%$ of the world's lettuce supply on only $13 \%$ of the production area (Mou, 2008) ${ }^{1}$. Approximately 4.4 million tons of lettuce is produced in the United States (Wu et al., 2011). Types grown in the U.S. include crisphead (head), cos/romaine, loose leaf (leaf), and butterhead (Mikel, 2007).

Crisphead lettuce forms a dense, tightly compact head with crisp, light green leaves and is widely available for the spring market because of its ease of transportation and storage

\footnotetext{
${ }^{1}$ China is the largest lettuce producer and accounts for about half of the world's total production and area, but lettuce is produced primarily for stems (Mou, 2008).
} 
(Saleh et al., 2009). The outer leaves are bright to dull green and progresses to a whitish or creamy yellow towards the center (Mou, 2008). 'Iceberg' is an example of the Batavia cultivar within the crisphead type (Mou, 2008) and is the most popular lettuce in terms of production, consumption, and export (Tudela et al., 2013). Romaine or cos lettuce has elongated, coarse, and relatively crisp textured leaves with prominent, broad mid-veins (Mou, 2008). Heads have an upright stature and are loaf-shaped, resulting in either a closed (heart) or open top (Mou, 2008). Leaf lettuces form a bunch or rosette of leaves that may have broad, elongated, or lobed shapes, like oak leaves, with smooth or frilled margins; Leaf texture ranges from crispy to soft (Mou, 2008). Butterhead lettuces produce a smaller less compact head than the crisphead type; leaves are broad, crumpled, relatively thin, and tender with a soft oily texture (Mou, 2008).

'Iceberg' lettuce has captured the most significant portion of the spring-cut market (Tudela et al., 2013) as the principle lettuce in prepared salads (Martinez-Sanchez et al., 2011); prepared salads are one of the most popular ready-to-eat (RTE) products in the U.S. However, consumer demand for softer leaves with variations in taste, shape, and color is increasing (Martinez-Sanchez et al., 2011). Lettuce cultivars offer a great diversity of color, shapes, sizes, and texture (Mou, 2008) that can meet consumer demand. In addition, increasing awareness about the health benefits of lettuce, as well as other fruits and vegetables, has led to an increase in consumption. The pro-health properties of lettuce are attributed to its low caloric value and large supply of vitamins (Zlotek et al., 2013). Lettuce is also considered an important source of dietary antioxidants (Myung-Min et al., 2009), which play an important role in appearance, flavor, and nutrition (Chon et al., 2012). Dietary antioxidants have been reported 
to reduce the risks of cardiovascular disease, cancer, and aging by protecting against free radical-mediated damage (Kenny and O'Beirne, 2009). These antioxidants are secondary metabolites and classified as anthocyanines, which causes the red pigmentation. 


\section{Chapter 3: Evaluating various lettuce types and cultivars for performance in a flow-through}

system

\subsection{Introduction}

This objective sought to compare productivity in aquaponic and hydroponic system, the more traditional form of soilless production. The nutrient concentration in hydroponics is higher and productivity was expected to be significantly higher. Twenty-eight (28) cultivars of lettuce (Table 1) were selected to provide diversity in the flow-through system (FTS) at Reymann Memorial Farm (RMF).

\subsection{Methods and Materials}

\subsubsection{Facility}

This experiment was conducted between August 15 and October 24, 2013 within HT 1

(Fig. 1), a structure measuring $26^{\prime}$ wide $\times 40^{\prime}$ long. HT 1 housed $11-4^{\prime}$ wide $\times 8^{\prime}$ long $\times 10.5^{\prime \prime}$ deep beds constructed of $3 / 4$ " plywood (Fig. 2A). A total of seven beds were used for this experiment. Each bed was subdivided into three, $15^{\prime \prime} \times 7^{\prime}$ channels. The channels were lined with Raven Industries' Dura-Skrim, R-Series, 20 mil, white polyethylene liner (Model R20WW;

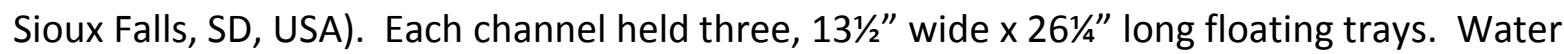
entered through a valve at the inlet and drained at the outlet. Flow rate was adjusted to 1.4 gpm $\left(0.005 \mathrm{~m}^{3} \cdot \mathrm{min}^{-1}\right)$ with 3/8" aperture (Dyer, 2006).

\subsubsection{Treatments}

Each channel was setup to have one of two treatments, aquaponic or hydroponic, and a spring water control (Fig. 3). The hydroponic treatment always remained in the middle channel and was flanked by either the aquaponic treatment or spring water control. Construction of 
the plumbing system limited the ability to have all three treatment contained in seven of the beds. Valves to each bed only allowed for either water from the aquaculture facility or spring to run individually, not simultaneously. Water in the hydroponic channels was circulated to distribute the fertilizer and to avoid heat retention and oxygen depletion. A barrel system was assembled to circulate the water in the hydroponic treatment (Fig. 4; Fig. 5). The barrel plumbing system was constructed using a 20 -gallon and a 55-gallon drum, pex-piping, and a submersible 350 gph utility pump (Danner Mfg. Inc., Supreme Classic Model 3, Islandia, NY).

Table 1. A List of 28 lettuce (Lactuca sativa) cultivars selected for evaluation in a cold water flow-through system

\begin{tabular}{l|rr}
\hline \multicolumn{1}{c|}{ Type and subtype } & Cultivar \\
\hline \multirow{2}{*}{ Bibb } & Green & Red \\
Butterhead & Winter Density (25) & Rhazes (26) \\
Leaf & Bambi (27) & Speckled Amish (28) \\
& Adriana (1) & Red Cross (2) \\
Lolla Rossa & Rex (3) & Vulcan (18) \\
& Two Star (17) & Red Sails (20) \\
Oakleaf & Waldmann's Dark Green (19) & Dark Rossa (10) \\
& Livigna (9) & Natividad (12) \\
Romaine & Bionda (11) & Red Saladbowl (14) \\
& Sulu (13) & Garrison (16) \\
Summer Crisp & Baby Oakleaf (15) & Outredgeous (22) \\
& Green Forest (21) & Flashy Trout Back (24) \\
& Jericho (23) & Magenta (6) \\
\hline
\end{tabular}

These 28 lettuce cultivars fall with the seven types and subtypes of lettuce including Bibb, butterhead, leaf, lolla rossa, oakleaf, romaine, and summer crisp. Numbers in sets of four (1-4, $5-8$, etc.) were randomly drawn and assigned to the different type and subtype. Individual (1, 2, $3,4)$ numbers were then assigned to each individual cultivar for placement in the channels. 
A.

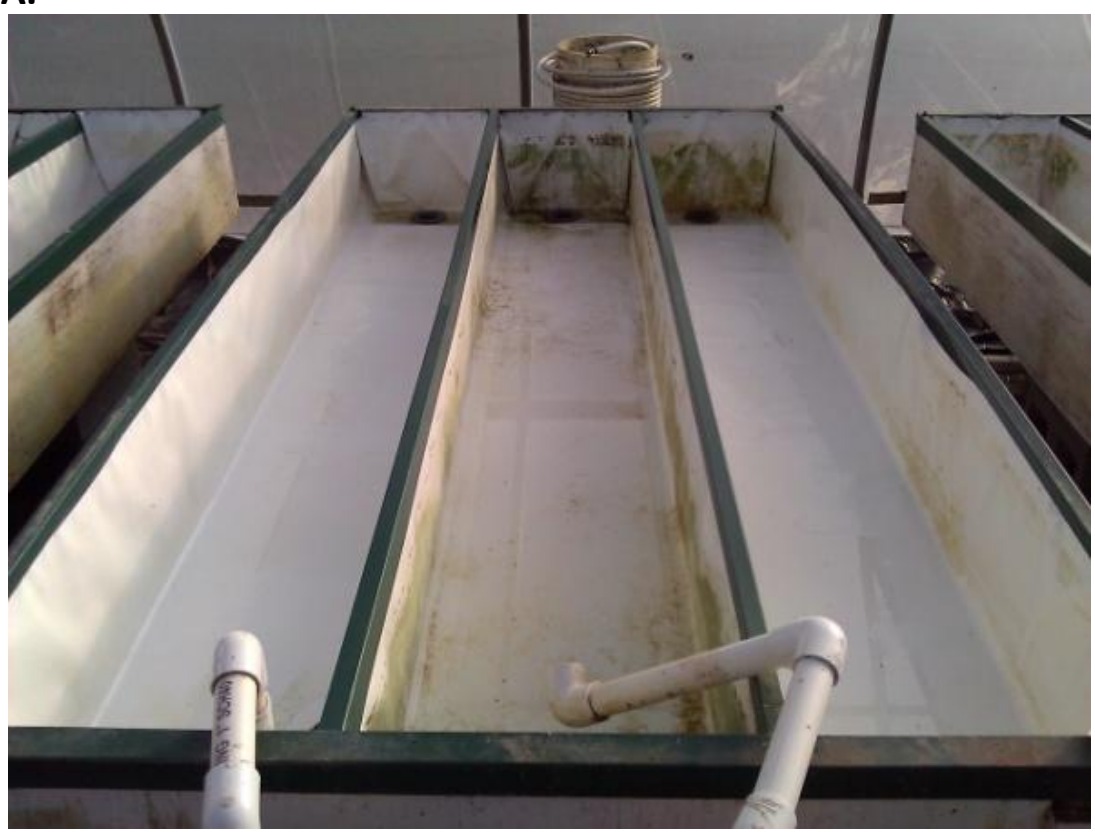

B.

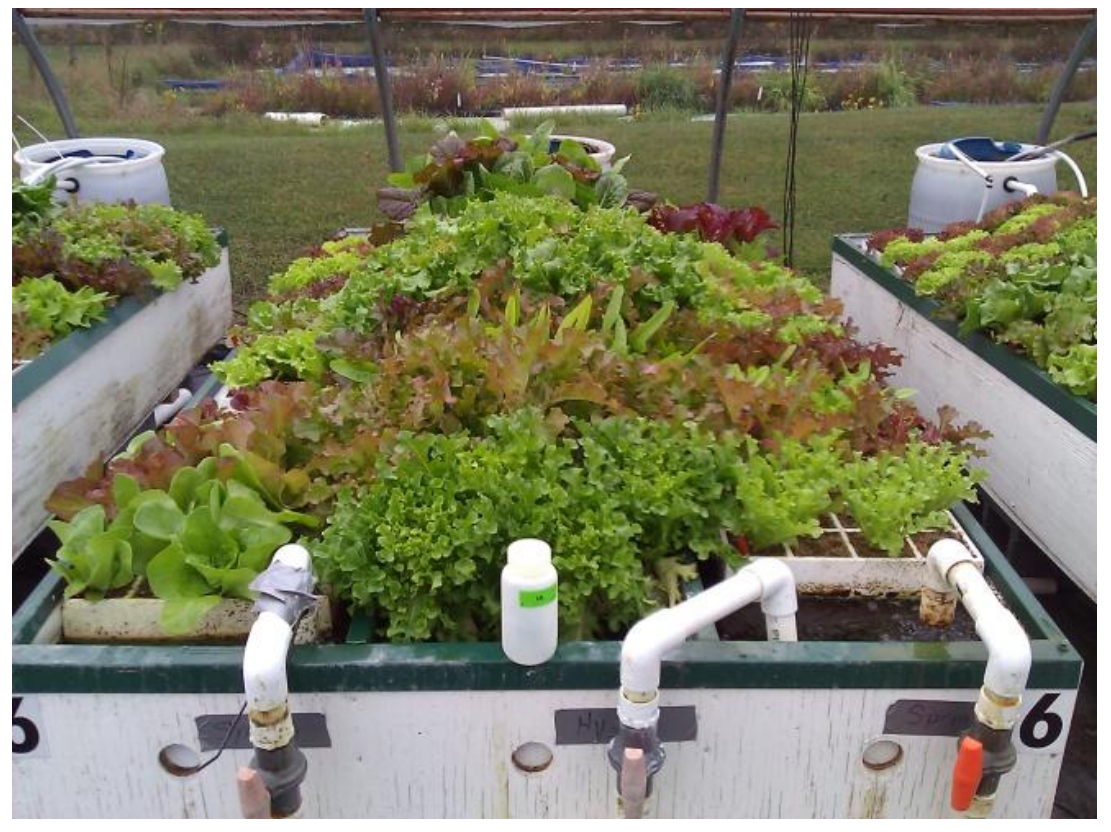

Figure 2. Image A shows an empty bed with three channels in HT 1. The channels were constructed 1/4" plywood and lined with white, polyethylene liner. Each channel held three, 32celled styrofoam trays, which were used to cultivate the 28 lettuce cultivars listed in Table 1. Image $B$ represents a bed that a hydroponic treatment in the middle channel, flanked by two spring treatments in October 2013. 


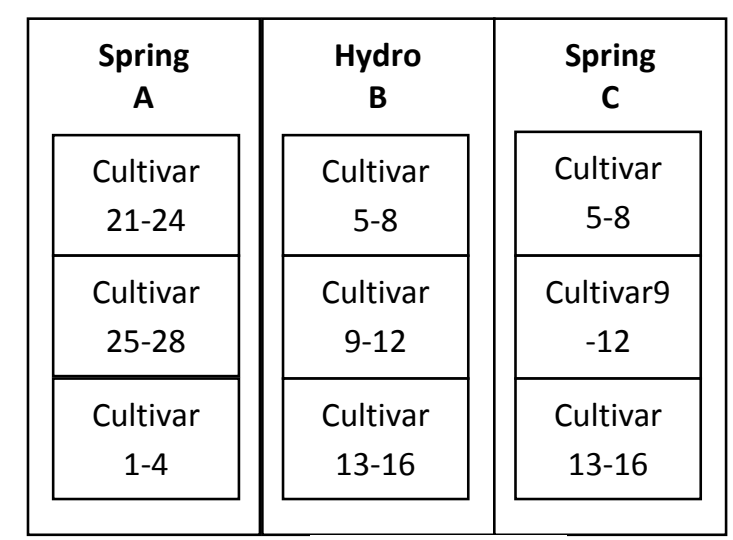

Bed 2

\begin{tabular}{|c|c|c|}
\hline $\begin{array}{c}\text { Aquaponic } \\
\text { A }\end{array}$ & $\begin{array}{c}\text { Hydro } \\
\text { B }\end{array}$ & $\begin{array}{c}\text { Aquaponic } \\
\text { C }\end{array}$ \\
\hline $\begin{array}{c}\text { Cultivar } \\
21-24\end{array}$ & $\begin{array}{c}\text { Cultivar } \\
21-24\end{array}$ & $\begin{array}{c}\text { Cultivar } \\
5-8\end{array}$ \\
\hline $\begin{array}{c}\text { Cultivar } \\
25-28\end{array}$ & $\begin{array}{c}\text { Cultivar } \\
25-28\end{array}$ & $\begin{array}{c}\text { Cultivar } \\
9-12\end{array}$ \\
\hline $\begin{array}{c}\text { Cultivar } \\
1-4\end{array}$ & $\begin{array}{c}\text { Cultivar } \\
1-4\end{array}$ & $\begin{array}{c}\text { Cultivar } \\
13-16\end{array}$ \\
\hline
\end{tabular}

Bed 3

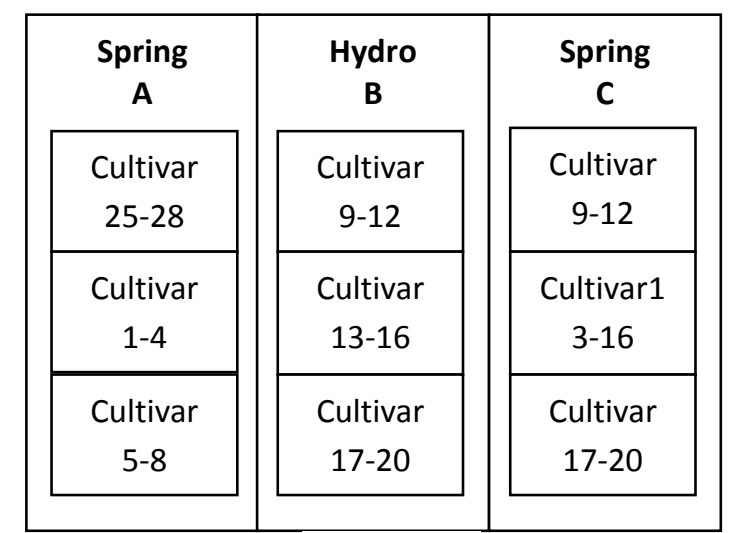

Bed 4

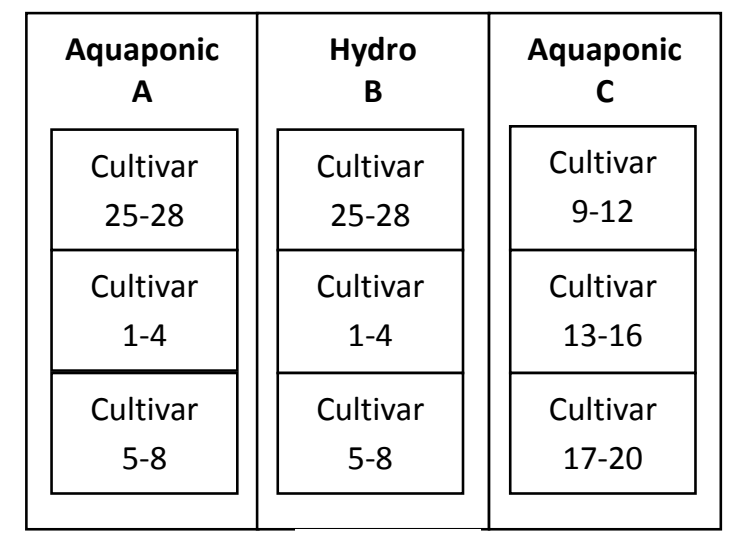

Bed 5

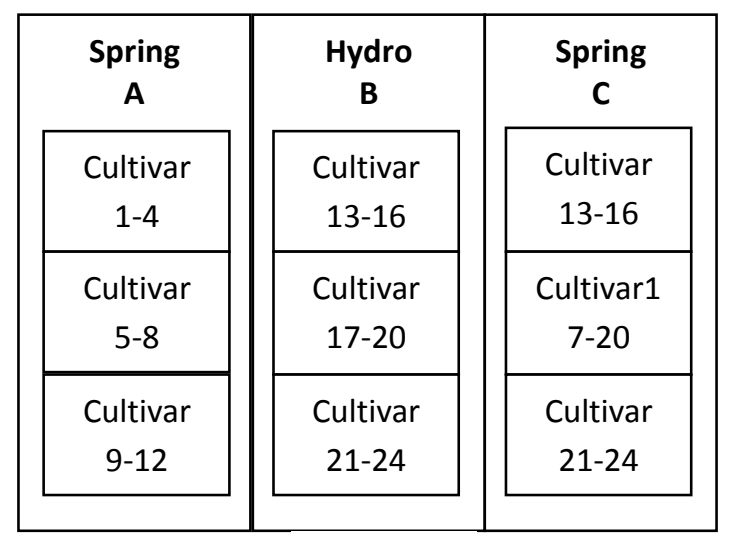

Bed 6

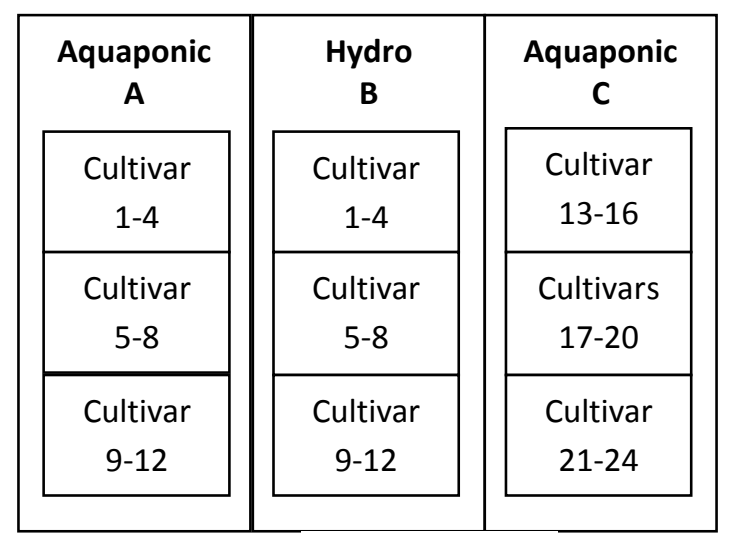

Bed 7

Figure 3. The experimental design layout for cultivar evaluation. Seven beds were used in order to achieve three replications of each cultivar for each treatment and spring water control. Numbers were randomly drawn and assigned to the different types and subtypes for placement into each treatment (Table 1). The hydroponic channel (B) was flanked by either the aquaponic treatment or spring water control. The first bed (not pictured) contained all three treatments with the third replication of cultivars $17-28$ in each channel. 


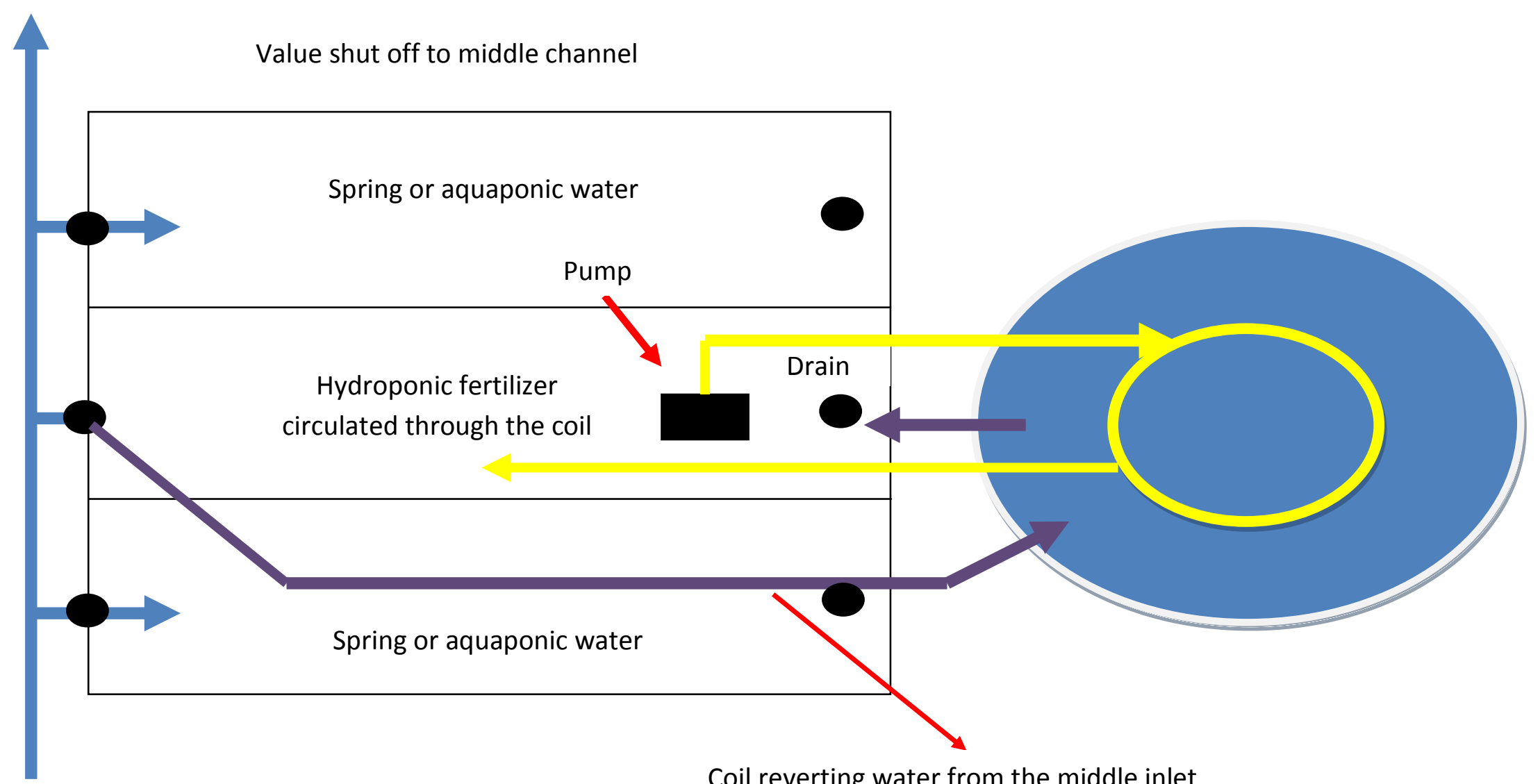

Coil reverting water from the middle inlet

Figure 4. A schematic of the barrel plumbing system used to maintain water temperature and circulate the hydroponic channels. The dark blue lines represent an open water system that was used to maintain cooler water temperatures in the recirculating hydroponic solution (yellow lines). Spring or aquaponic water was diverted from the middle inlet into a 55-gallon barrel and allowed to flow down the drain. Within the 55-gallon barrel, a 20-gallon barrel with piping holding the hydroponic solution was coiled around it. The hydroponic solution was pumped from the head of the channel around the 20 -gallon barrel and back to the tail end of the channel 
A.

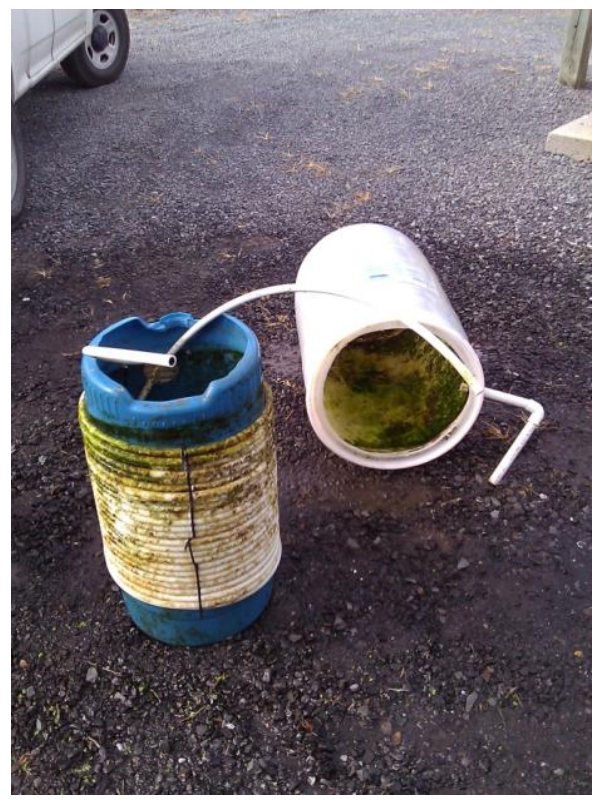

C.

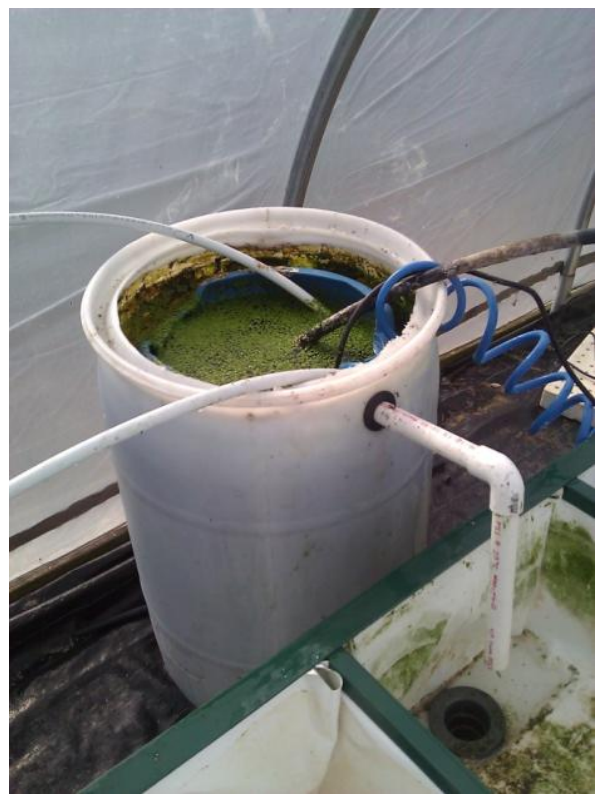

B.

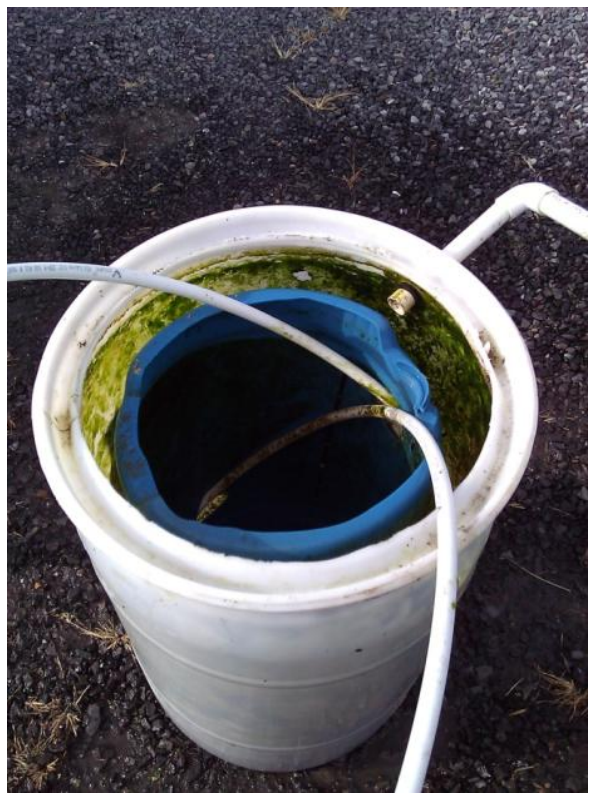

D.

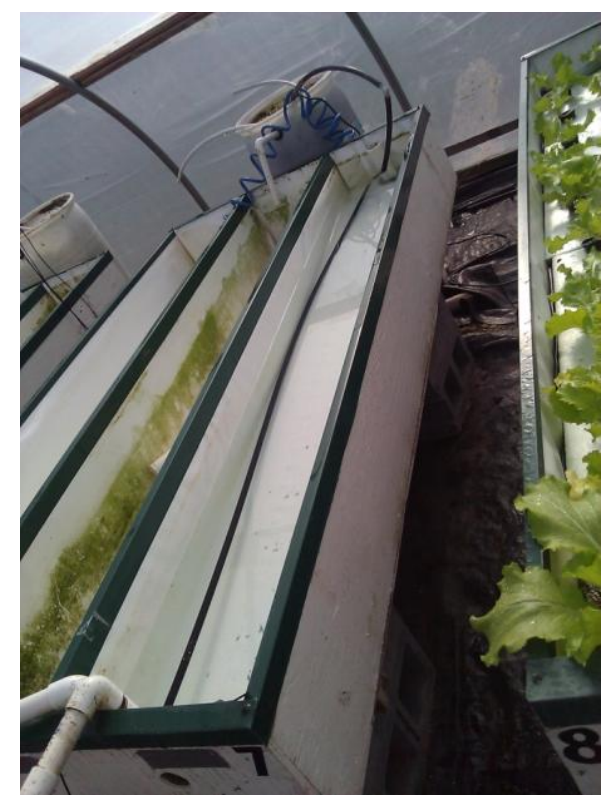

Figure 5. Images of the two barrel system used to maintain the water temperature in the hydroponic channels. Pex-piping was coiled around the 20-gallon barrel (blue) (A) and connected to a submersible pump (The hydroponic solution circulated within the pex-piping. The 20-gallon barrel was set inside a 55-gallon barrel (B), which was filled with cool water (C) from the middle inlet (D). The hydroponic solution circulating within the pex-piping was kept cool while the 20-gallon barrel rested inside the 55-gallon barrel. The piping used to fill the 55gallon barrel was lowered in flanking channels (D) to keep the cool water insulated as it traveled to the barrel. 
To generate the hydroponic treatment, water from the inlet was disconnected from each hydroponic channel. The hydroponic channels were filled with spring water and mixed with fertilizer. Hydroponic solution was pumped through pex-piping by a submersible $350 \mathrm{gph}$ utility pump. The pex-piping was coiled around the 20-gallon barrel and connected to the pump. The pump was submerged into the hydroponic channel and circulated the solution through the pex-piping and returned to the channel. The 20-gallon barrel was set inside the 55gallon drum, which was filled with cool water from the inlet. Another plumbing system was assembled from the inlet to the 55-gallon barrel to allow cool water to continuously enter the barrel. Water in the 55-gallon barrel would drain into the outlet after reaching a certain level in the barrel to prevent water overflow in the HT.

The nutrient recipe in the hydroponic treatment was formulated by Crop King Inc. (Lodi, $\mathrm{OH}$, USA) (Table 2). The formulation was based on laboratory results from on-site samples of the spring and were intended to reach macro and micronutrient targets specific for leafy crops in NFT systems. It was designed to be used as a two part stock concentrate to prevent precipitation of salts at these targets. A concentrated stock solution included calcium and potassium nitrates, iron chelate, potassium and magnesium sulfates, and potassium phosphate. The micro-mix included other micronutrients including manganese, zinc and sulfates, Solubor (boron), and sodium molybdate. Each hydroponic channel was setup as a closed system with the channel filled with spring water weekly and the desired fertilizer added. The water level was checked daily and additional spring water was added to maintain the same volume. They hydroponic solution was changed weekly to ensure minimal nutrient depletion. 
The conveyor production system (CPS) developed by Adler et al., 2000 was

implemented to ensure all plants were exposed to higher nutrient concentrations at the inlet and lower nutrient concentrations at the outlet by rotating trays. Trays were rotated weekly where the tray closest to the inlet was moved to the end of the channel, close to the outlet, while the preceding trays were pushed towards the inlet.

Table 2. Hydroponic Solution Formulation

\begin{tabular}{l|cc}
\hline \multicolumn{1}{c|}{ Nutrient } & \multicolumn{2}{c}{ Nutrient } \\
& Spring Water & Target Hydroponic Solution \\
Phosphorus (P) & 0.20 & $40-50$ \\
Potassium (K) & 1.20 & 300 \\
Nitrate-Nitrogen (NO3-N) & 0.00 & 200 \\
Calcium (Ca) & 29.80 & 190 \\
Magnesium (Mg) & 3.20 & $40-50$ \\
Zinc (Zn) & 0.01 & \\
Copper (Cu) & 0.00 & \\
Manganese (Mn) & 0.01 & \\
Iron (Fe) & 0.03 & \\
Sulfur (S) & 5.00 & \\
Boron (B) & 0.01 & \\
Sodium (Na) & 1.00 & \\
Chlorine (Cl) & 0.60 & \\
\hline
\end{tabular}

This formula was created using target concentrations used by conventional hydroponic lettuce (Lactuca sativa) growers using nutrient film technique (NFT) systems. The concentrations of existing elements in the spring water were subtracted from the target concentration to reach proper formulation for the hydroponic fertilizer.

\subsubsection{Plant Material}

Twenty-eight lettuce cultivars were selected for yield and market evaluation (Table 1).

These cultivars fell within seven types and subtypes including Bibb (a subtype of butterhead), butterhead, leaf, lolla rossa (a subtype of leaf), oakleaf (a subtype of leaf), romaine, and summer crisp (a subtype of crisphead). Seeds were hand-sown into 32-celled trays (Speedling, Inc., Model 32; Ruskin, FL, USA) using vermiculite (Therm-O-Rock East Inc., Grade 3A; New 
Eagle, PA) as the substrate. Cultivars were subdivided into color, green and red. Red cultivars were classified as any lettuce plant having red coloring, even if the leaves were only lightly colored or speckled. Seven beds were used in order to achieve three replications of each cultivar for each treatment and spring water control. Numbers were randomly drawn and assigned to the different types and subtypes for placement into each treatment (Table 1, Figure 2). The hydroponic channel in the middle was flanked by either the aquaponic treatment or spring water control. The first bed contained all three treatments with the third replication of cultivars $17-28$ in each channel.

\subsubsection{Stand Establishment and Productivity}

Stand establishment (SE) is the ability of the seedling to survive after germination and was recorded two weeks after sowing. SE was determined by the average number of visible seedlings per cultivar per tray. SE was calculated among treatments (aquaponic vs. hydroponic vs. spring) and among cultivars within each type (i.e. 'Nevada' vs. 'Magenta' vs. 'Concept' vs. 'Teide' within the summer crisp subtype in the aquaponic treatment). Harvestable fresh weight was measured in productivity per week as some types were harvested earlier than others. Bibb and butterhead cultivars grown in the hydroponic treatment were harvested after six weeks of growth, while all other types were harvested in seven weeks. Lettuce varieties grown in the aquaponic and spring water treatments were harvested after eight weeks of growth.

\subsubsection{Growing Environment}

Air temperature and light intensity were measured using a Watchdog 2475 Plant Growth Station (Spectrum Technologies, Inc.; Model 3686WD; Aurora, IL, USA) every 15 minutes. Shade cloth was installed approximately three months prior to the experiment to limit 
increasing temperatures and light exposure within the structure. Media and water temperature were monitored every 15 minutes using a Watchdog 1400 Micro Station (Spectrum Technologies, Inc. Model 3680WD1; Aurora, IL, USA). Temperature sensors were inserted into the media and water. Electrical conductivity and $\mathrm{pH}$ were measured every two weeks using a multi-parameter tester (Hanna Instruments, Model: H198129; Woonsocket, RI, USA). Dissolved oxygen (DO) was measured every two weeks using a handheld optical DO meter (YSI Inc.; Model ProODO; Yellow Springs, OH, USA). Water samples were collected from the inlet and outlet of each channel. Water samples were taken every two week and analyzed according to methods delineated by the American Public Health Association (APHA, 1995) for nutrient content. Parameters measured were ammonia $\left(\mathrm{NH}_{3}\right)$, nitrate $\left(\mathrm{NO}_{3}{ }^{-}\right)$, nitrite $\left(\mathrm{NO}_{2}{ }^{-}\right)$, combined for total nitrogen concentration, and phosphate $\left(\mathrm{PO}_{4}{ }^{-}\right)$.

\subsubsection{Market Quality}

Market quality of lettuce was evaluated based on a quality scale developed by Kader et al., (1973) (Table 3). Ratings were based on presumed consumer acceptance. Color, decay, maturity, texture, and visual quality descriptions were evaluated.

\subsubsection{Statistical Analysis}

Tukey HSD was conducted on SE, yield, and market rating variables. Different letters denote significant differences, while means separation defined by the same letters were not significantly different at $P \leq 0.05$. Statistical analysis was measured using JMP v. 11 (2013). 


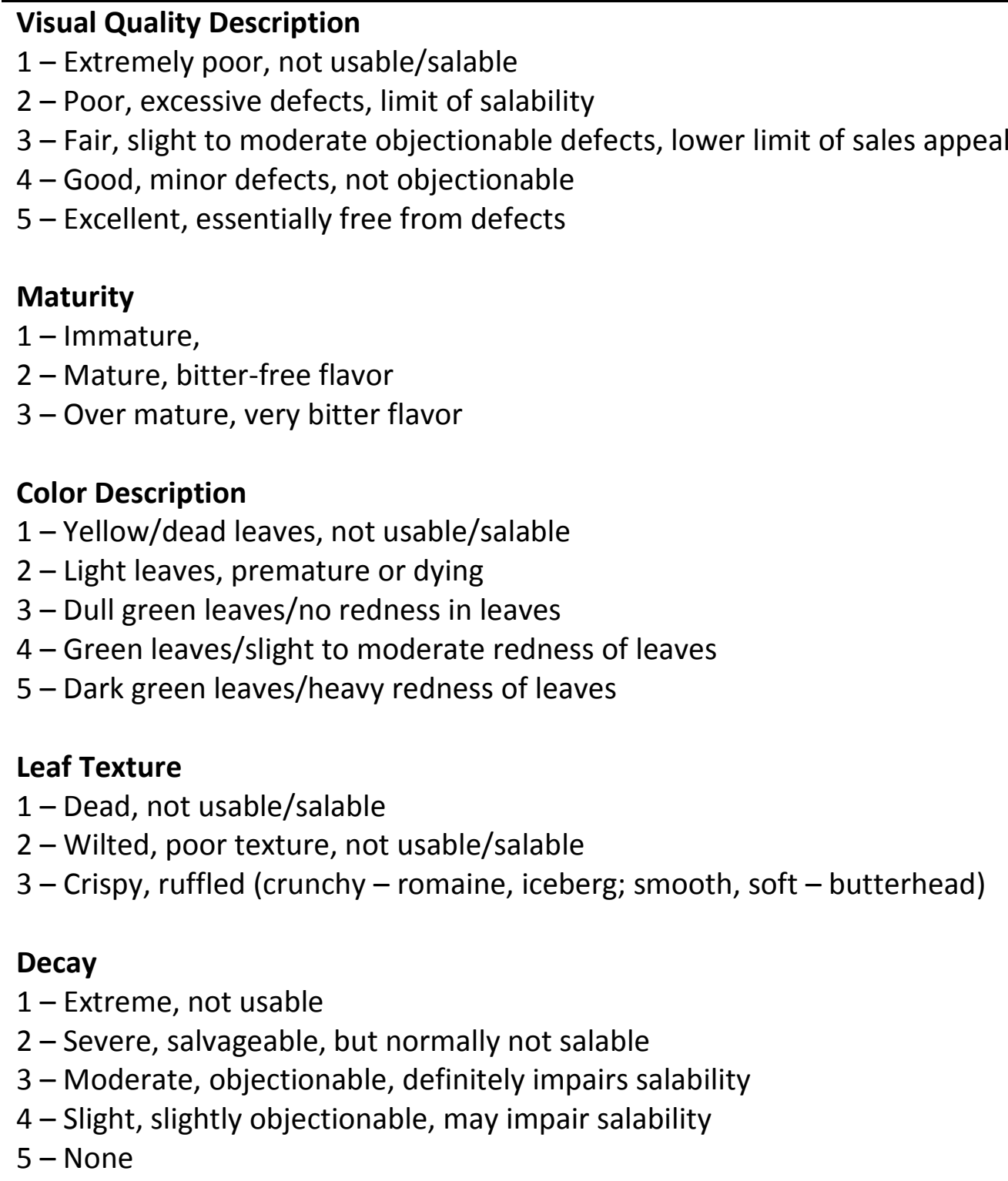

\section{Rating scale for defects not specified}

1 - Extreme, 2 - Severe, 3 - Moderate, 4 - Slight, 5 - None

A rating scale was used by Kader et al. to evaluate lettuce quality (1973). Ratings are based on presumed consumer acceptance and are related to factors such as decay, wilting, color, maturity, and how overall visual quality is impacted. Quality rating varies based on the quality description, but a rating of one is lease desirable. The exception to the desireability is maturity. The production of baby-leaf lettuce may be an exception to the maturity rating where an immature rating is desirable. 


\subsection{Results}

\subsubsection{Growing Environment}

Results of the growing parameters collected are summarized in Table 4.

Table 4. Growing Conditions

\begin{tabular}{|c|c|c|c|}
\hline Variable & \multicolumn{2}{|c|}{ Day } & Night \\
\hline $\begin{array}{c}\text { Air Temperature } \\
\text { Light Intensity } \\
\end{array}$ & \multicolumn{2}{|c|}{$\begin{array}{c}19.7 \pm 7.41^{\circ} \mathrm{C}(\mathrm{a}) \\
412.3 \pm 96.4 \mu \text { moles } \mathrm{m}^{-2} \mathrm{~s}^{-1}\end{array}$} & $\begin{array}{c}13.0 \pm 4.57^{\circ} \mathrm{C}(\mathrm{b}) \\
\mathrm{n} / \mathrm{a}\end{array}$ \\
\hline Variable & Hydroponic & Aquaponic & Spring \\
\hline Media Temperature & $12.6 \pm 1.93^{\circ} \mathrm{C}(\mathrm{c})$ & $12.9 \pm 1.09^{\circ} \mathrm{C}(\mathrm{b})$ & $13.5 \pm 4.14^{\circ} \mathrm{C}(\mathrm{a})$ \\
\hline Water Temperature & $16.2 \pm 2.13^{\circ} \mathrm{C}(\mathrm{a})$ & $14.4 \pm 0.91^{\circ} \mathrm{C}(\mathrm{b})$ & $14.4 \pm 0.92^{\circ} \mathrm{C}(\mathrm{b})$ \\
\hline Electrical Conductivity & $1.94 \pm 0.31 \mu \mathrm{S} \cdot \mathrm{m}^{-1}(\mathrm{a})$ & $0.13 \pm 0.01 \mu \mathrm{s} \cdot \mathrm{m}^{-1}(\mathrm{~b})$ & $0.19 \pm 0.34 \mu \mathrm{S} \cdot \mathrm{m}^{-1}(\mathrm{~b})$ \\
\hline $\mathrm{pH}$ & $6.82 \pm 0.31(b)$ & $7.06 \pm 0.19$ (a) & $7.05 \pm 0.17(a)$ \\
\hline Dissolved Oxygen & $8.78 \pm 1.49 \mathrm{mg} \cdot \mathrm{L}^{-1}(\mathrm{a})$ & $8.10 \pm 0.37 \mathrm{mg} \cdot \mathrm{L}^{-1}(\mathrm{~b})$ & $8.26 \pm 0.30 \mathrm{mg} \cdot \mathrm{L}^{-1}(\mathrm{~b})$ \\
\hline
\end{tabular}

Data are mean \pm std. dev. and means separation denoted by the same letter across a row (e.g. aquaponic vs. hydroponic vs. spring water) were not significantly different $(P \leq 0.05$, Tukey HSD, $n=3)$.

\subsubsection{Stand Establishment}

There was no difference in stand establishment among treatments and with types/subtypes (Table 5). 
Table 5. Average Stand Establishment of Lettuce Cultivars

\begin{tabular}{|c|c|c|c|}
\hline Cultivar & \multicolumn{3}{|c|}{ Stand Establishment (\%) } \\
\hline Bibb & Aquaponic & Hydroponic & Spring Water \\
\hline Winter Density & $67 \pm 58(\mathrm{Aa})$ & $100 \pm 0(\mathrm{Aa})$ & $96 \pm 7(\mathrm{Aa})$ \\
\hline Rhazes & $92 \pm 14$ (Aa) & $92 \pm 14(\mathrm{Aa})$ & $96 \pm 7(\mathrm{Aa})$ \\
\hline Bambi & $67 \pm 58(\mathrm{Aa})$ & $100 \pm 0(\mathrm{Aa})$ & $100 \pm 0(\mathrm{Aa})$ \\
\hline Speckled Amish & $100 \pm 0(\mathrm{Aa})$ & $100 \pm 0(\mathrm{Aa})$ & $96 \pm 7(\mathrm{Aa})$ \\
\hline \multicolumn{4}{|l|}{ Butterhead } \\
\hline Adriana & $100 \pm 0(\mathrm{Aa})$ & $100 \pm 0(\mathrm{Aa})$ & $100 \pm 0(\mathrm{Aa})$ \\
\hline Red Cross & $100 \pm 0(\mathrm{Aa})$ & $100 \pm 0(\mathrm{Aa})$ & $100 \pm 0(\mathrm{Aa})$ \\
\hline Rex & $100 \pm 0(\mathrm{Aa})$ & $100 \pm 0(\mathrm{Aa})$ & $100 \pm 0(\mathrm{Aa})$ \\
\hline Skyphos & $100 \pm 0(\mathrm{Aa})$ & $96 \pm 7(\mathrm{Aa})$ & $100 \pm 0(\mathrm{Aa})$ \\
\hline \multicolumn{4}{|l|}{ Leaf } \\
\hline Two Star & $96 \pm 7(\mathrm{Aa})$ & $96 \pm 7(\mathrm{Aa})$ & $96 \pm 7(\mathrm{Aa})$ \\
\hline Vulcan & $100 \pm 0(\mathrm{Aa})$ & $100 \pm 0(\mathrm{Aa})$ & $100 \pm 0(\mathrm{Aa})$ \\
\hline Waldmann's Dark Green & $100 \pm 0(\mathrm{Aa})$ & $100 \pm 0(\mathrm{Aa})$ & $100 \pm 0(\mathrm{Aa})$ \\
\hline Red Sails & $100 \pm 0(\mathrm{Aa})$ & $100 \pm 0(\mathrm{Aa})$ & $100 \pm 0(\mathrm{Aa})$ \\
\hline \multicolumn{4}{|l|}{ Lolla Rossa } \\
\hline Livigna & $96 \pm 7(\mathrm{Aa})$ & $100 \pm 0(\mathrm{Aa})$ & $67 \pm 58(\mathrm{Aa})$ \\
\hline Dark Rossa & $100 \pm 0(\mathrm{Aa})$ & $100 \pm 0(\mathrm{Aa})$ & $100 \pm 0(\mathrm{Aa})$ \\
\hline Bionda & $96 \pm 7(\mathrm{Aa})$ & $100 \pm 0(\mathrm{Aa})$ & $100 \pm 0(\mathrm{Aa})$ \\
\hline Natividad & $92 \pm 14(\mathrm{Aa})$ & $92 \pm 14(\mathrm{Aa})$ & $96 \pm 7(\mathrm{Aa})$ \\
\hline \multicolumn{4}{|l|}{ Oakleaf } \\
\hline Sulu & $100 \pm 0(\mathrm{Aa})$ & $100 \pm 0(\mathrm{Aa})$ & $100 \pm 0(\mathrm{Aa})$ \\
\hline Red Saladbowl & $100 \pm 0(\mathrm{Aa})$ & $100 \pm 0(\mathrm{Aa})$ & $100 \pm 0(\mathrm{Aa})$ \\
\hline Baby Oakleaf & $100 \pm 0(\mathrm{Aa})$ & $100 \pm 0(\mathrm{Aa})$ & $100 \pm 0(\mathrm{Aa})$ \\
\hline Garrison & $100 \pm 0(\mathrm{Aa})$ & $100 \pm 0(\mathrm{Aa})$ & $100 \pm 0(\mathrm{Aa})$ \\
\hline \multicolumn{4}{|l|}{ Romaine } \\
\hline Green Forest & $96 \pm 7(\mathrm{Aa})$ & $75 \pm 43(\mathrm{Aa})$ & $96 \pm 7(\mathrm{Aa})$ \\
\hline Outredgeous & $100 \pm 0(\mathrm{Aa})$ & $96 \pm 7(\mathrm{Aa})$ & $100 \pm 0(\mathrm{Aa})$ \\
\hline Jericho & $92 \pm 14(\mathrm{Aa})$ & $83 \pm 29(\mathrm{Aa})$ & $92 \pm 14(\mathrm{Aa})$ \\
\hline Flashy Trout Back & $100 \pm 0(\mathrm{Aa})$ & $92 \pm 14(\mathrm{Aa})$ & $100 \pm 0(\mathrm{Aa})$ \\
\hline \multicolumn{4}{|l|}{ Summer Crisp } \\
\hline Nevada & $100 \pm 0(\mathrm{Aa})$ & $100 \pm 0(\mathrm{Aa})$ & $100 \pm 0(\mathrm{Aa})$ \\
\hline Magenta & $96 \pm 7(\mathrm{Aa})$ & $100 \pm 0(\mathrm{Aa})$ & $100 \pm 0(\mathrm{Aa})$ \\
\hline Concept & $100 \pm 0(\mathrm{Aa})$ & $100 \pm 0(\mathrm{Aa})$ & $100 \pm 0(\mathrm{Aa})$ \\
\hline Teide & $100 \pm 0(\mathrm{Aa})$ & $96 \pm 7(\mathrm{Aa})$ & $100 \pm 0(\mathrm{Aa})$ \\
\hline
\end{tabular}

Stand establishment is a measurement of seedling survival, two weeks after sowing. Data are mean \pm std. dev. and means separation denoted by the same capital letter down a column (cultivars within a single treatment) were not significantly different. Means separation denoted by the same lower case letters across a row (e.g. aquaponic vs. hydroponic vs. spring water) within a single cultivar were not significantly different $(P \leq 0.05$, Tukey HSD, $n=3)$. 


\subsubsection{Productivity}

Lettuce productivity per week varied among the cultivars (Table 6). Productivity was calculated by grams of harvestable fresh weight divided by the number of growing weeks until harvest $\left(\mathrm{g} \cdot \mathrm{wk}^{-1}\right)$. 'Speckled Amish', $46.1 \pm 2.1 \mathrm{~g} \cdot \mathrm{wk}^{-1}$, was the only cultivar in the aquaponic treatment to have higher productivity than its hydroponic counterparts. There was no difference between the aquaponic and hydroponic treatment in $21 \%$ of cultivars, 'Garrison', 'Concept', 'Magenta', 'Skyphos', 'Red Sails', 'Teide', but were different from the same cultivars grown in the spring treatment. There was no difference among all treatments, including the spring control in $46 \%$ of cultivars. Twenty cultivars, or $71 \%$, in the aquaponic treatment either had productivity that was higher or no different from the hydroponic treatment. The hydroponic treatment had the best productivity in $29 \%$ of cultivars including 'Two Star', 'Waldmann's Dark Green', 'Livigna', 'Dark Rossa', 'Natividad', 'Baby Oakleaf', 'Flashy Trout Back', and 'Nevada', compared to the same cultivars grown in the aquaponic treatment.

Differences in productivity by cultivar were also evaluated within a single treatment (Table 6). The lowest productivity per week in Bibb cultivars occurred with 'Rhazes' and 'Speckled Amish' in both the hydroponic and spring water treatments. There were no differences among Bibb cultivars in the aquaponic treatment. 'Skyphos' had the lowest productivity per week among butterhead cultivars in the aquaponic and spring water treatments. There were no differences among butterhead cultivars in the hydroponic treatment. 'Vulcan' and 'Waldmann' had the lowest productivity in the leaf cultivars within the aquaponic treatment. There were no differences among leaf cultivars within the hydroponic or spring water treatments. The same scenario observed in the leaf cultivars occurred in the 
romaine cultivars as well. 'Green Forest' had the lowest productivity in the aquaponic treatment, but there were no differences in the romaine cultivars within the hydroponic or spring water treatment. There were no differences in the oakleaf and summer crisp cultivars in either the aquaponic, hydroponic, or spring water treatments.

\subsubsection{Market Rating}

Cultivars showed no difference in color, decay, leaf texture, and visual market ratings (Tables 7, 8, 10, 11), but were different in the maturity ratings among the treatments (Table 9). Maturity ratings followed (1) immature, (2), mature, and (3) over-mature. There was no difference among all treatments in 16 cultivars. Eight cultivars showed no difference between the aquaponic and hydroponic treatments, but were different from the spring water control. Two oakleaf cultivars, 'Sulu' and 'Red Saladbowl' $(1.7 \pm 0.3)$ had maturity ratings that were different in the aquaponic treatment compared to the same cultivars grown in hydroponic treatment and spring water control $(2.0 \pm 0.0 \mathrm{~g})$. 'Outredgeous' in the hydroponic treatment was the only cultivar to over-mature $(3.0 \pm 0.0)$, bolt in the system, and not mature in the spring water treatment. 
Table 6. Average Lettuce Productivity per Week

\begin{tabular}{|c|c|c|c|}
\hline Cultivar & \multicolumn{3}{|c|}{ Productivity Per Week $\left(g \cdot w^{-1}\right)$} \\
\hline Bibb & Aquaponic & Hydroponic & Spring Water \\
\hline Winter Density & $65.0 \pm 43.9$ (Aa) & $58.9 \pm 8.5(\mathrm{Aa})$ & $52.4 \pm 1.5(\mathrm{Aa})$ \\
\hline Rhazes & $44.1 \pm 8.2(\mathrm{Aa})$ & $29.5 \pm 3.1(\mathrm{Ab})$ & $27.5 \pm 11.7(\mathrm{Ab})$ \\
\hline Bambi & $43.7 \pm 32.6(\mathrm{Aa})$ & $44.1 \pm 1.2(\mathrm{Aab})$ & $33.4 \pm 7.9$ (Aab) \\
\hline Speckled Amish & $57.7 \pm 4.5(\mathrm{Aa})$ & $40.3 \pm 10.8(\mathrm{Bb})$ & $28.0 \pm 4.1(\mathrm{Bb})$ \\
\hline \multicolumn{4}{|l|}{ Butterhead } \\
\hline Adriana & $52.7 \pm 7.6(\mathrm{Aa})$ & $45.4 \pm 40.3(\mathrm{Aa})$ & $31.9 \pm 16.8$ (Aab) \\
\hline Red Cross & $55.7 \pm 6.3(\mathrm{Aa})$ & $14.4 \pm 38.3(\mathrm{Aa})$ & $40.8 \pm 6.6(\mathrm{Aa})$ \\
\hline $\operatorname{Rex}$ & $65.6 \pm 7.3(\mathrm{Aa})$ & $41.9 \pm 36.7$ (Aa) & $41.0 \pm 6.1(\mathrm{Aa})$ \\
\hline Skyphos & $34.8 \pm 4.2(\mathrm{ABb})$ & $55.1 \pm 19.2(\mathrm{Aa})$ & $15.2 \pm 2.0(\mathrm{Bb})$ \\
\hline \multicolumn{4}{|l|}{ Leaf } \\
\hline Two Star & $65.3 \pm 10.5(\mathrm{Bab})$ & $123.1 \pm 14.9(\mathrm{Aa})$ & $58.1 \pm 17.7$ (Ba) \\
\hline Vulcan & $57.3 \pm 12.3(\mathrm{Ab})$ & $77.2 \pm 23.1$ (Aa) & $37.7 \pm 13.2(\mathrm{Aa})$ \\
\hline Waldmann's Dark Green & $45.1 \pm 6.5(\mathrm{Bb})$ & $83.0 \pm 11.6(\mathrm{Aa})$ & $43.7 \pm 13.1$ (Ba) \\
\hline Red Sails & $83.0 \pm 8.8(\mathrm{ABa})$ & $116.8 \pm 30.3(\mathrm{Aa})$ & $55.5 \pm 20.5$ (Ba) \\
\hline \multicolumn{4}{|l|}{ Lolla Rossa } \\
\hline Livigna & $55.8 \pm 13.0(\mathrm{Ba})$ & $108.9 \pm 1.4(\mathrm{Aa})$ & $34.1 \pm 25.1$ (Ba) \\
\hline Dark Rossa & $28.0 \pm 9.2(\mathrm{Bb})$ & $79.5 \pm 11.8$ (Aab) & $28.8 \pm 9.8(\mathrm{Ba})$ \\
\hline Bionda & $41.2 \pm 12.8$ (Aab) & $66.1 \pm 16.3(\mathrm{Ab})$ & $32.8 \pm 13.0(\mathrm{Aa})$ \\
\hline Natividad & $28.3 \pm 2.6(\mathrm{Bb})$ & $62.3 \pm 18.9(\mathrm{Ab})$ & $13.5 \pm 7.4(\mathrm{Ba})$ \\
\hline \multicolumn{4}{|l|}{ Oakleaf } \\
\hline Sulu & $49.9 \pm 27.8$ (Аа) & $109.8 \pm 35.1(\mathrm{Aa})$ & $75.3 \pm 28.9$ (Aa) \\
\hline Red Saladbowl & $60.9 \pm 45.8(\mathrm{Aa})$ & $109.3 \pm 9.8(\mathrm{Aa})$ & $60.1 \pm 26.4(\mathrm{Aa})$ \\
\hline Baby Oakleaf & $51.9 \pm 7.0(\mathrm{Ba})$ & $72.2 \pm 8.0(\mathrm{Aa})$ & $44.0 \pm 3.5(\mathrm{Ba})$ \\
\hline Garrison & $65.9 \pm 2.2(\mathrm{Aa})$ & $84.7 \pm 7.2(\mathrm{Aa})$ & $41.7 \pm 11.7$ (Ba) \\
\hline \multicolumn{4}{|l|}{ Romaine } \\
\hline Green Forest & $54.0 \pm 7.2(\mathrm{Ab})$ & $45.7 \pm 79.1(\mathrm{Aa})$ & $23.5 \pm 4.2(\mathrm{Aa})$ \\
\hline Outredgeous & $95.9 \pm 7.0(\mathrm{Aa})$ & $93.7 \pm 46.4$ (Aa) & $50.0 \pm 20.0(\mathrm{Aa})$ \\
\hline Jericho & $73.3 \pm 4.9$ (Aab) & $64.6 \pm 71.4$ (Aa) & $35.8 \pm 6.8(\mathrm{Aa})$ \\
\hline Flashy Trout Back & $70.5 \pm 17.8$ (Bab) & $116.5 \pm 13.5(\mathrm{Aa})$ & $36.8 \pm 9.8(\mathrm{Ba})$ \\
\hline \multicolumn{4}{|l|}{ Summer Crisp } \\
\hline Nevada & $58.3 \pm 9.1(\mathrm{Ba})$ & $100.5 \pm 12.8(\mathrm{Aa})$ & $38.7 \pm 24.1$ (Ba) \\
\hline Magenta & $58.9 \pm 3.0(\mathrm{ABa})$ & $72.0 \pm 7.1(\mathrm{Aa})$ & $34.0 \pm 19.7$ (Ba) \\
\hline Concept & $68.5 \pm 2.2(\mathrm{Aa})$ & $94.8 \pm 17.3$ (Aa) & $39.1 \pm 6.7(\mathrm{Ba})$ \\
\hline Teide & $64.5 \pm 4.8(\mathrm{Aa})$ & $74.0 \pm 8.6(\mathrm{Aa})$ & $32.4 \pm 17.2(\mathrm{Ba})$ \\
\hline
\end{tabular}

Productivity was calculated by grams of harvestable fresh weight divided by the number of growing weeks until harvest. Data are mean \pm std. dev. and means separation denoted by the same capital letter across a row (e.g. aquaponic vs. hydroponic vs. spring) were not significantly different. Means separation denoted by the same lower case letters down a column (cultivars within a single treatment) within a single cultivar were not significantly different $(P \leq 0.05$, Tukey HSD, $n=3$ ). 
Table 7. Average Color Rating of Lettuce Cultivars by Treatment

\begin{tabular}{|c|c|c|c|}
\hline Cultivar & \multicolumn{3}{|c|}{ Color Rating } \\
\hline Bibb & Aquaponic & Hydroponic & Spring Water \\
\hline Winter Density & $5.0 \pm 0.0(\mathrm{~A})$ & $5.0 \pm 0.0(\mathrm{~A})$ & $5.0 \pm 0.0(\mathrm{~A})$ \\
\hline Rhazes & $5.0 \pm 0.0(\mathrm{~A})$ & $5.0 \pm 0.0(\mathrm{~A})$ & $5.0 \pm 0.0(\mathrm{~A})$ \\
\hline Bambi & $5.0 \pm 0.0(\mathrm{~A})$ & $5.0 \pm 0.0(\mathrm{~A})$ & $5.0 \pm 0.0(\mathrm{~A})$ \\
\hline Speckled Amish & $5.0 \pm 0.0(\mathrm{~A})$ & $5.0 \pm 0.0(\mathrm{~A})$ & $4.7 \pm 0.6(A)$ \\
\hline \multicolumn{4}{|l|}{ Butterhead } \\
\hline Adriana & $3.7 \pm 2.3(\mathrm{~A})$ & $5.0 \pm 0.0(\mathrm{~A})$ & $2.3 \pm 2.3(\mathrm{~A})$ \\
\hline Red Cross & $5.0 \pm 0.0(\mathrm{~A})$ & $5.0 \pm 0.0(\mathrm{~A})$ & $5.0 \pm 0.0(\mathrm{~A})$ \\
\hline Rex & $5.0 \pm 0.0(\mathrm{~A})$ & $5.0 \pm 0.0(\mathrm{~A})$ & $3.7 \pm 1.3(\mathrm{~A})$ \\
\hline Skyphos & $5.0 \pm 0.0(\mathrm{~A})$ & $5.0 \pm 0.0(\mathrm{~A})$ & $5.0 \pm 0.0(\mathrm{~A})$ \\
\hline \multicolumn{4}{|l|}{ Leaf } \\
\hline Two Star & $5.0 \pm 0.0(\mathrm{~A})$ & $5.0 \pm 0.0(\mathrm{~A})$ & $5.0 \pm 0.0(\mathrm{~A})$ \\
\hline Vulcan & $5.0 \pm 0.0(\mathrm{~A})$ & $5.0 \pm 0.0(\mathrm{~A})$ & $5.0 \pm 0.0(\mathrm{~A})$ \\
\hline Waldmann's Dark Green & $5.0 \pm 0.0(\mathrm{~A})$ & $5.0 \pm 0.0(\mathrm{~A})$ & $5.0 \pm 0.0(A)$ \\
\hline Red Sails & $5.0 \pm 0.0(A)$ & $5.0 \pm 0.0(A)$ & $5.0 \pm 0.0(A)$ \\
\hline \multicolumn{4}{|l|}{ Lolla Rossa } \\
\hline Livigna & $5.0 \pm 0.0(A)$ & $5.0 \pm 0.0(A)$ & $5.0 \pm 0.0(A)$ \\
\hline Dark Rossa & $3.7 \pm 1.2(\mathrm{~A})$ & $5.0 \pm 0.0(\mathrm{~A})$ & $5.0 \pm 0.0(\mathrm{~A})$ \\
\hline Bionda & $5.0 \pm 0.0(\mathrm{~A})$ & $5.0 \pm 0.0(\mathrm{~A})$ & $5.0 \pm 0.0(A)$ \\
\hline Natividad & $5.0 \pm 0.0(\mathrm{~A})$ & $5.0 \pm 0.0(\mathrm{~A})$ & $5.0 \pm 0.0(\mathrm{~A})$ \\
\hline \multicolumn{4}{|l|}{ Oakleaf } \\
\hline Sulu & $5.0 \pm 0.0(\mathrm{~A})$ & $5.0 \pm 0.0(\mathrm{~A})$ & $5.0 \pm 0.0(A)$ \\
\hline Red Saladbowl & $5.0 \pm 0.0(\mathrm{~A})$ & $5.0 \pm 0.0(\mathrm{~A})$ & $5.0 \pm 0.0(\mathrm{~A})$ \\
\hline Baby Oakleaf & $5.0 \pm 0.0(\mathrm{~A})$ & $4.7 \pm 0.6(\mathrm{~A})$ & $5.0 \pm 0.0(A)$ \\
\hline Garrison & $5.0 \pm 0.0(A)$ & $5.0 \pm 0.0(A)$ & $5.0 \pm 0.0(A)$ \\
\hline \multicolumn{4}{|l|}{ Romaine } \\
\hline Green Forest & $5.0 \pm 0.0(A)$ & $5.0 \pm 0.0(\mathrm{~A})$ & $5.0 \pm 0.0(A)$ \\
\hline Outredgeous & $5.0 \pm 0.0(A)$ & $5.0 \pm 0.0(A)$ & $5.0 \pm 0.0(A)$ \\
\hline Jericho & $5.0 \pm 0.0(\mathrm{~A})$ & $5.0 \pm 0.0(\mathrm{~A})$ & $5.0 \pm 0.0(\mathrm{~A})$ \\
\hline Flashy Trout Back & $5.0 \pm 0.0(A)$ & $5.0 \pm 0.0(\mathrm{~A})$ & $5.0 \pm 0.0(A)$ \\
\hline \multicolumn{4}{|l|}{ Summer Crisp } \\
\hline Nevada & $5.0 \pm 0.0(\mathrm{~A})$ & $5.0 \pm 0.0(\mathrm{~A})$ & $5.0 \pm 0.0(A)$ \\
\hline Magenta & $5.0 \pm 0.0(A)$ & $5.0 \pm 0.0(A)$ & $5.0 \pm 0.0(A)$ \\
\hline Concept & $3.7 \pm 2.3(\mathrm{~A})$ & $5.0 \pm 0.0(\mathrm{~A})$ & $5.0 \pm 0.0(A)$ \\
\hline Teide & $5.0 \pm 0.0(\mathrm{~A})$ & $5.0 \pm 0.0(\mathrm{~A})$ & $5.0 \pm 0.0(\mathrm{~A})$ \\
\hline
\end{tabular}

The color rating scale follows from (1) yellow/dead leaves, (2) light/premature/dying leaves, (3) dull green/no red in leaves, (4) green leaves/slight to moderate redness of leaves, (5), dark green/heavy reddening of leaves. Data are mean \pm std. dev. and means separation denoted by the same letter across a row (e.g. aquaponic vs. hydroponic vs. spring water) within a cultivar were not significantly different $(P \leq 0.05$, Tukey HSD, $n=3)$. 
Table 8. Average Decay Rating of Lettuce Cultivars by Treatment

\begin{tabular}{|c|c|c|c|}
\hline Cultivar & \multicolumn{3}{|c|}{ Decay Rating } \\
\hline Bibb & Aquaponic & Hydroponic & Spring Water \\
\hline Winter Density & $5.0 \pm 0.0(A)$ & $5.0 \pm 0.0(A)$ & $5.0 \pm 0.0(A)$ \\
\hline Rhazes & $5.0 \pm 0.0(\mathrm{~A})$ & $5.0 \pm 0.0(\mathrm{~A})$ & $5.0 \pm 0.0(A)$ \\
\hline Bambi & $5.0 \pm 0.0(A)$ & $5.0 \pm 0.0(\mathrm{~A})$ & $5.0 \pm 0.0(\mathrm{~A})$ \\
\hline Speckled Amish & $5.0 \pm 0.0(\mathrm{~A})$ & $5.0 \pm 0.0(A)$ & $4.3 \pm 1.2(\mathrm{~A})$ \\
\hline \multicolumn{4}{|l|}{ Butterhead } \\
\hline Adriana & $5.0 \pm 0.0(\mathrm{~A})$ & $5.0 \pm 0.0(\mathrm{~A})$ & $3.7 \pm 2.3(\mathrm{~A})$ \\
\hline Red Cross & $5.0 \pm 0.0(\mathrm{~A})$ & $5.0 \pm 0.0(\mathrm{~A})$ & $5.0 \pm 0.0(A)$ \\
\hline Rex & $5.0 \pm 0.0(\mathrm{~A})$ & $5.0 \pm 0.0(\mathrm{~A})$ & $3.7 \pm 2.3(\mathrm{~A})$ \\
\hline Skyphos & $5.0 \pm 0.0(\mathrm{~A})$ & $5.0 \pm 0.0(\mathrm{~A})$ & $5.0 \pm 0.0(\mathrm{~A})$ \\
\hline \multicolumn{4}{|l|}{ Leaf } \\
\hline Two Star & $3.7 \pm 2.3(\mathrm{~A})$ & $5.0 \pm 0.0(\mathrm{~A})$ & $5.0 \pm 0.0(\mathrm{~A})$ \\
\hline Vulcan & $5.0 \pm 0.0(\mathrm{~A})$ & $5.0 \pm 0.0(\mathrm{~A})$ & $5.0 \pm 0.0(A)$ \\
\hline Waldmann's Dark Green & $5.0 \pm 0.0(\mathrm{~A})$ & $5.0 \pm 0.0(\mathrm{~A})$ & $5.0 \pm 0.0(\mathrm{~A})$ \\
\hline Red Sails & $5.0 \pm 0.0(\mathrm{~A})$ & $5.0 \pm 0.0(\mathrm{~A})$ & $5.0 \pm 0.0(\mathrm{~A})$ \\
\hline \multicolumn{4}{|l|}{ Lolla Rossa } \\
\hline Livigna & $5.0 \pm 0.0(A)$ & $5.0 \pm 0.0(\mathrm{~A})$ & $5.0 \pm 0.0(\mathrm{~A})$ \\
\hline Dark Rossa & $2.3 \pm 2.3(\mathrm{~A})$ & $5.0 \pm 0.0(\mathrm{~A})$ & $5.0 \pm 0.0(\mathrm{~A})$ \\
\hline Bionda & $5.0 \pm 0.0(\mathrm{~A})$ & $5.0 \pm 0.0(\mathrm{~A})$ & $5.0 \pm 0.0(A)$ \\
\hline Natividad & $5.0 \pm 0.0(\mathrm{~A})$ & $5.0 \pm 0.0(\mathrm{~A})$ & $5.0 \pm 0.0(\mathrm{~A})$ \\
\hline \multicolumn{4}{|l|}{ Oakleaf } \\
\hline Sulu & $5.0 \pm 0.0(\mathrm{~A})$ & $5.0 \pm 0.0(A)$ & $5.0 \pm 0.0(A)$ \\
\hline Red Saladbowl & $5.0 \pm 0.0(\mathrm{~A})$ & $5.0 \pm 0.0(\mathrm{~A})$ & $5.0 \pm 0.0(\mathrm{~A})$ \\
\hline Baby Oakleaf & $2.3 \pm 2.3(\mathrm{~A})$ & $5.0 \pm 0.0(\mathrm{~A})$ & $5.0 \pm 0.0(A)$ \\
\hline Garrison & $5.0 \pm 0.0(\mathrm{~A})$ & $5.0 \pm 0.0(A)$ & $5.0 \pm 0.0(A)$ \\
\hline \multicolumn{4}{|l|}{ Romaine } \\
\hline Green Forest & $5.0 \pm 0.0(\mathrm{~A})$ & $5.0 \pm 0.0(A)$ & $5.0 \pm 0.0(A)$ \\
\hline Outredgeous & $5.0 \pm 0.0(A)$ & $5.0 \pm 0.0(A)$ & $5.0 \pm 0.0(A)$ \\
\hline Jericho & $5.0 \pm 0.0(\mathrm{~A})$ & $5.0 \pm 0.0(\mathrm{~A})$ & $5.0 \pm 0.0(\mathrm{~A})$ \\
\hline Flashy Trout Back & $5.0 \pm 0.0(A)$ & $5.0 \pm 0.0(A)$ & $5.0 \pm 0.0(A)$ \\
\hline \multicolumn{4}{|l|}{ Summer Crisp } \\
\hline Nevada & $5.0 \pm 0.0(\mathrm{~A})$ & $5.0 \pm 0.0(\mathrm{~A})$ & $5.0 \pm 0.0(A)$ \\
\hline Magenta & $5.0 \pm 0.0(A)$ & $5.0 \pm 0.0(A)$ & $5.0 \pm 0.0(A)$ \\
\hline Concept & $5.0 \pm 0.0(\mathrm{~A})$ & $5.0 \pm 0.0(\mathrm{~A})$ & $5.0 \pm 0.0(A)$ \\
\hline Teide & $5.0 \pm 0.0(\mathrm{~A})$ & $5.0 \pm 0.0(\mathrm{~A})$ & $5.0 \pm 0.0(\mathrm{~A})$ \\
\hline
\end{tabular}

The decay rating scale follows (1) extreme/not useable or salable, (2) severe or salvageable/no salable, (3) moderate/impaired salability, (4) slight/may impair salability, and (5) no decay. Data are mean \pm std. dev. and means separation denoted by the same letter across a row (e.g. aquaponic vs. hydroponic vs. spring water) within a single cultivar were not significantly different $(P \leq 0.05$, Tukey HSD, $\mathrm{n}=3)$. 
Table 9. Average Leaf Texture Rating of Cultivars by Treatment

\begin{tabular}{|c|c|c|c|}
\hline Cultivar & \multicolumn{3}{|c|}{ Leaf Texure Rating } \\
\hline Bibb & Aquaponic & Hydroponic & Spring Water \\
\hline Winter Density & $3.0 \pm 0.0(\mathrm{~A})$ & $3.0 \pm 0.0(\mathrm{~A})$ & $3.0 \pm 0.0(A)$ \\
\hline Rhazes & $3.0 \pm 0.0(\mathrm{~A})$ & $3.0 \pm 0.0(\mathrm{~A})$ & $3.0 \pm 0.0(A)$ \\
\hline Bambi & $3.0 \pm 0.0(\mathrm{~A})$ & $3.0 \pm 0.0(\mathrm{~A})$ & $3.0 \pm 0.0(\mathrm{~A})$ \\
\hline Speckled Amish & $3.0 \pm 0.0(\mathrm{~A})$ & $3.0 \pm 0.0(\mathrm{~A})$ & $3.0 \pm 0.0(A)$ \\
\hline \multicolumn{4}{|l|}{ Butterhead } \\
\hline Adriana & $3.0 \pm 0.0(\mathrm{~A})$ & $3.0 \pm 0.0(\mathrm{~A})$ & $3.0 \pm 0.0(\mathrm{~A})$ \\
\hline Red Cross & $3.0 \pm 0.0(\mathrm{~A})$ & $3.0 \pm 0.0(\mathrm{~A})$ & $3.0 \pm 0.0(A)$ \\
\hline Rex & $3.0 \pm 0.0(\mathrm{~A})$ & $3.0 \pm 0.0(\mathrm{~A})$ & $3.0 \pm 0.0(\mathrm{~A})$ \\
\hline Skyphos & $3.0 \pm 0.0(\mathrm{~A})$ & $3.0 \pm 0.0(\mathrm{~A})$ & $3.0 \pm 0.0(\mathrm{~A})$ \\
\hline \multicolumn{4}{|l|}{ Leaf } \\
\hline Two Star & $3.0 \pm 0.0(\mathrm{~A})$ & $3.0 \pm 0.0(\mathrm{~A})$ & $3.0 \pm 0.0(\mathrm{~A})$ \\
\hline Vulcan & $3.0 \pm 0.0(\mathrm{~A})$ & $3.0 \pm 0.0(\mathrm{~A})$ & $3.0 \pm 0.0(A)$ \\
\hline Waldmann's Dark Green & $3.0 \pm 0.0(\mathrm{~A})$ & $3.0 \pm 0.0(\mathrm{~A})$ & $3.0 \pm 0.0(\mathrm{~A})$ \\
\hline Red Sails & $3.0 \pm 0.0(\mathrm{~A})$ & $3.0 \pm 0.0(\mathrm{~A})$ & $3.0 \pm 0.0(\mathrm{~A})$ \\
\hline \multicolumn{4}{|l|}{ Lolla Rossa } \\
\hline Livigna & $3.0 \pm 0.0(\mathrm{~A})$ & $3.0 \pm 0.0(\mathrm{~A})$ & $3.0 \pm 0.0(\mathrm{~A})$ \\
\hline Dark Rossa & $2.3 \pm 1.2(\mathrm{~A})$ & $3.0 \pm 0.0(\mathrm{~A})$ & $3.0 \pm 0.0(\mathrm{~A})$ \\
\hline Bionda & $3.0 \pm 0.0(\mathrm{~A})$ & $3.0 \pm 0.0(\mathrm{~A})$ & $3.0 \pm 0.0(A)$ \\
\hline Natividad & $3.0 \pm 0.0(\mathrm{~A})$ & $3.0 \pm 0.0(\mathrm{~A})$ & $3.0 \pm 0.0(\mathrm{~A})$ \\
\hline \multicolumn{4}{|l|}{ Oakleaf } \\
\hline Sulu & $3.0 \pm 0.0(\mathrm{~A})$ & $3.0 \pm 0.0(\mathrm{~A})$ & $3.0 \pm 0.0(A)$ \\
\hline Red Saladbowl & $3.0 \pm 0.0(\mathrm{~A})$ & $3.0 \pm 0.0(\mathrm{~A})$ & $3.0 \pm 0.0(\mathrm{~A})$ \\
\hline Baby Oakleaf & $3.0 \pm 0.0(\mathrm{~A})$ & $3.0 \pm 0.0(\mathrm{~A})$ & $3.0 \pm 0.0(A)$ \\
\hline Garrison & $3.0 \pm 0.0(\mathrm{~A})$ & $3.0 \pm 0.0(\mathrm{~A})$ & $3.0 \pm 0.0(A)$ \\
\hline \multicolumn{4}{|l|}{ Romaine } \\
\hline Green Forest & $3.0 \pm 0.0(\mathrm{~A})$ & $3.0 \pm 0.0(\mathrm{~A})$ & $3.0 \pm 0.0(A)$ \\
\hline Outredgeous & $3.0 \pm 0.0(\mathrm{~A})$ & $3.0 \pm 0.0(A)$ & $3.0 \pm 0.0(A)$ \\
\hline Jericho & $3.0 \pm 0.0(\mathrm{~A})$ & $3.0 \pm 0.0(\mathrm{~A})$ & $3.0 \pm 0.0(\mathrm{~A})$ \\
\hline Flashy Trout Back & $3.0 \pm 0.0(A)$ & $3.0 \pm 0.0(\mathrm{~A})$ & $3.0 \pm 0.0(A)$ \\
\hline \multicolumn{4}{|l|}{ Summer Crisp } \\
\hline Nevada & $3.0 \pm 0.0(\mathrm{~A})$ & $3.0 \pm 0.0(\mathrm{~A})$ & $3.0 \pm 0.0(A)$ \\
\hline Magenta & $3.0 \pm 0.0(\mathrm{~A})$ & $3.0 \pm 0.0(A)$ & $3.0 \pm 0.0(A)$ \\
\hline Concept & $3.0 \pm 0.0(\mathrm{~A})$ & $3.0 \pm 0.0(\mathrm{~A})$ & $3.0 \pm 0.0(A)$ \\
\hline Teide & $3.0 \pm 0.0(\mathrm{~A})$ & $3.0 \pm 0.0(\mathrm{~A})$ & $3.0 \pm 0.0(\mathrm{~A})$ \\
\hline
\end{tabular}

The leaf texture rating scale follows from (1) dead/not usable or salable, (2) wilted/not usable to salable, and (3) crispy, ruffled for Romaine and leaf types/subtypes or smooth, soft for Bibb and butterhead types/subtypes. Data are mean \pm std. dev. and means separation denoted by the same letter across a row (e.g. aquaponic vs. hydroponic vs. spring water) within a single cultivar were not significantly different $(P \leq 0.05$, Tukey HSD, $\mathrm{n}=3$ ). 
Table 10. Average Maturity Rating of Lettuce Cultivars by Treatment

\begin{tabular}{|c|c|c|c|}
\hline Cultivar & \multicolumn{3}{|c|}{ Maturity Rating } \\
\hline Bibb & Aquaponic & Hydroponic & Spring Water \\
\hline Winter Density & $2.0 \pm 0.0(\mathrm{~A})$ & $2.0 \pm 0.0(\mathrm{~A})$ & $2.0 \pm 0.0(\mathrm{~A})$ \\
\hline Rhazes & $2.0 \pm 0.0(\mathrm{~A})$ & $2.0 \pm 0.0(\mathrm{~A})$ & $1.7 \pm 0.6(\mathrm{~A})$ \\
\hline Bambi & $1.7 \pm 0.6(\mathrm{~A})$ & $2.0 \pm 0.0(\mathrm{~A})$ & $2.0 \pm 0.0(\mathrm{~A})$ \\
\hline Speckled Amish & $2.0 \pm 0.0(\mathrm{~A})$ & $2.0 \pm 0.0(\mathrm{~A})$ & $2.0 \pm 0.0(\mathrm{~A})$ \\
\hline \multicolumn{4}{|l|}{ Butterhead } \\
\hline Adriana & $2.0 \pm 0.0(\mathrm{~A})$ & $2.0 \pm 0.0(\mathrm{~A})$ & $2.0 \pm 0.0(\mathrm{~A})$ \\
\hline Red Cross & $2.0 \pm 0.0(\mathrm{~A})$ & $2.0 \pm 0.0(\mathrm{~A})$ & $1.7 \pm 0.6(\mathrm{~A})$ \\
\hline $\operatorname{Rex}$ & $2.0 \pm 0.0(\mathrm{~A})$ & $2.0 \pm 0.0(\mathrm{~A})$ & $2.0 \pm 0.0(\mathrm{~A})$ \\
\hline Skyphos & $2.0 \pm 0.0(\mathrm{~A})$ & $2.0 \pm 0.0(\mathrm{~A})$ & $1.0 \pm 0.0(B)$ \\
\hline \multicolumn{4}{|l|}{ Leaf } \\
\hline Two Star & $2.0 \pm 0.0(\mathrm{~A})$ & $2.0 \pm 0.0(\mathrm{~A})$ & $2.0 \pm 0.0(\mathrm{~A})$ \\
\hline Vulcan & $2.0 \pm 0.0(\mathrm{~A})$ & $2.0 \pm 0.0(\mathrm{~A})$ & $2.0 \pm 0.0(\mathrm{~A})$ \\
\hline Waldmann's Dark Green & $2.0 \pm 0.0(\mathrm{~A})$ & $2.0 \pm 0.0(\mathrm{~A})$ & $2.0 \pm 0.0(\mathrm{~A})$ \\
\hline Red Sails & $2.0 \pm 0.0(\mathrm{~A})$ & $2.0 \pm 0.0(\mathrm{~A})$ & $2.0 \pm 0.0(\mathrm{~A})$ \\
\hline \multicolumn{4}{|l|}{ Lolla Rossa } \\
\hline Livigna & $1.7 \pm 0.6(\mathrm{~A})$ & $2.0 \pm 0.0(\mathrm{~A})$ & $1.0 \pm 0.0(B)$ \\
\hline Dark Rossa & $1.7 \pm 0.6(\mathrm{~A})$ & $2.0 \pm 0.0(\mathrm{~A})$ & $1.0 \pm 0.0$ (B) \\
\hline Bionda & $2.0 \pm 0.0(\mathrm{~A})$ & $2.0 \pm 0.0(\mathrm{~A})$ & $1.0 \pm 0.0$ (B) \\
\hline Natividad & $1.0 \pm 0.0$ (B) & $2.0 \pm 0.0(\mathrm{~A})$ & $1.0 \pm 0.0(B)$ \\
\hline \multicolumn{4}{|l|}{ Oakleaf } \\
\hline Sulu & $1.7 \pm 0.6(A B)$ & $2.0 \pm 0.0(\mathrm{~A})$ & $2.0 \pm 0.0(\mathrm{~A})$ \\
\hline Red Saladbowl & $1.7 \pm 0.6(A B)$ & $2.0 \pm 0.0(\mathrm{~A})$ & $2.0 \pm 0.0(\mathrm{~A})$ \\
\hline Baby Oakleaf & $2.0 \pm 0.0(\mathrm{~A})$ & $1.7 \pm 0.6(\mathrm{~A})$ & $2.0 \pm 0.0(\mathrm{~A})$ \\
\hline Garrison & $2.0 \pm 0.0(\mathrm{~A})$ & $2.0 \pm 0.0(\mathrm{~A})$ & $2.0 \pm 0.0(\mathrm{~A})$ \\
\hline \multicolumn{4}{|l|}{ Romaine } \\
\hline Green Forest & $2.0 \pm 0.0(\mathrm{~A})$ & $2.0 \pm 0.0(\mathrm{~A})$ & $1.0 \pm 0.0$ (B) \\
\hline Outredgeous & $2.0 \pm 0.0$ (B) & $3.0 \pm 0.0(\mathrm{~A})$ & $1.0 \pm 0.0(C)$ \\
\hline Jericho & $2.0 \pm 0.0(\mathrm{~A})$ & $2.0 \pm 0.0(\mathrm{~A})$ & $1.0 \pm 0.0$ (B) \\
\hline Flashy Trout Back & $2.0 \pm 0.0(\mathrm{~A})$ & $2.0 \pm 0.0(\mathrm{~A})$ & $1.0 \pm 0.0$ (B) \\
\hline \multicolumn{4}{|l|}{ Summer Crisp } \\
\hline Nevada & $2.0 \pm 0.0(\mathrm{~A})$ & $2.0 \pm 0.0(\mathrm{~A})$ & $1.3 \pm 0.6(\mathrm{~A})$ \\
\hline Magenta & $2.0 \pm 0.0(\mathrm{~A})$ & $2.0 \pm 0.0(\mathrm{~A})$ & $1.0 \pm 0.0(\mathrm{~B})$ \\
\hline Concept & $2.0 \pm 0.0(\mathrm{~A})$ & $2.0 \pm 0.0(\mathrm{~A})$ & $1.3 \pm 0.6(\mathrm{~A})$ \\
\hline Teide & $2.0 \pm 0.0(\mathrm{~A})$ & $2.0 \pm 0.0(\mathrm{~A})$ & $1.7 \pm 0.6(\mathrm{~A})$ \\
\hline
\end{tabular}

The maturity rating scale follows from (1) immature, (2) mature, (3) and over-mature. Data are mean \pm std. dev. and means separation denoted by the same letter across a row (e.g. aquaponic vs. hydroponic vs. spring water) within a single cultivar were not significantly different $(P \leq 0.05$, Tukey HSD, $\mathrm{n}=3)$. 
Table 11. Average Visual Rating of Lettuce Cultivars by Treatment

\begin{tabular}{|c|c|c|c|}
\hline Visual Rating & \multicolumn{3}{|c|}{ Market Rating } \\
\hline Bibb & Aquaponic & Hydroponic & Spring Water \\
\hline Winter Density & $5.0 \pm 0.0(\mathrm{~A})$ & $5.0 \pm 0.0(\mathrm{~A})$ & $5.0 \pm 0.0(\mathrm{~A})$ \\
\hline Rhazes & $5.0 \pm 0.0(\mathrm{~A})$ & $5.0 \pm 0.0(\mathrm{~A})$ & $5.0 \pm 0.0(\mathrm{~A})$ \\
\hline Bambi & $5.0 \pm 0.0(\mathrm{~A})$ & $5.0 \pm 0.0(\mathrm{~A})$ & $5.0 \pm 0.0(A)$ \\
\hline Speckled Amish & $5.0 \pm 0.0(\mathrm{~A})$ & $5.0 \pm 0.0(A)$ & $4.3 \pm 1.2(\mathrm{~A})$ \\
\hline \multicolumn{4}{|l|}{ Butterhead } \\
\hline Adriana & $4.3 \pm 0.7(\mathrm{~A})$ & $5.0 \pm 0.0(\mathrm{~A})$ & $3.0 \pm 1.2(\mathrm{~A})$ \\
\hline Red Cross & $5.0 \pm 0.0(\mathrm{~A})$ & $5.0 \pm 0.0(A)$ & $5.0 \pm 0.0(A)$ \\
\hline Rex & $5.0 \pm 0.0(\mathrm{~A})$ & $5.0 \pm 0.0(\mathrm{~A})$ & $2.7 \pm 1.2(\mathrm{~A})$ \\
\hline Skyphos & $5.0 \pm 0.0(\mathrm{~A})$ & $5.0 \pm 0.0(A)$ & $5.0 \pm 0.0(A)$ \\
\hline \multicolumn{4}{|l|}{ Leaf } \\
\hline Two Star & $3.7 \pm 1.3(\mathrm{~A})$ & $5.0 \pm 0.0(\mathrm{~A})$ & $5.0 \pm 0.0(A)$ \\
\hline Vulcan & $5.0 \pm 0.0(A)$ & $5.0 \pm 0.0(A)$ & $5.0 \pm 0.0(A)$ \\
\hline Waldmann's Dark Green & $5.0 \pm 0.0(A)$ & $5.0 \pm 0.0(A)$ & $5.0 \pm 0.0(A)$ \\
\hline Red Sails & $5.0 \pm 0.0(\mathrm{~A})$ & $5.0 \pm 0.0(A)$ & $5.0 \pm 0.0(A)$ \\
\hline \multicolumn{4}{|l|}{ Lolla Rossa } \\
\hline Livigna & $5.0 \pm 0.0(\mathrm{~A})$ & $5.0 \pm 0.0(\mathrm{~A})$ & $5.0 \pm 0.0(A)$ \\
\hline Dark Rossa & $2.7 \pm 1.2(\mathrm{~A})$ & $5.0 \pm 0.0(A)$ & $5.0 \pm 0.0(A)$ \\
\hline Bionda & $5.0 \pm 0.0(\mathrm{~A})$ & $5.0 \pm 0.0(\mathrm{~A})$ & $5.0 \pm 0.0(A)$ \\
\hline Natividad & $5.0 \pm 0.0(\mathrm{~A})$ & $5.0 \pm 0.0(\mathrm{~A})$ & $5.0 \pm 0.0(A)$ \\
\hline \multicolumn{4}{|l|}{ Oakleaf } \\
\hline Sulu & $5.0 \pm 0.0(\mathrm{~A})$ & $5.0 \pm 0.0(\mathrm{~A})$ & $5.0 \pm 0.0(A)$ \\
\hline Red Saladbowl & $5.0 \pm 0.0(A)$ & $5.0 \pm 0.0(\mathrm{~A})$ & $5.0 \pm 0.0(A)$ \\
\hline Baby Oakleaf & $2.7 \pm 1.2(\mathrm{~A})$ & $5.0 \pm 0.0(A)$ & $5.0 \pm 0.0(A)$ \\
\hline Garrison & $5.0 \pm 0.0(\mathrm{~A})$ & $5.0 \pm 0.0(\mathrm{~A})$ & $5.0 \pm 0.0(A)$ \\
\hline \multicolumn{4}{|l|}{ Romaine } \\
\hline Green Forest & $5.0 \pm 0.0(A)$ & $5.0 \pm 0.0(A)$ & $5.0 \pm 0.0(A)$ \\
\hline Outredgeous & $5.0 \pm 0.0(\mathrm{~A})$ & $5.0 \pm 0.0(\mathrm{~A})$ & $5.0 \pm 0.0(A)$ \\
\hline Jericho & $5.0 \pm 0.0(\mathrm{~A})$ & $5.0 \pm 0.0(\mathrm{~A})$ & $5.0 \pm 0.0(\mathrm{~A})$ \\
\hline Flashy Trout Back & $5.0 \pm 0.0(A)$ & $5.0 \pm 0.0(A)$ & $5.0 \pm 0.0(A)$ \\
\hline \multicolumn{4}{|l|}{ Summer Crisp } \\
\hline Nevada & $5.0 \pm 0.0(\mathrm{~A})$ & $5.0 \pm 0.0(\mathrm{~A})$ & $5.0 \pm 0.0(\mathrm{~A})$ \\
\hline Magenta & $5.0 \pm 0.0(\mathrm{~A})$ & $5.0 \pm 0.0(\mathrm{~A})$ & $5.0 \pm 0.0(A)$ \\
\hline Concept & $4.3 \pm 0.7(A)$ & $5.0 \pm 0.0(\mathrm{~A})$ & $5.0 \pm 0.0(A)$ \\
\hline Teide & $5.0 \pm 0.0(\mathrm{~A})$ & $5.0 \pm 0.0(\mathrm{~A})$ & $5.0 \pm 0.0(A)$ \\
\hline
\end{tabular}

The visual rating scale follows from (1) extremely poor/not useable or salable, (2) poor/excessive defects, (3) fair/slight to moderate, (4) good with minor defects, and (5) excellent/essentially free from defects (5). Data are mean \pm std. dev. and means separation denoted by the same letter across a row (e.g. aquaponic vs. hydroponic vs. spring water) within a single cultivar were not significantly different ( $P \leq 0.05$, Tukey HSD, $n=3$ ). 


\subsubsection{Nutrient Removal}

There was little to no removal in total nitrogen and phosphate in the system (Table 12). Table 12 lists the average influent and effluent nutrient concentrations, and the respective removal percentage of each treatment. Removal was calculated by subtracting the effluent concentration from the influent concentration. A negative concentration indicated removal while a positive concentration indicated no removal. There were no significant differences between nitrogen and phosphate influent and effluent concentrations among treatments. Significance was only observed in the average rate of removal. Nitrogen concentrations increased in the hydroponic, $9.63 \pm 45.7 \mathrm{mg} \cdot \mathrm{L}^{-1}$, and spring treatments, $0.008 \pm 0.04 \mathrm{mg} \cdot \mathrm{L}^{-1}$. Differences in the average removal rate were observed in the aquaponic treatment, $-0.008 \pm$ $0.03 \mathrm{mg} \cdot \mathrm{L}^{-1}$. Nitrogen and phosphate were higher in the influent of the hydroponic treatment compared to the aquaponic and spring treatments $\left(49.0 \pm 69.4 \mathrm{mg} \cdot \mathrm{L}^{-1,} 30.2 \pm 8 \mathrm{mg} \cdot \mathrm{L}^{-1}\right.$, respectively). However, influent nitrogen concentrations in the aquaponic treatment, $0.21 \pm$ $0.15 \mathrm{mg} \cdot \mathrm{L}^{-1}$, were different from concentrations in the spring treatment, $0.09 \pm 0.13 \mathrm{mg} \cdot \mathrm{L}^{-1}$, however.

There were differences in nutrient removal among individual dates, however (Figure 6). Nitrogen concentration decreased most rapidly in the hydroponic treatment during the first two weeks of the experiment. There were no differences in removal following the second week in the hydroponic treatment. No differences in nitrogen concentration were observed in the aquaponic treatment among dates. Nitrogen concentrations remained below $0 \mathrm{mg} \cdot \mathrm{L}^{-1}$ indicating removal. There was no significant removal of nitrogen in the spring water treatment until the eighth and final week of the experiment. 
Table 12. Average Nutrient Influent, Removal, and Effluent Concentration of Treatments

\begin{tabular}{c|cccrc}
\hline Treatment & Nutrient & $\begin{array}{c}\text { Influent } \\
\left(\mathrm{mg} \cdot \mathrm{L}^{-1}\right)\end{array}$ & $\begin{array}{c}\text { Effluent } \\
\left(\mathrm{mg} \cdot \mathrm{L}^{-1}\right)\end{array}$ & $\begin{array}{c}\text { Removal } \\
\left(\mathrm{mg} \cdot \mathrm{L}^{-1}\right)\end{array}$ & $\begin{array}{c}\% \\
\text { Removal }\end{array}$ \\
\hline Hydroponic & Nitrogen & $49.0 \pm 69.40(\mathrm{Aa})$ & $58.6 \pm 94.90(\mathrm{Aa})$ & $9.63 \pm 45.70(\mathrm{~A})$ & $0 \%$ \\
Aquaponic & Nitrogen & $0.21 \pm 0.15(\mathrm{Ba})$ & $0.20 \pm 0.14(\mathrm{Ba})$ & $-0.008 \pm 0.03(\mathrm{C})$ & $5 \%$ \\
Spring & Nitrogen & $0.09 \pm 0.13(\mathrm{Ca})$ & $0.10 \pm 0.13(\mathrm{Ca})$ & $0.008 \pm 0.04(\mathrm{~B})$ & $0 \%$ \\
\hline
\end{tabular}

\begin{tabular}{c|lccrc}
\hline Treatment & Nutrient & $\begin{array}{c}\text { Influent } \\
\left(\mathrm{mg} \cdot \mathrm{L}^{-1}\right)\end{array}$ & $\begin{array}{c}\text { Effluent } \\
\left(\mathrm{mg} \cdot \mathrm{L}^{-1}\right)\end{array}$ & $\begin{array}{c}\text { Removal } \\
\left(\mathrm{mg} \cdot \mathrm{L}^{-1}\right)\end{array}$ & $\begin{array}{c}\% \\
\text { Removal }\end{array}$ \\
\hline Hydroponic & Phosphate & $30.2 \pm 8.00(\mathrm{Aa})$ & $32.8 \pm 9.1(\mathrm{Aa})$ & $2.51 \pm 11.8(\mathrm{~A})$ & $0 \%$ \\
Aquaponic & Phosphate & $0.13 \pm 0.04(\mathrm{Ba})$ & $0.14 \pm 0.02(\mathrm{Ba})$ & $-0.003 \pm 0.009(\mathrm{~A})$ & $0 \%$ \\
Spring & Phosphate & $0.12 \pm 0.03(\mathrm{Ba})$ & $0.13 \pm 0.02(\mathrm{Ba})$ & $-0.002 \pm 0.009(\mathrm{~A})$ & $0 \%$ \\
\hline
\end{tabular}

Data are mean \pm std. dev. and means separation denoted by a capital letter across a row (e.g. aquaponic vs. hydroponic vs. spring) were not significantly different. Means separation denoted by a lower case letter down a column (e.g. within the hydroponic, aquaponic, or spring treatment) were not significantly different. ( $P \leq 0.05$, Tukey HSD, $\mathrm{n}=3$ )

Decreases in phosphate concentration were also observed across dates (Figure 6).

Phosphate concentrations were the same in the hydroponic treatment during the first two weeks. Significant removal in the hydroponic treatment occurred during the sixth week and remained the same into the final week. Phosphate removal in the spring treatment mirrored removal in the hydroponic treatment. There was no significant removal during the first two weeks in the spring treatment. Significant removal occurred during the sixth week and remained the same into the final week in the spring treatment. Phosphate removal in the aquaponic treatment was significant by the second week. Concentrations in the aquaponic treatment continued to decrease during the sixth week. 


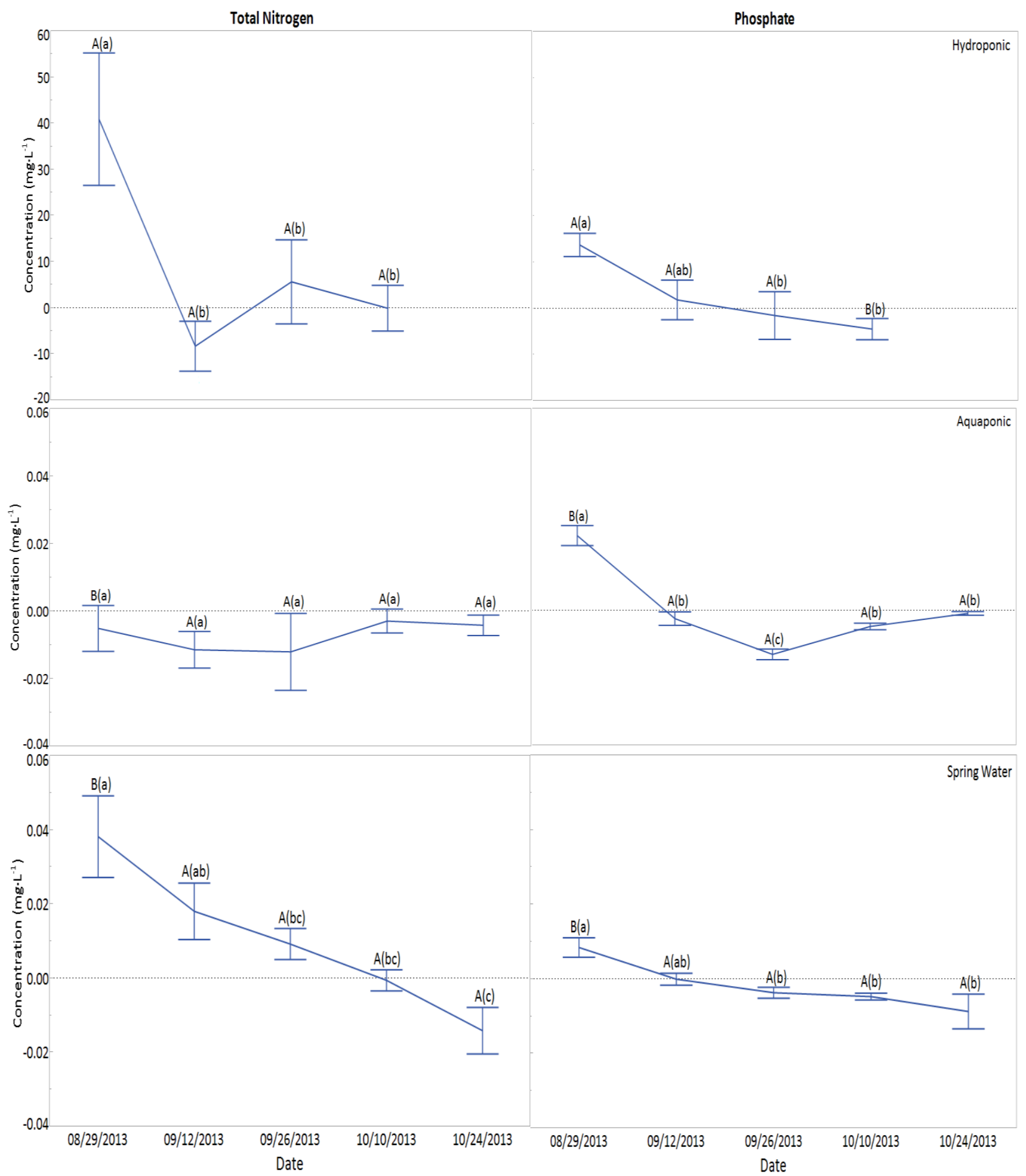

Figure 6. Average total nitrogen and phosphorus concentration removed by lettuce from the each treatment. Values below $0 \mathrm{mg} \cdot \mathrm{L}^{-1}$ indicate removal and values above $0 \mathrm{mg} \cdot \mathrm{L}^{-1}$ no removal. Vertical bars represent std. error and means separation denoted by the same capital letter were not significantly different among treatments. Means separation denote by the same lower case letter were no significantly different within a single treatment $(P \leq 0.05$, Tukey HSD, $n=3)$. 


\subsection{Discussion}

\subsubsection{Productivity}

Productivity from the aquaponic treatment is expected to be significantly lower than yields from the hydroponic treatment due to the lower nutrient concentrations. Nitrogen concentrations were $200 \mathrm{mg} \cdot \mathrm{L}^{-1}$ in the hydroponic treatment compared to concentrations $\leq 1$ $\mathrm{mg} \cdot \mathrm{L}^{-1}$ in the aquaponic treatment. However, productivity in $71 \%$ of cultivars grown in the aquaponic treatment was higher or no different than that of the hydroponic treatment. All Bibb and butterhead cultivars, along with $75 \%$ of the oakleaf, romaine, and summer crisp cultivars are within the aforementioned $71 \%$ of cultivars. Conversely, $50 \%$ of leaf cultivars and $75 \%$ of lollo rossa cultivars had better productivity in the hydroponic treatment indicating that this type and subtype may have higher nutrient demands.

However, reduced growing time is an advantage that hydroponic production has over aquaponic production. Bibb and butterhead cultivars in the hydroponic treatment were harvested from the system two weeks prior to the same cultivars grown in the aquaponic and spring water treatments. Other cultivars in the hydroponic treatment were harvested one week prior to cultivars in the aquaponic and spring water treatments. Nitrogen concentration decreased rapidly during the first two weeks of the experiment in the hydroponic treatment. Higher productivity within a shorter growing period would have been a benefit from the early uptake of nutrients in the hydroponic treatment.

\subsubsection{Market Rating}

Maturity was the only market description to show differences in the ratings (Table 9). Ratings followed (1) immature, (2) mature, and (3) immature. Low ratings occurred 
predominately in cultivars grown in the spring water control. Exposure to low nutrient concentrations may be the cause for limited growth in the cultivars. However, the lolla rossa subtype was exposed to nutrients in the aquaponic treatment and productivity was still lower to the hydroponic treatment. This may suggest that lolla rossa subtypes need high nutrient concentrations and may be sensitive to environmental conditions such as $\mathrm{pH}$ and water temperature.

'Outredgeous' was the only cultivar to over-mature, and even bolted, in the hydroponic treatment. Bolting occurs when high temperatures shift a plant from a vegetative state to an irreversible flowering state (Dufault et al., 2009). Dufault et al. also observed romaine types bolting when exposed to long photoperiods (2009). Lettuce cultivars spent the majority of the growing period in the summer with high air temperatures and light intensity. A combination of high air temperatures, water temperatures, and light intensity may have caused 'Outredgeous' to over-mature.

\subsubsection{Nutrient Removal}

From the data present in Table 12, there was little to no nutrient removal from the system in all treatments. The only observed nutrient removal occurred in the aquaponic treatment. Only $5 \%$ of nitrogen was removed from the aquaponic treatment, but was no different from removal rates in the hydroponic and spring treatments. However, there were differences in removal rate among individual dates. There was no removal of nutrients in the system prior to plant biomass. After establishment, nitrogen and phosphorus uptake occurred as the lettuce grew. The most significant nitrogen removal was experienced in the hydroponic treatment during the first two weeks. Phosphate was not removed as quickly in the hydroponic 
channels indicating that as nitrogen became limited, phosphate was not assimilated by plant roots. Nutrient concentrations aquaponic and spring treatments were significantly lower compared to the hydroponic treatment.

\subsection{Conclusion}

\subsubsection{Productivity}

A variety of lettuce types and cultivars were suitable for production in this flowthrough system. 'Speckled Amish', was the only cultivar to have better productivity than its hydroponic counterpart. Nineteen other cultivars grown aquaponically also had productivity that was no different from cultivars grown hydroponically. This included three Bibbs ('Winter Density', 'Rhazes', 'Bambi'), all butterheads ('Adriana', 'Red Cross', 'Rex', 'Skyphos'), two leaf ('Red Sails', 'Vulcan'), one lolla rossa ('Bionda'), three oakleaf ('Sulu', 'Red Saladbowl', 'Garrison'), three romaines ('Green Forest', 'Outredgeous', 'Jericho'), and three summer crisps ('Concept', 'Magenta', 'Teide'). Immaturity was the only problem associated with cultivars, but was observed predominately in the spring water treatment. However, growers may harvest baby-leaf lettuces for ready-to-eat salads. Baby-sized leaves at immature stages are high quality lettuce for the fresh-cut market (Matinez-Sanchez et al., 2012).

\subsubsection{Nutrient Removal}

Lettuce was observed to be poor at nutrient removal in FTS (Buzby et al., 2009, Buzby and Lin, 2014). Overall removal of both nitrogen and phosphorus was minor in most treatments. However, removal occurred on individual dates indicating the lettuce crop was actively assimilating nutrients for growth. Despite inefficiencies in nutrient removal, lettuce does grow well in the FTS. Lettuce was highly productive and maintained high quality ratings. 
Chapter 4: Comparing two methods of harvesting lettuce for productivity, nutrient removal, and market quality in a flow-through system

\subsection{Introduction}

Growers may use two harvesting strategies: once-and-done (OD) and cut-and-comeagain (CC). With the OD strategy, all plants in the system are planted and harvested at the same time (Rakocy et al., 2006). After harvest, a successive crop is planted to complete a new growing cycle. With the CC strategy, all plants in the system are sown at one time, like OD, but only the lettuce leaves about the meristem are harvested to allow for continued growth without replanting. A successive crop is resown only when the crop can no longer produce. Because there is no need to constantly resow a crop harvested as a CC, the CC mthods could be potentially beneficial for growers by reducing labor and material (seed, media, etc) costs.

Comparable yields have been observed in batch (OD) and staggered (CC) production of basil in recirculating systems (Rakocy et al., 2004).

\subsection{Methods and Materials}

\subsubsection{Facility}

This experiment was conducted between May 23 and July 25, 2013 within HT 1 (Fig. 1), a structure measuring $26^{\prime}$ wide $\times 40^{\prime}$ long. HT 1 housed $13-4^{\prime}$ wide $\times 8^{\prime}$ long $\times 10.5^{\prime}$ deep beds constructed of $3 / 4 "$ plywood (Fig. 2A). A total of seven beds were used for this experiment. Each bed was subdivided into three, 15" $x 7^{\prime}$ channels. The channels were lined with Raven Industries' Dura-Skrim, R-Series, 20 mil, white polyethylene liner (Model R20WW; Sioux Falls,

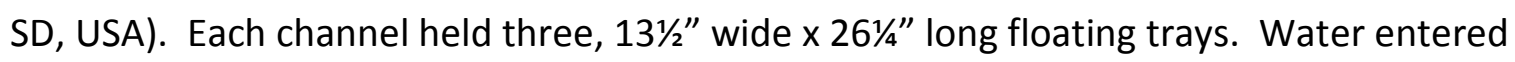


through a valve at the inlet and drained at the outlet. Flow rate was adjusted to $1.4 \mathrm{gpm}$ (0.005 $\mathrm{m}^{3} \cdot \mathrm{min}^{-1}$ ) with $3 / 8^{\prime \prime}$ aperture (Dyer, 2006).

\subsubsection{Treatments}

$\mathrm{OD}$ and $\mathrm{CC}$ harvesting treatments were compared to determine the best yield and market quality of Lactuca sativa 'Red Sails' lettuce. A total of 8 beds or 24 channels (Fig. 7) were used for this experiment; three channels were used for the CC strategy, three channels for a control, and 18 for the OD strategy. To evaluate nutrient removal by lettuce by harvesting method, the control trays were not seeded. Aquaponic nutrient concentrations in the control channels served to compare any differences with the harvesting treatments. This experiment was a completely randomized design. Three OD sets were sown for every single CC set (3:1). The three OD sets were planted weekly to coincide with the continual harvests of the CC sets, ensuring that an OD set was available to harvest when the $\mathrm{CC}$ reached initial harvest, and successive harvests, on a weekly basis.

\subsubsection{Plant Material}

The seeds of Lactuca sativa 'Red Sails' was vacuumed-seeded in 128-celled trays (Speedling, Inc., Model 32; Ruskin, FL, USA) using vermiculite (Therm-O-Rock East Inc., Grade 3A; New Eagle, PA) as the substrate. The conveyor production system of tray rotation, described in the 'Materials and Methods' section of Chapter 3, was used in this objective. 


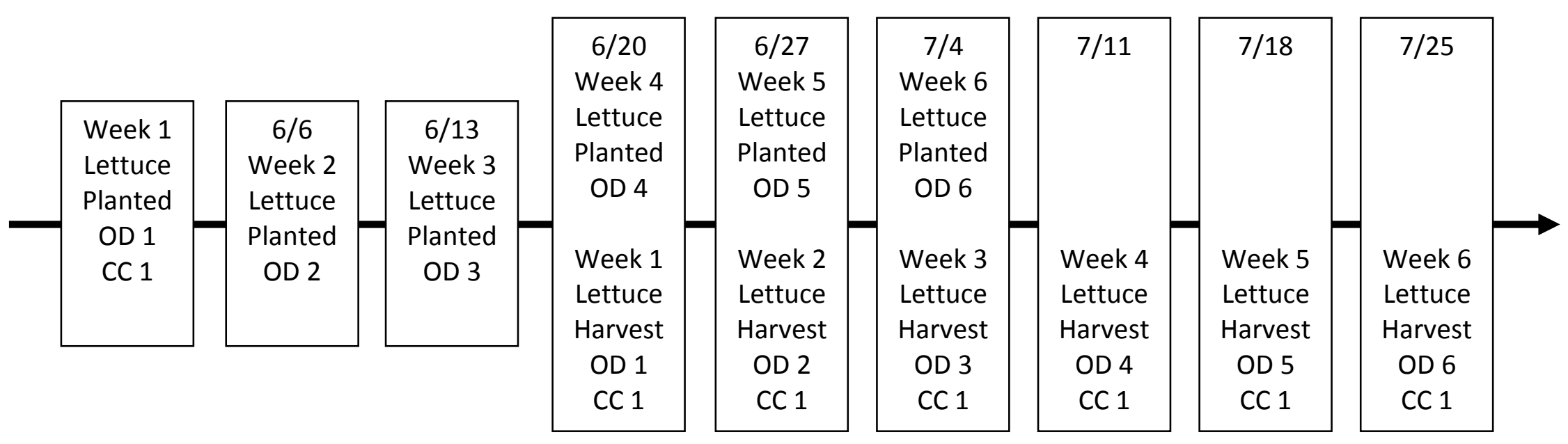

Figure 7. A timeline for harvesting method evaluation. Eight beds were used to achieve three replications for once-and-done (OD), cut-and-come-again (CC), and empty trays as a control to monitor nutrient removal. Treatments were randomly assigned to each channel. Six OD treatments were sown to follow the six harvests of the CC treatment. Once crops grown for the OD method were harvested, a successive OD crop was able to match the continued growth of the CC crop. 


\subsubsection{Stand Establishment and Harvesting Methods}

Stand establishment (SE) describes the ability of the seedling to survive after germination. Stand establishment was determined two weeks after sowing by averaging the number of emerged seedlings per tray. SE for all staggered OD trays were averaged together and compared to SE for the CC trays. Lettuce was harvested when it reached 5-6" tall as measured from media level to the top of the tallest leaf (Western SARE, 2013). Lettuce for the OD method was cut at the base and the entire plant was harvested as a batch, while lettuce for the CC method was cut 1" above the meristem to allow for continued growth. The lettuce for the CC method would then be harvested again when it reached 5-6". Lettuce productivity was determined by the amount of time needed to reach harvest. Both $\mathrm{CC}$ and $\mathrm{OD}$ crops required five weeks to reach the first harvest. After the first harvest, a successive OD batch took another five weeks before reaching the second to sixth harvests. CC batches only needed one week to reach harvest following the first harvest because the meristem was intact and allowed for continued growth after harvesting.

\subsubsection{Growing Environment}

Air temperature and light intensity were regularly measured using a Watchdog 2475 Plant Growth Station (Spectrum Technologies, Inc.; Model 3686WD; Aurora, IL, USA) every 15 minutes. Shade cloth was installed approximately three months prior to the experiment to limit increasing temperatures and light exposure within the structure. Media and water temperature were monitored every 15 minutes using a Watchdog 1400 Micro Station (Spectrum Technologies, Inc. Model 3680WD1; Aurora, IL, USA). Temperature sensors probes were inserted into the media and water. Electrical conductivity and $\mathrm{pH}$ were measured every 
two weeks using a multi-parameter tester (Hanna Instruments, Model: H198129; Woonsocket, RI, USA). Dissolved oxygen (DO) was measured every two weeks using a handheld optical DO meter (YSI Inc.; Model ProODO; Yellow Springs, OH, USA). Water samples were taken every two week and analyzed according to methods delineated by the American Public Health Association (APHA, 1995) for nutrient content. Nutrient identified included Ammonia $\left(\mathrm{NH}_{3}\right)$, nitrate $\left(\mathrm{NO}_{3}{ }^{-}\right)$, nitrite $\left(\mathrm{NO}_{2}{ }^{-}\right)$, combined for total nitrogen concentration, and phosphate $\left(\mathrm{PO}_{4}{ }^{-}\right)$.

\subsubsection{Market Quality}

Market quality of lettuce was evaluated based on quality scales developed by Kader et al., (1973) (Table 3). Ratings were based on presumed consumer acceptance. Color, decay, maturity, texture, and visual quality descriptions were evaluated.

\subsubsection{Statistical Analysis}

A student t-test was conducted on stand establishment, productivity, and market rating variables between the CC and OD treatments. Nutrient removal was analyzed using Tukey HSD for all treatments including the control. Different letters denote significant differences, while means separation defined by the same letters were not significantly different at $P \leq 0.05$. Statistical analysis was measured using JMP v. 11 (2013).

\subsection{Results}

\subsubsection{Growing Environment}

Results of the growing parameters collected are summarized in Table 13. 
Table 13. Growing Conditions

\begin{tabular}{|c|c|c|c|}
\hline Variable & \multicolumn{2}{|c|}{ Day } & Night \\
\hline $\begin{array}{c}\text { Air Temperature } \\
\text { Light Intensity } \\
\end{array}$ & \multicolumn{2}{|c|}{$\begin{array}{c}25.1 \pm 3.8^{\circ} \mathrm{C}(\mathrm{a}) \\
310.3 \pm 11.5 \mu \text { moles } \mathrm{m}^{-2} \mathrm{~s}^{-1}\end{array}$} & $\begin{array}{c}18.3 \pm 3.6{ }^{\circ} \mathrm{C}(\mathrm{b}) \\
\mathrm{n} / \mathrm{a}\end{array}$ \\
\hline Variable & Cut-and-Come-Again & Once-and-Done & Control \\
\hline Media Temperature & $14.4 \pm 0.1^{\circ} \mathrm{C}(\mathrm{b})$ & $18.2 \pm 5.0^{\circ} \mathrm{C}(\mathrm{a})$ & $18.7 \pm 5.0^{\circ} \mathrm{C}(\mathrm{a})$ \\
\hline Water Temperature & $16.6 \pm 4.7^{\circ} \mathrm{C}(\mathrm{a})$ & $16.7 \pm 0.2^{\circ} \mathrm{C}(\mathrm{a})$ & $17.3 \pm 0.1^{\circ} \mathrm{C}(\mathrm{a})$ \\
\hline Electrical Conductivity & $0.13 \pm 0.01 \mu \mathrm{S} \cdot \mathrm{m}^{-1}(\mathrm{a})$ & $0.13 \pm 0.01 \mu \mathrm{S} \cdot \mathrm{m}^{-1}(\mathrm{a})$ & $0.13 \pm 0.01 \mu \mathrm{S} \cdot \mathrm{m}^{-1}(\mathrm{a})$ \\
\hline $\mathrm{pH}$ & $7.0 \pm 0.09(a)$ & $7.0 \pm 0.08(a)$ & $7.0 \pm 0.07(a)$ \\
\hline Dissolved Oxygen & $7.98 \pm 0.78 \mathrm{mg} \cdot \mathrm{L}^{-1}(\mathrm{a})$ & $8.05 \pm 0.71 \mathrm{mg} \cdot \mathrm{L}^{-1}(\mathrm{a})$ & $7.92 \pm 0.80 \mathrm{mg} \cdot \mathrm{L}^{-1}(\mathrm{a})$ \\
\hline
\end{tabular}

Data are mean \pm std. dev. and means separation denoted by the same letter across a row (e.g. $\mathrm{CC}$ vs. OD vs. Control) were not significantly different $(P \leq 0.05$, Tukey HSD, $\mathrm{n}=3)$.

\subsubsection{Productivity}

Lettuce was harvested for the first time on June 20,2013 , five weeks after sowing. CC is more productive when growing weeks are factored into the harvest weight (g. $\mathrm{wk}^{-1}$ ) (Fig. 9A). CC yields were actually higher during the second, $225.8 \pm 47.6 \mathrm{~g} \cdot \mathrm{wk}^{-1}$, and third, $131.0 \pm 52.3$ $\mathrm{g} \cdot \mathrm{wk}^{-1}$, harvests compared to OD yields during the same harvest, $46.6 \pm 15.6 \mathrm{~g} \cdot \mathrm{wk}^{-1}$ and $92.0 \pm$ $11.5 \mathrm{~g} \cdot \mathrm{wk}^{-1}$, respectively. Productivity in the CC treatment continued to decline while the productivity of the OD treatment increased. OD productivity was significantly higher on the fifth, $81.3 \pm 12.6 \mathrm{~g} \cdot \mathrm{wk}^{-1}$, and sixth, $114.5 \pm 21.6 \mathrm{~g} \cdot \mathrm{wk}^{-1}$, harvests than the CC treatment during the same harvests.

Lettuce grown for the $\mathrm{CC}$ method was least productive on the first harvest (Fig. 9B). Initial productivity was low because it required five weeks to reach harvest compared to weekly harvesting on the second to sixth harvests. Productivity was highest on the second, but declined significantly afterwards. In comparison, lettuce grown for the OD methods was least 
productive on the first two harvests and most productive on the fourth and sixth harvests (Fig.

9C). Productivity for the OD method is expected to be lower than productivity for the CC method because a five-week growing period was incorporated for each OD harvest.

\subsubsection{Market Rating}

There was no difference in quality rating among the color, leaf texture, and maturity across all six harvests for both CC and OD methods (Table 14, capital letters). Differences in ratings between lettuce harvested from the $\mathrm{CC}$ and $\mathrm{OD}$ methods were observed, however, in decay and visual ratings (Table 14; Fig. 10). There was no difference in decay and visual rating during the first two harvests between $C C$ and $O D$ methods, but decay and visual ratings declined significantly afterwards in the CC methods. Declining decay and visual ratings after the second harvest can be seen when comparing within the CC methods (Table 14, lowercase letters; Fig. 10). There were no differences within the OD method in color, decay, leaf texture, and maturity ratings. Visual rating within the OD method was lower on the fourth harvest compared to other harvests in the OD method due to some minor decay. The decay rating was during the fourth harvest was no different other harvest, however. 


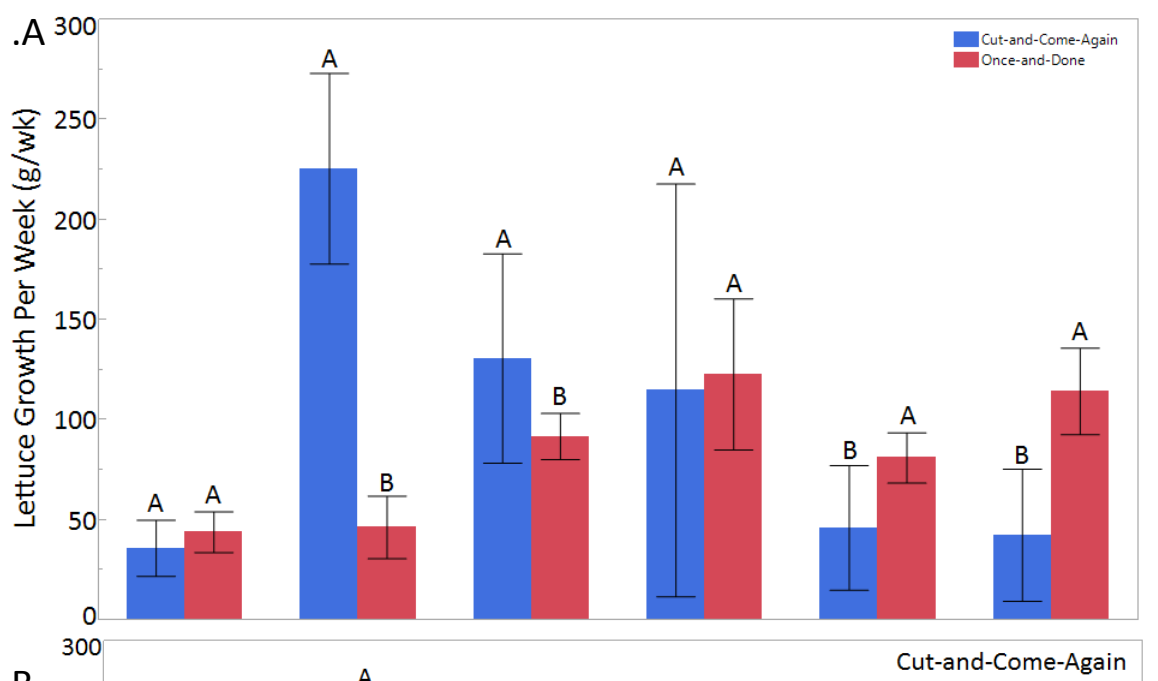

B.

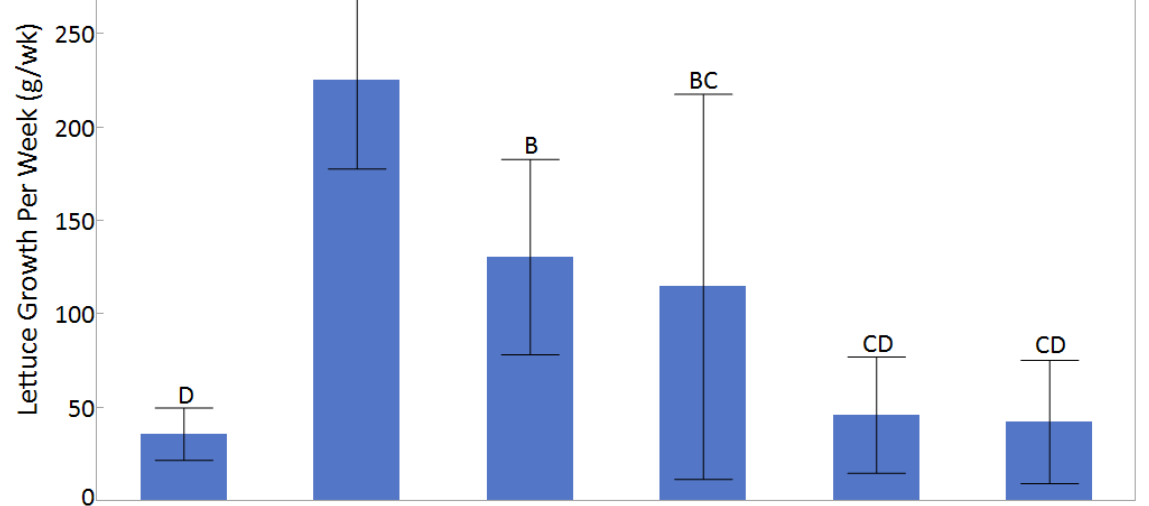

C. 300

Once-and-Done

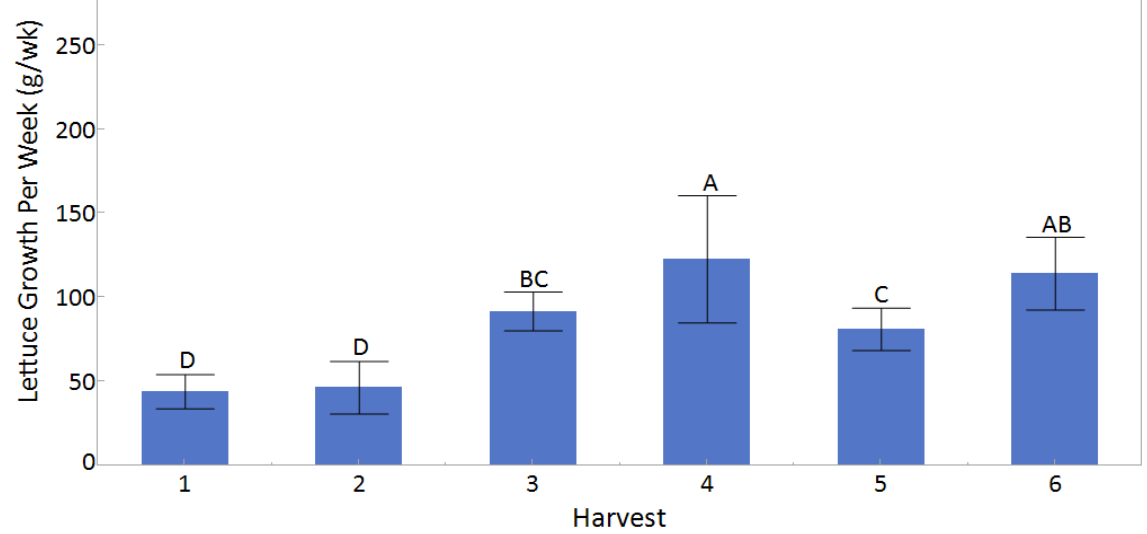

Figure 9. Productivity of Lactuca sativa 'Red Sails' for two harvest methods over a six week harvest period. Productivity is the yield in grams at harvest divided by the number of weeks to harvest. The top graphic compares productivity between methods. Figures B and C compares productivity within a single harvest method. Vertical bars represent standard deviation and means separation denoted by the same letter within a treatment were not significantly different. ( $P \leq 0.05$, Tukey HSD, $\mathrm{n}=3$ ) 
Table 14. Average Color, Decay, Leaf Texture, Maturity, and Visual Rating Comparison of Lactuca sativa 'Red Sails' by Treatment

\begin{tabular}{|c|c|c|}
\hline Market Description & \multicolumn{2}{|c|}{ Rating } \\
\hline Color (1-5) & Cut-and-Come-Again (CC) & Once-and-Done (OD) \\
\hline - Harvest 1 & $4.0 \pm 0.0(\mathrm{Aa})$ & $4.0 \pm 0.0(\mathrm{Aa})$ \\
\hline - $\quad$ Harvest 2 & $4.0 \pm 0.0(\mathrm{Aa})$ & $4.0 \pm 0.0(\mathrm{Aa})$ \\
\hline - Harvest 3 & $4.0 \pm 0.0(\mathrm{Aa})$ & $4.0 \pm 0.0(\mathrm{Aa})$ \\
\hline - $\quad$ Harvest 4 & $4.3 \pm 0.2(\mathrm{Aa})$ & $4.0 \pm 0.0(\mathrm{Aa})$ \\
\hline - Harvest 5 & $4.3 \pm 0.2(\mathrm{Aa})$ & $4.0 \pm 0.0(\mathrm{Aa})$ \\
\hline - Harvest 6 & $4.0 \pm 0.0(\mathrm{Aa})$ & $4.0 \pm 0.0(\mathrm{Aa})$ \\
\hline \multicolumn{3}{|l|}{ Decay (1-5) } \\
\hline - Harvest 1 & $5.0 \pm 0.0(\mathrm{Aa})$ & $5.0 \pm 0.0(\mathrm{Aa})$ \\
\hline - $\quad$ Harvest 2 & $5.0 \pm 0.0(\mathrm{Aa})$ & $5.0 \pm 0.0(\mathrm{Aa})$ \\
\hline - Harvest 3 & $4.3 \pm 0.2(\mathrm{Ba})$ & $5.0 \pm 0.0(\mathrm{Aa})$ \\
\hline - $\quad$ Harvest 4 & $2.3 \pm 0.4(\mathrm{Bb})$ & $4.6 \pm 0.2(\mathrm{Aa})$ \\
\hline - Harvest 5 & $2.3 \pm 0.4(\mathrm{Bb})$ & $5.0 \pm 0.0(\mathrm{Aa})$ \\
\hline - Harvest 6 & $2.1 \pm 0.4(\mathrm{Bb})$ & $5.0 \pm 0.0(\mathrm{Aa})$ \\
\hline \multicolumn{3}{|l|}{ Leaf Texture (1-3) } \\
\hline - Harvest 1 & $3.0 \pm 0.0(\mathrm{Aa})$ & $3.0 \pm 0.0(\mathrm{Aa})$ \\
\hline - $\quad$ Harvest 2 & $3.0 \pm 0.0(\mathrm{Aa})$ & $3.0 \pm 0.0(\mathrm{Aa})$ \\
\hline - Harvest 3 & $3.0 \pm 0.0(\mathrm{Aa})$ & $3.0 \pm 0.0(\mathrm{Aa})$ \\
\hline - $\quad$ Harvest 4 & $3.0 \pm 0.0(\mathrm{Aa})$ & $2.8 \pm 0.1(\mathrm{Aa})$ \\
\hline - Harvest 5 & $3.0 \pm 0.0(\mathrm{Aa})$ & $3.0 \pm 0.0(\mathrm{Aa})$ \\
\hline - Harvest 6 & $3.0 \pm 0.0(\mathrm{Aa})$ & $3.0 \pm 0.0(\mathrm{Aa})$ \\
\hline \multicolumn{3}{|l|}{ Maturity (1-5) } \\
\hline - $\quad$ Harvest 1 & $2.0 \pm 0.0(\mathrm{Aa})$ & $2.0 \pm 0.0(\mathrm{Aa})$ \\
\hline - $\quad$ Harvest 2 & $2.0 \pm 0.0(\mathrm{Aa})$ & $2.0 \pm 0.0(\mathrm{Aa})$ \\
\hline - Harvest 3 & $1.7 \pm 0.2(\mathrm{Aa})$ & $2.0 \pm 0.0(\mathrm{Aa})$ \\
\hline - $\quad$ Harvest 4 & $1.8 \pm 0.2(\mathrm{Aa})$ & $2.0 \pm 0.0(\mathrm{Aa})$ \\
\hline - Harvest 5 & $1.7 \pm 0.2(\mathrm{Aa})$ & $2.0 \pm 0.0(\mathrm{Aa})$ \\
\hline - Harvest 6 & $2.0 \pm 0.0(\mathrm{Aa})$ & $2.0 \pm 0.0(\mathrm{Aa})$ \\
\hline \multicolumn{3}{|l|}{ Visual (1-5) } \\
\hline - $\quad$ Harvest 1 & $5.0 \pm 0.0(\mathrm{Aa})$ & $5.0 \pm 0.0(\mathrm{Aa})$ \\
\hline - $\quad$ Harvest 2 & $5.0 \pm 0.0(\mathrm{Aa})$ & $5.0 \pm 0.0(\mathrm{Aa})$ \\
\hline - $\quad$ Harvest 3 & $3.7 \pm 0.3(\mathrm{Bb})$ & $5.0 \pm 0.0(\mathrm{Aa})$ \\
\hline - $\quad$ Harvest 4 & $2.3 \pm 0.4(\mathrm{Bc})$ & $4.6 \pm 0.2(\mathrm{Aa})$ \\
\hline - Harvest 5 & $2.3 \pm 0.4(\mathrm{Bc})$ & $5.0 \pm 0.0(\mathrm{Aa})$ \\
\hline - $\quad$ Harvest 6 & $2.8 \pm 0.3(\mathrm{Bbc})$ & $5.0 \pm 0.0(\mathrm{Aa})$ \\
\hline
\end{tabular}

Data are mean \pm std. dev. and means separation denoted by a capital letter across a row (e.g. CC vs. OD) were not significantly different. Means separation denoted by a lower case letter down a column (e.g. within CC method or within OD method) were not significantly different. $(P \leq 0.05$, Student- $\mathrm{T}, \mathrm{n}=3)$ 


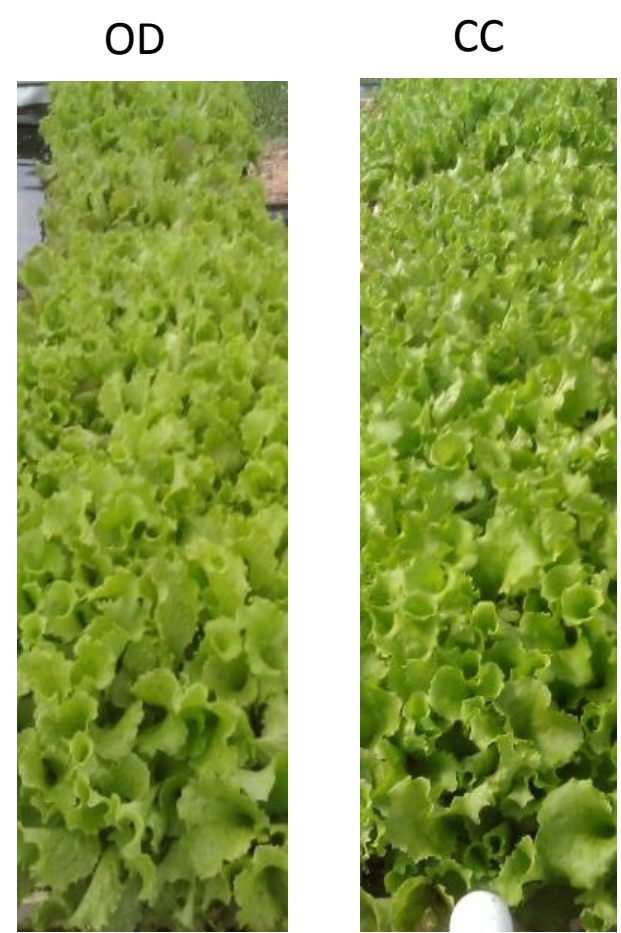

Harvest 1

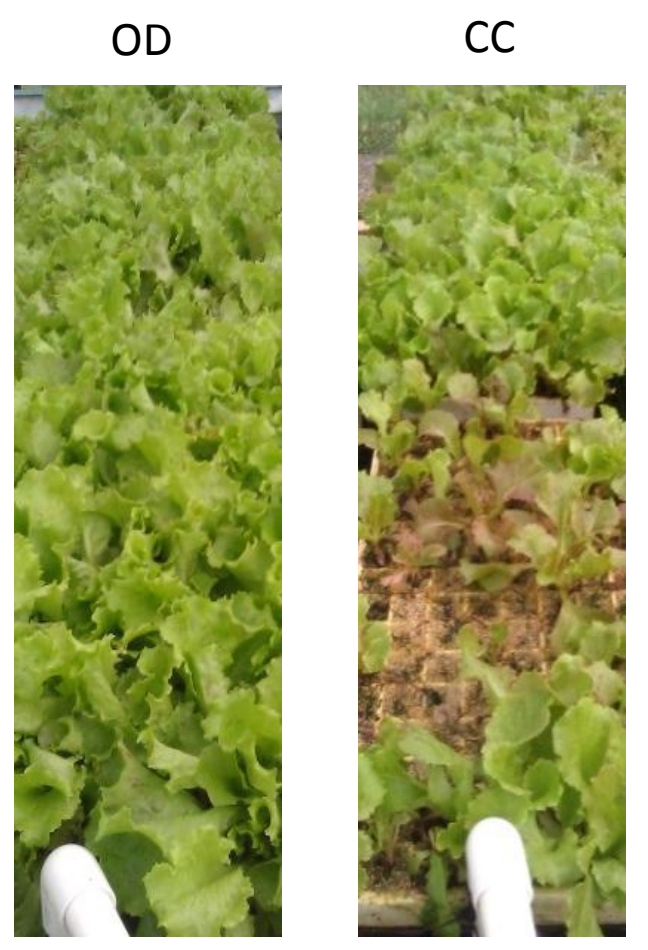

Harvest 4
CC
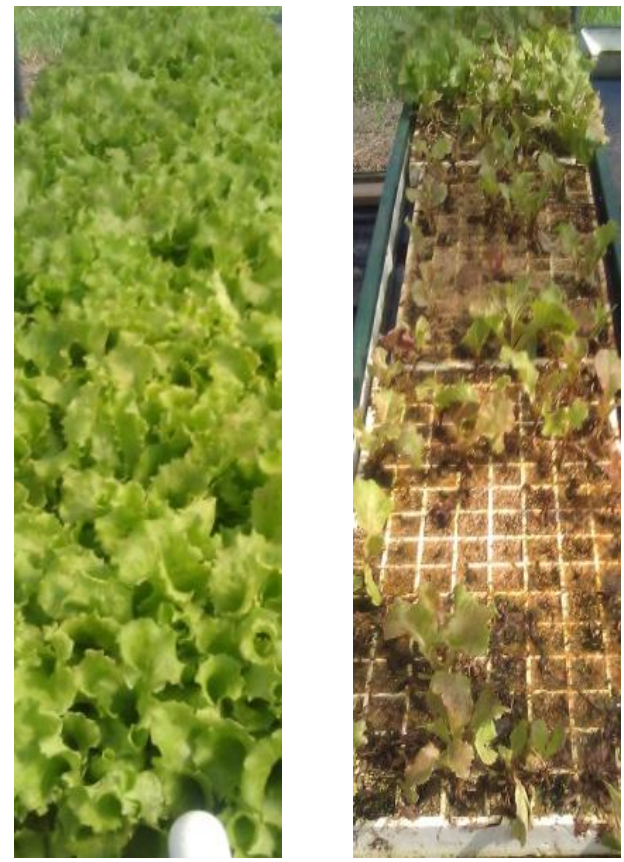

Harvest 6

Figure 10. Representative photos of Lactuca sativa 'Red Sails' during the first, fourth, and sixth harvests for the OD (left) and CC (right) methods. 


\subsubsection{Nutrient Removal}

From the data present in Table 15, there was no significant nutrient removal from the system in all treatments. Table 15 lists the average influent and effluent nutrient concentrations, and the respective removal percentage of each treatment. There were no differences between the starting influent and effluent concentrations in any of the treatments. No differences were observed in the rate of removal in the treatments as well.

The average nitrogen and phosphate concentration within each method is shown in Figure 11. There were differences between the beginning and ending total nitrogen concentrations in both treatments. The first harvest was on June 20,2013 , which was between the second and third sampling dates. Nitrogen removal can be seen in the CC treatment, -0.007 $\pm 0.01 \mathrm{mg} \cdot \mathrm{L}^{-1}$ following the first harvest, on June 27,2013 . Nitrogen removal continued in the CC treatment $\left(-0.04 \pm 0.01 \mathrm{mg} \cdot \mathrm{L}^{-1} ;-0.03 \pm 0.01 \mathrm{mg} \cdot \mathrm{L}^{-1}\right.$, respectively) through the final harvest. Phosphate accumulated more in the CC channels as well.

Phosphate removal was only observed on June $13,-0.008 \pm 0.003 \mathrm{mg} \cdot \mathrm{L}^{-1}$, and July $25,-$ $0.002 \pm 0.003 \mathrm{mg} \cdot \mathrm{L}^{-1}$. The same trend of phosphate removal was observed in the OD treatment. Phosphate in the OD treatment was only removed on the same two sampling dates, June 13, $0.007 \pm 0.002 \mathrm{mg} \cdot \mathrm{L}^{-1}$, and July $25,-0.006 \pm 0.002 \mathrm{mg} \cdot \mathrm{L}^{-1}$. Nitrogen removal in the OD channels followed trend similar to the CC treatment. However, there was no removal of nitrogen following the first harvest. 
Table 15. Average Nutrient Influent, Removal, and Effluent Concentration of Treatments

\begin{tabular}{c|ccccc}
\hline \multicolumn{1}{|c}{ Treatment } & Nutrient & $\begin{array}{c}\text { Influent } \\
\left(\mathrm{mg} \cdot \mathrm{L}^{-1}\right)\end{array}$ & $\begin{array}{c}\text { Effluent } \\
\left(\mathrm{mg} \cdot \mathrm{L}^{-1}\right)\end{array}$ & $\begin{array}{c}\text { Removal } \\
\left(\mathrm{mg} \cdot \mathrm{L}^{-1}\right)\end{array}$ & $\begin{array}{c}\% \\
\text { Removal }\end{array}$ \\
\hline CC & Nitrogen & $0.20 \pm 0.15(\mathrm{Aa})$ & $0.21 \pm 0.15(\mathrm{Aa})$ & $-0.014 \pm 0.03(\mathrm{~A})$ & $0 \%$ \\
OD & Nitrogen & $0.21 \pm 0.15(\mathrm{Aa})$ & $0.21 \pm 0.14(\mathrm{Aa})$ & $-0.006 \pm 0.04(\mathrm{~A})$ & $0 \%$ \\
Control & Nitrogen & $0.21 \pm 0.13(\mathrm{Aa})$ & $0.21 \pm 0.13(\mathrm{Aa})$ & $-0.013 \pm 0.03(\mathrm{~A})$ & $0 \%$ \\
\hline
\end{tabular}

\begin{tabular}{c|ccccc}
\hline Treatment & Nutrient & $\begin{array}{c}\text { Influent } \\
\left(\mathrm{mg} \cdot \mathrm{L}^{-1}\right)\end{array}$ & $\begin{array}{c}\text { Effluent } \\
\left(\mathrm{mg} \cdot \mathrm{L}^{-1}\right)\end{array}$ & $\begin{array}{c}\text { Removal } \\
\left(\mathrm{mg} \cdot \mathrm{L}^{-1}\right)\end{array}$ & $\begin{array}{c}\% \\
\text { Removal }\end{array}$ \\
\hline CC & Phosphate & $0.16 \pm 0.14(\mathrm{Aa})$ & $0.17 \pm 0.15(\mathrm{Aa})$ & $0.005 \pm 0.009(\mathrm{~A})$ & $0 \%$ \\
OD & Phosphate & $0.16 \pm 0.15(\mathrm{Aa})$ & $0.17 \pm 0.16(\mathrm{Aa})$ & $0.004 \pm 0.010(\mathrm{~A})$ & $0 \%$ \\
Control & Phosphate & $0.16 \pm 0.14(\mathrm{Aa})$ & $0.16 \pm 0.01(\mathrm{Aa})$ & $0.002 \pm 0.011(\mathrm{~A})$ & $0 \%$ \\
\hline
\end{tabular}

Data are mean \pm std. dev. and means separation denoted by a capital letter across a row (e.g. CC vs. OD vs. Control) were not significantly different. Means separation denoted by a lower case letter down a column (e.g. within the CC, OD, or Control treatment) were not significantly different. ( $P \leq 0.05$, Tukey HSD, $\mathrm{n}=3$ )

\subsection{Discussion}

\subsubsection{Productivity and Market Rating}

Lettuce yields in the CC method were better when growing time was incorporated (Fig.

9). The initial lettuce crop for both harvesting methods took five weeks to harvest. After the first harvest, lettuce grown in the OD method took another five weeks until it could be harvested again, while lettuce grown for the CC treatment was harvestable the next week. However, productivity in the CC treatment declined significantly following the second harvest

(Fig. 9, Fig. 10). Productivity in the OD method was eventually greater by the fifth harvest (Fig. 9).

Decreased productivity of lettuce grown for the CC method is related to differences in decay and visual ratings. Decay and visual ratings were the only observed difference in quality ratings (Table 13). Decay and visual quality descriptions were consistently better for lettuce in the OD treatment. The quality of lettuce in the CC treatment began to decline significantly 
after the first two harvests. Poor quality renders the lettuce unmarketable. Harvesting continuously stresses the plant and affected growth. Lettuce in the CC treatment became stunted and turned red in pigmentation, in response to the stress (Figure 10). Decay also impacted the quality of the CC lettuce.

\subsubsection{Nutrient Removal}

There was no difference in nitrogen concentrations among influent, effluent, and amount of removal indicating lettuce is inefficient at nutrient removal. However, there were differences in the amount of nitrogen among treatments on specific dates. Significant nitrogen removal was observed on July 11, 2013 within both the CC and OD treatments. No differences were observed in removal rates among the dates within the control indicating that lettuce was actively assimilating nitrogen in the CC and OD treatments. When comparing treatments, nitrogen was removed from the OD treatment at greater rates than the $\mathrm{CC}$ and control treatments on July 25,20013 . The declining productivity of the lettuce crop in the CC method attributed the decreased removal rates of nitrogen.

There was no difference in phosphate concentrations among influent, effluent, and amount of removal indicating lettuce is inefficient at nutrient removal. However, there were differences in the amount of phosphate among treatments on specific dates. Differences in phosphate removal were observed on June 13, 2013 among all treatments. Phosphate removal was also observed on July 25,2013 , but only within the OD treatment. Phosphate removal was not as severe as nitrogen removal across dates. Buzby and Lin (2014) reported that phosphate removal rates were fastest when the plants were the youngest and decreased over time. Higher phosphate concentrations are needed for root development, which occurs at greater 
rates when plants are young (Buzby and Lin, 2014). Additionally, many plants engage in luxury uptake of phosphate when plants are young to offset anticipated demands later (Buzby and Lin, 2014).

\subsubsection{Economic Feasibility}

Cost may be a determining factor for which harvesting methods a grower pursues. Each sowing requires additional materials (seed and vermiculite) and labor for harvesting, cleaning, and seeding. Harvesting as a CC crop may result in lower costs because there are two weeks of continuous harvesting compared to the weekly harvesting of an OD crop. Table 16 shows a comparison budget on harvesting CC and OD. Lettuce grown in the CC treatment was determined to be profitable when harvests reached approximately $300 \mathrm{~g}$ or $2 / 3$ pounds per tray (see sales at yield rates below the table). An $\$ 8.00$ per pound price premium was added to the lettuce to complement prices found at local grocers and farmers markets. Bagged lettuce cost approximately $\$ 3.00$ for $8 \mathrm{oz}$ at the local Kroger grocery store; this is equivalent to $\$ 6.00$ per pound. Lettuce generally ranges from $\$ 6$ to $\$ 10$ per pound at the Morgantown Farmers' Market. 


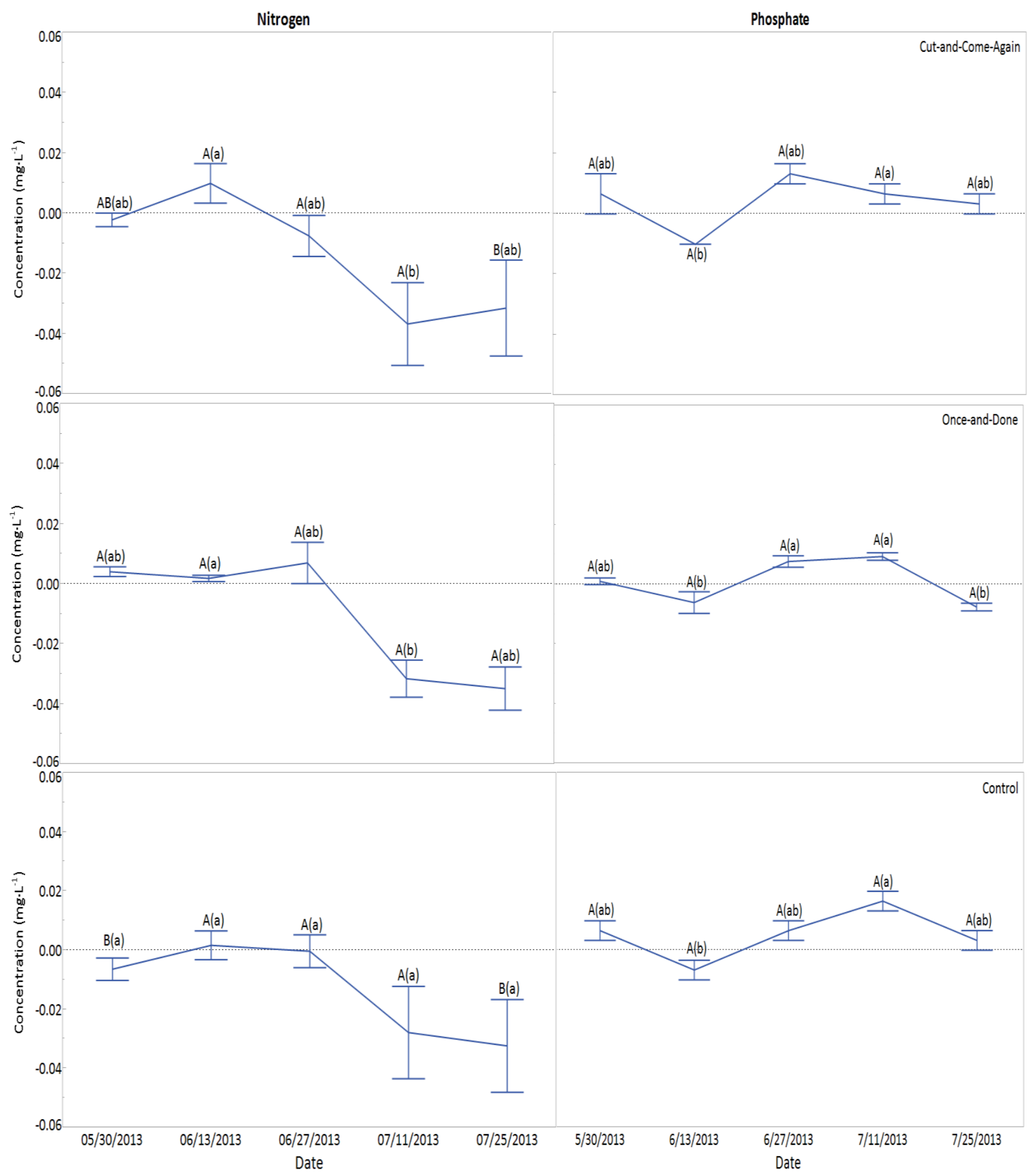

Figure 11. Average nitrogen and phosphorus concentration removed from each treatment by Lactuca sativa 'Red Sails'. Values below $0 \mathrm{mg} \cdot \mathrm{L}^{-1}$ indicate removal and values above $0 \mathrm{mg} \cdot \mathrm{L}^{-1}$ indicate accumulation. Vertical bars represent std. error and means separation denoted by the same letter were not significantly different. Upper case letters compare mean separation among treatment ( $C C$ vs. OD vs. $C$ ) and lower case letters compare mean separation within a treatment (CC or OD or $\mathrm{C})$. ( $\mathrm{P} \leq 0.05$, Tukey HSD, $\mathrm{n}=3$ ) 
Table 16. An economic comparison of OD and CC harvests of lettuce (Lactuca sativa) in the experimental flow-through system at RMF

\begin{tabular}{|c|c|}
\hline \multicolumn{2}{|l|}{ Estimated Monthly Costs } \\
\hline $\begin{array}{l}\text { Part-time labor }-\$ 10 \text { per hour, } 20 \text { hours per week } \\
20 \mathrm{hrs} / \mathrm{wk} \times \$ 10 / \mathrm{hr} \times 52 \mathrm{wks} / \mathrm{yr}=\$ 10,400 / \mathrm{yr}\end{array}$ & $\$ 866.67$ \\
\hline $\begin{array}{l}\text { Electric - Average Cost: } \$ 0.09 / \mathrm{kWh} \\
\text { Estimated Usage: } 3,000 \mathrm{kWh} / \text { month } \\
3,000 \mathrm{kWh} / \text { month } \times \$ 0.09 / \mathrm{kWh}\end{array}$ & $\$ 270.00$ \\
\hline \multicolumn{2}{|l|}{ Itemized Costs } \\
\hline $\begin{array}{r}\text { Vermiculite }-\$ 18.71 \text { per bag } \\
2.5 \text { bags fills } 36 \text { trays }\end{array}$ & $\$ 1.30 /$ tray \\
\hline $\begin{array}{r}\text { Seed }-\$ 100.00 \text { per pound } \\
1 \mathrm{llb}=400,000 \text { seeds }\end{array}$ & $\$ 0.00025 / \mathrm{seec}$ \\
\hline $\begin{array}{l}\text { Styrofoam trays } \\
\quad \$ 11.99 \text { per } 128 \text {-celled tray }\end{array}$ & $\$ 11.99 /$ tray \\
\hline \multicolumn{2}{|l|}{ Cost for CC Production } \\
\hline $\begin{array}{l}\text { Vermiculite } \\
72 \text { trays (based on number of trays able to fill all } 8 \text { beds in HT 1) } \\
\text { Trays sown twice a month or every other week ( } 144 \text { trays) } \\
10 \text { bags needed }\end{array}$ & $\$ 187.10 /$ montr \\
\hline $\begin{array}{l}\text { Seed } \\
18,432 \text { seeds per } 128 \text {-celled tray (if providing two seeds per cell) } \\
72 \text { trays }\end{array}$ & $\$ 10.00 /$ montr \\
\hline Total (Materials + Labor + Electric $+40 \%$ shipping cost $(\$ 78.84))$ & $\$ 1,412.61 /$ month \\
\hline \multicolumn{2}{|l|}{ Cost for OD Production } \\
\hline $\begin{array}{l}\text { All materials are doubled because trays are sown four times a month or } \\
\text { every week }\end{array}$ & $\$ 394.20 /$ month \\
\hline Total (Materials + Labor + Electric + 40\% shipping cost (\$157.68)) & $\$ 1,688.55 /$ month \\
\hline
\end{tabular}

\begin{tabular}{c|c}
\hline Lettuce Sales at Average Yield Rates & Income (72 trays, 4 harvests per month) \\
\hline$\$ 8.00 / \mathrm{lb}(200 \mathrm{~g}$ of lettuce/tray $=0.44 \mathrm{lbs} /$ tray) & $\$ 1,013.76 /$ month \\
$\$ 8.00 / \mathrm{lb}$ (300 g of lettuce/tray $=0.66 \mathrm{lbs} /$ tray) & $\$ 1,520.64 /$ month \\
$\$ 8.00 / \mathrm{lb}(400 \mathrm{~g}$ of lettuce/tray $=0.88 \mathrm{lbs} /$ tray) & $\$ 2,027.52 /$ month \\
$\$ 8.00 / \mathrm{lb}(500 \mathrm{~g}$ of lettuce/tray $=1.10 \mathrm{lbs} /$ tray) & $\$ 2,534.40 /$ month \\
$\$ 8.00 / \mathrm{lb}(600 \mathrm{~g}$ of lettuce/tray $=1.32 \mathrm{lbs} /$ tray) & $\$ 3,041.28 /$ month \\
$\$ 8.00 / \mathrm{lb}(700 \mathrm{~g}$ of lettuce/tray $=1.54 \mathrm{lbs} /$ tray) & $\$ 3,548.16 /$ month \\
\hline
\end{tabular}

Yield rates are listed to determine the amount of pounds needed per tray for sales. An $\$ 8.00$ per pound price premium on lettuce crops complement prices found at grocers and farmers markets. Bagged lettuce cost approximately $\$ 3.00$ for $8 \mathrm{oz}$ at local grocery stores; equivalent to $\$ 6.00$ per pound. Prices generally range from $\$ 6$ to $\$ 10$ per pound at the local farmers market. 


\subsection{Conclusion}

\subsubsection{Productivity}

Rackocy et al. (2004) reported comparable yields of basil between batch (OD) and staggered (CC) harvesting methods. Four harvests of the basil in the staggered (CC) method were achieved in a RAQS, while two lettuce harvests were obtained in the FTS in the CC treatment. However, the first two harvests from the $\mathrm{CC}$ method were more productive than the first two harvests from the OD method. While productivity in the lettuce grown for the CC treatment was greater beyond the second harvest, low market ratings occurred. Lettuce started to decay after the second harvest, which affected visual ratings. Some of the lettuce biomass was salvageable, but a grower would have to decide if it is worth placing effort into harvesting sanitarily without spreading the decay. Reduced quality can potentially impact the profitability of the harvest, however. Profitability is further impacted by labor, material, and utility costs. Minimum profitability of the CC methods was achieved in this FTS when lettuce harvests averaged approximately $300 \mathrm{~g}$ per tray; approximately $350 \mathrm{~g}$ of lettuce yield per tray were needed to achieve profitability with the OD method.

\subsubsection{Nutrient Removal}

Cropping systems will strongly influent the degree of nutrient removal in the system (Buzby and Lin, 2014). Plants grown in a batch system, where all the plants are the same age and size, will have poorer nutrient removal per unit biomass (Buzby and Lin, 2014). Lettuce grown for both the CC and OD treatment were grown as batches and no removal was observed between the influent and effluent in the treatments. No differences were observed in the removal rate between treatments as well. Nutrient removal may be more consistent over time 
if plants were introduced in cohorts at the beginning of the channel and cohorts get

progressively older and bigger toward the end of the channel (Buzby and Lin, 2014). However, lettuce was observed to be poor at nutrient removal in FTS (Buzby et al., 2009, Buzby and Lin, 2014) and little to no removal should be expected when producing lettuce. 


\section{Chapter 5 Evaluating Year-Round Lettuce Production in a Pilot Scale Setting for Yield and Economic Viability}

\subsection{Introduction}

Protected cultivation is increasingly shifting from traditional soil-based systems to soilless cultivation (Castoldi, et. al., 2011). Tolerance for colder temperatures makes aquaponic production of lettuce and trout possible year-round with season extension structures like HTs. Cold-tolerant crops are able to grow during winter months for both a longer cropping season and a winter market season (Borrelli, et. al., 2013). HTs can be used to exploit market conditions where supply is limited and prices are high (Castoldi, et. al., 2011). Many factors including production costs, fish and lettuce sales, insurance, market demand and location (metropolitan vs. rural), permits, and distribution/transportation can all influence profitability. The commercial aquaponics industry is in its infancy in the United States (Savidov, 2004) and the economic, nutrient reduction, and production capabilities of aquaponics must be evaluated on a large-scale.

\subsection{Methods and Materials}

\subsubsection{Facility}

This experiment was performed between December 1, 2011 and December 21, 2012 within HT 2 (Fig 1), a structure $26^{\prime}$ wide by $48^{\prime}$ long. HT 2 housed three, 4' wide by $42^{\prime}$ long channels with walls made from cinderblocks; a fourth channel, constructed of $3 / 4$ " plywood (Fig. 12) to simulate beds in HT 1, was also present, but was not considered a replication in this objective. The channels were lined with Firestone Pondgard EPDM (ethylene propylene diene monomer), 45 mil, heavy-duty, black plastic pond liner (Model PG 5000; Indianapolis, Indiana, 
USA). Each channel held 45, 131/2" wide by 261/4" long floating trays (Speedling, Inc., Model 32;

Ruskin, FL, USA). Water entered through a 2-inch valve at the inlet and drained through a stand pipe at the outlet. Flow rate was adjusted to $20 \mathrm{gal} \cdot \mathrm{min}^{-1}\left(0.075 \mathrm{~m}^{3} \cdot \mathrm{min}^{-1}\right)$.

\subsubsection{Plant Material, Stand Establishment, and Harvesting}

Lactuca sativa 'Red Sails' was vacuumed-seeded in 128-celled trays (Speedling, Inc., Model 32; Ruskin, FL, USA) using vermiculite (Therm-O-Rock East Inc., Grade 3A; New Eagle, PA) as the substrate. Stand establishment (SE) was recorded two weeks after sowing. Lettuce was harvested when it reached 5-6" tall as measured from media level to the top of the tallest leaf (Western SARE, 2013) as an OD method. The conveyor production system of tray rotation, described in the 'Materials and Methods' section of Chapter 3, was used in this objective.

\subsubsection{Growing Environment}

Air temperature and light intensity were regularly measured using a Watchdog 2475 Plant Growth Station (Spectrum Technologies, Inc.; Model 3686WD; Aurora, IL, USA) every hour. Shade cloth was installed approximately on June 29, 2012 to limit increasing temperatures and light exposure within the structure. Growing parameters were separated by season. Seasons were as followed: December 20 - March 19 (winter); March 20 - June 19 (spring); June 20 - September 21 (summer); September 22 - December 19 (fall).

\subsubsection{Statistical Analysis}

Tukey HSD was conducted on SE and yield variables. Different letters denote significant differences, while means separation defined by the same letters were not significantly different at $P \leq 0.05$. Statistical analysis was measured using JMP v. 11 (2013). 


\subsection{Results}

\subsubsection{Growing Environment}

Results of the growing parameters collected are summarized in Table 16.

Table 16. Growing Conditions

\begin{tabular}{|c|c|c|c|c|}
\hline Variable & Winter & Spring & Summer & Fall \\
\hline $\begin{array}{c}\text { Day Air Temperature } \\
\left({ }^{\circ} \mathrm{C}\right)\end{array}$ & $18.3 \pm 11.4$ (c) & $23.6 \pm 8.8(b)$ & $26.8 \pm 5.9(\mathrm{a})$ & $18.5 \pm 9.7(\mathrm{c})$ \\
\hline $\begin{array}{c}\text { Night Air Temperature } \\
\left({ }^{\circ} \mathrm{C}\right)\end{array}$ & $2.5 \pm 4.5(d)$ & $11.4 \pm 5.6(b)$ & $17.4 \pm 4.1(\mathrm{a})$ & $6.1 \pm 5.6(c)$ \\
\hline $\begin{array}{l}\text { Light Intensity } \\
\left(\mu \mathrm{moles} \mathrm{m}^{-2} \mathrm{~s}^{-1}\right)\end{array}$ & $395 \pm 348$ (b) & $650 \pm 538(a)$ & $350 \pm 319$ (c) & $349 \pm 303(c)$ \\
\hline
\end{tabular}

Data are mean \pm std. dev. and means separation denoted by the same letter across a row (e.g. winter vs. spring vs. summer vs. fall) were not significantly different $(P \leq 0.05$, Tukey HSD, $\mathrm{n}=$ 3).

\subsubsection{Stand Establishment}

SE was highest in summer, $88.2 \pm 12.3 \%$, and winter, $85.3 \pm 9.2 \%$ (Fig 13A). Winter and fall, $83.9 \pm 9.1 \%$, SE was the same. Spring, $74.5 \pm 14.3 \%$, had the lowest SE of all seasons.

\subsubsection{Yield and Productivity}

Lettuce was harvested on 30 occasions ( 9 times in the summer, 10 times in the spring, 8 times in the fall, and 3 times in the winter). Lettuce yields per tray were greatest during the spring, $715.2 \pm 302.0 \mathrm{~g}$, followed by summer, $652.9 \pm 265.0 \mathrm{~g}$, then fall, $510.8 \pm 117.0 \mathrm{~g}$ (Fig. 13B). Yield was lowest during the winter, $420.0 \pm 149.0 \mathrm{~g}$ (Fig. 13B). When growing weeks were factored in to determine productivity, summer had the highest productivity, $128.5 \pm 14.9$ $\mathrm{g} \cdot \mathrm{wk}^{-1} \cdot \mathrm{tray}^{-1}$, compared to spring, $103.9 \pm 45 \mathrm{~g} \cdot \mathrm{wk}^{-1} \cdot \mathrm{tray}^{-1}$ (Fig. 13C). Productivity remained lowest for fall, $76 \pm 25.3 \mathrm{~g} \cdot \mathrm{wk}^{-1} \cdot \operatorname{tray}^{-1}$, and winter $47.0 \pm 14.9 \mathrm{~g} \cdot \mathrm{wk}^{-1} \cdot \operatorname{tray}^{-1}$ (Fig. 13C). Time to reach harvest (5-6" tall) ranged between 8-10 weeks during the winter, 8-11 weeks during the fall, 6-7 weeks during the spring, and 4-5 weeks during the summer. 
A subsample of the harvested lettuce was measured to obtain fresh and dry weight (Fig. 14A, Fig. 14B). Three individual lettuce plants were randomly chosen for sub-sampling and weighed. The samples were dried in an oven for three days following harvest. Both fresh and dry weights were greater during the spring. Weights gradually declined as the seasons progressed to winter. The carbon left from the loss of water in the drying process, however, shows that carbon percentage is more consistent across seasons than individual fresh and dry weights (Fig. 14C). Percent carbon is higher towards the end winter and the end of fall, but no gradual declines were observed as with the fresh and dry weights. 


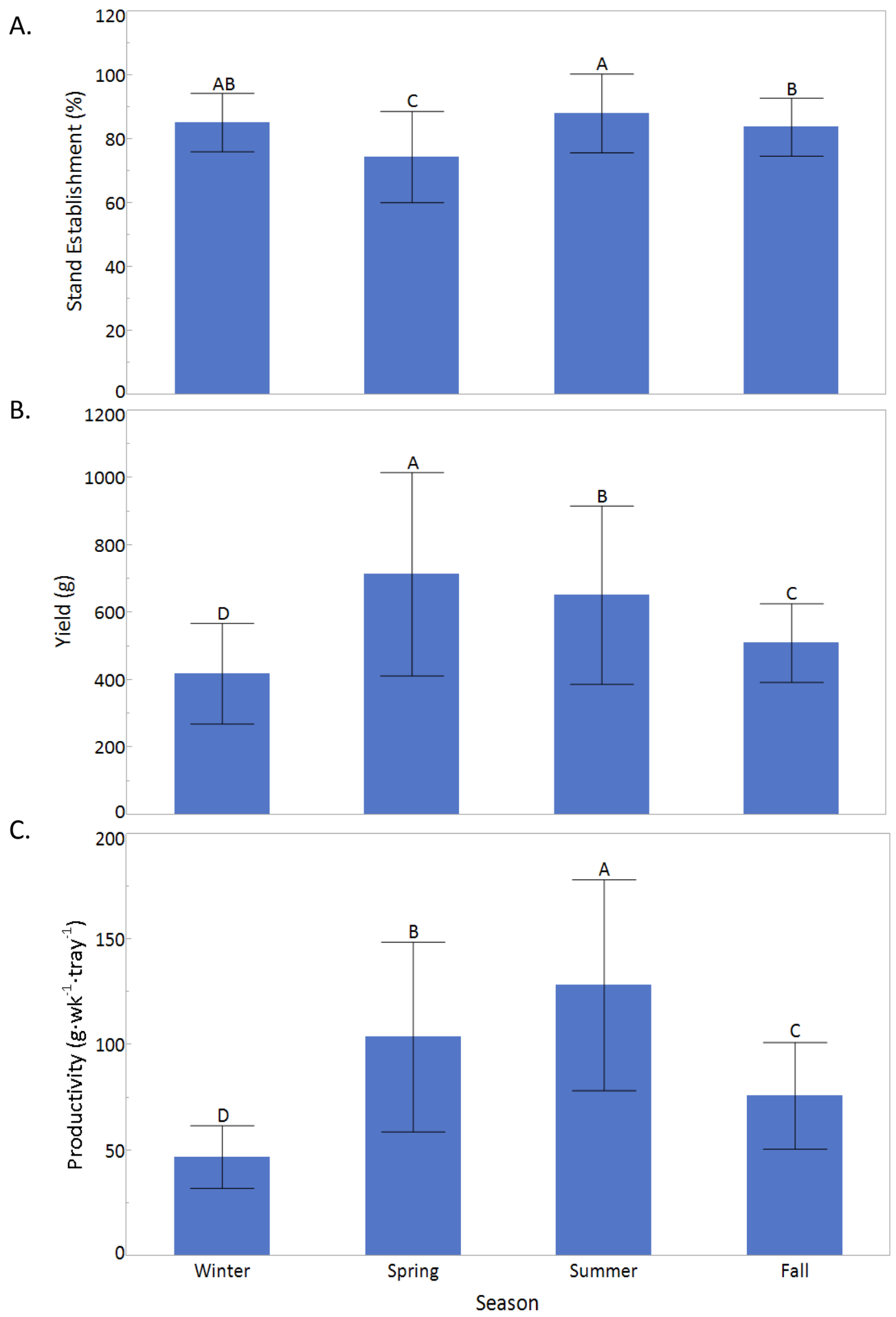

Figure 13. Stand establishment (A), yield (B), and productivity (C) of Lactuca sativa 'Red Sails' from each season during 2012. Vertical bars represent standard deviation and means separation denoted by the same letter across a season were not significantly different $(P \leq 0.05$, Tukey HSD, $n=3$ ). 


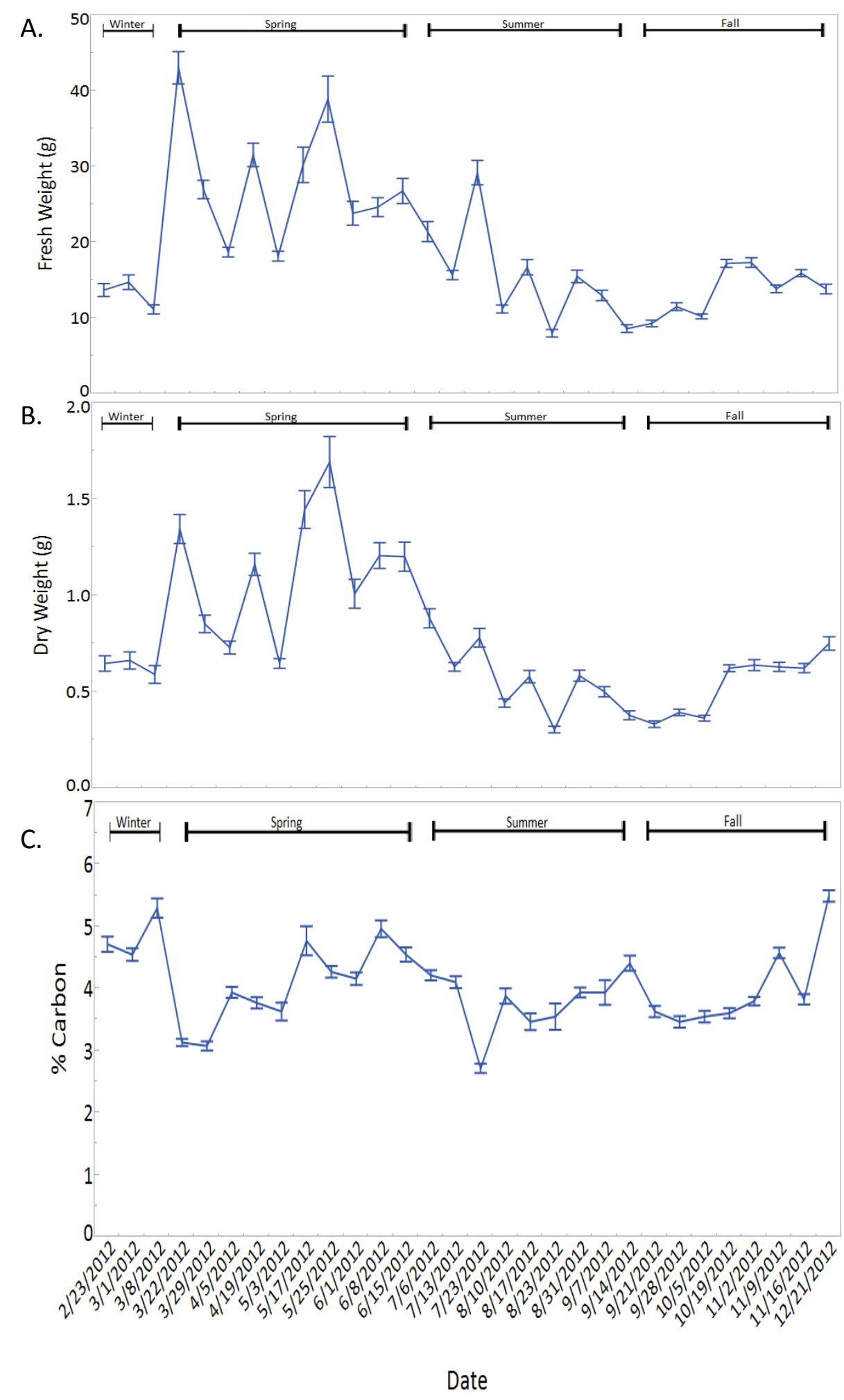

Figure 14. Fresh and dry weights (g) and \% carbon Lactuca sativa 'Red Sails'. Carbon was calculated by dividing the dry weight by the fresh weight of three plant subsample from each tray. 


\subsubsection{Nutrient Removal}

The average nutrient concentration removed by season was variable (Fig. 15).

Ammonia $\left(\mathrm{NH}_{3}\right)$ was removed in all seasons, but removal was greatest during the summer, 0.03 $\pm 0.007 \mathrm{mg} \cdot \mathrm{L}^{-1}$, followed by spring, $0.02 \pm 0.02 \mathrm{mg} \cdot \mathrm{L}^{-1}$, and winter, $-0.01 \pm 0.006 \mathrm{mg} \cdot \mathrm{L}^{-1}$. There was no difference in $\mathrm{NH}_{3}$ removal between spring and winter. Removal was lowest during fall, $0.01 \pm 0.005 \mathrm{mg} \cdot \mathrm{L}^{-1}$, but not different than winter or spring. There was no removal of nitrite $\left(\mathrm{NO}_{2}{ }^{-}\right)$in any of the seasons. Concentrations were highest during the winter, $0.004 \pm 0.0003$ $\mathrm{mg} \cdot \mathrm{L}^{-1}$. There was no difference among spring, $0.0007 \pm 0.0003 \mathrm{mg} \cdot \mathrm{L}^{-1}$, summer, $0.0003 \pm$ $0.0003 \mathrm{mg} \cdot \mathrm{L}^{-1}$, and fall, $0.0002 \pm 0.0003 \mathrm{mg} \cdot \mathrm{L}^{-1}$. Nitrate $\left(\mathrm{NO}_{3}{ }^{-}\right)$was removed during all season, but there was no difference in removal among winter, $-0.004 \pm 0.008 \mathrm{mg} \cdot \mathrm{L}^{-1}$, spring, $-0.02 \pm$ $0.008 \mathrm{mg} \cdot \mathrm{L}^{-1}$, summer, $-0.02 \pm 0.009 \mathrm{mg} \cdot \mathrm{L}^{-1}$, and fall, $-0.02 \pm 0.007 \mathrm{mg} \cdot \mathrm{L}^{-1}$, however. Phosphate removal was greatest during the spring, $-0.009 \pm 0.003 \mathrm{mg} \cdot \mathrm{L}^{-1}$, followed by summer, $-0.0009 \pm$ $0.003 \mathrm{mg} \cdot \mathrm{L}^{-1}$. Phosphate accumulation occurred during the fall, $0.002 \pm 0.003 \mathrm{mg} \cdot \mathrm{L}^{-1}$, and winter, $0.0005 \pm 0.003 \mathrm{mg} \cdot \mathrm{L}^{-1}$.

\subsection{Discussion}

\subsubsection{Yield and Productivity}

The FTS was capable of year-round production of lettuce. Spring was the best season for lettuce production, even though spring had the lowest stand establishment. Meanwhile, summer had the highest SE, but was second in yield production (Fig. 13A). Yield may have been impacted by light intensity. High light intensity enhances photosynthetic process (Liu and Yang, 2012). Light intensity was higher in the spring compared to summer (Table 15) and could 


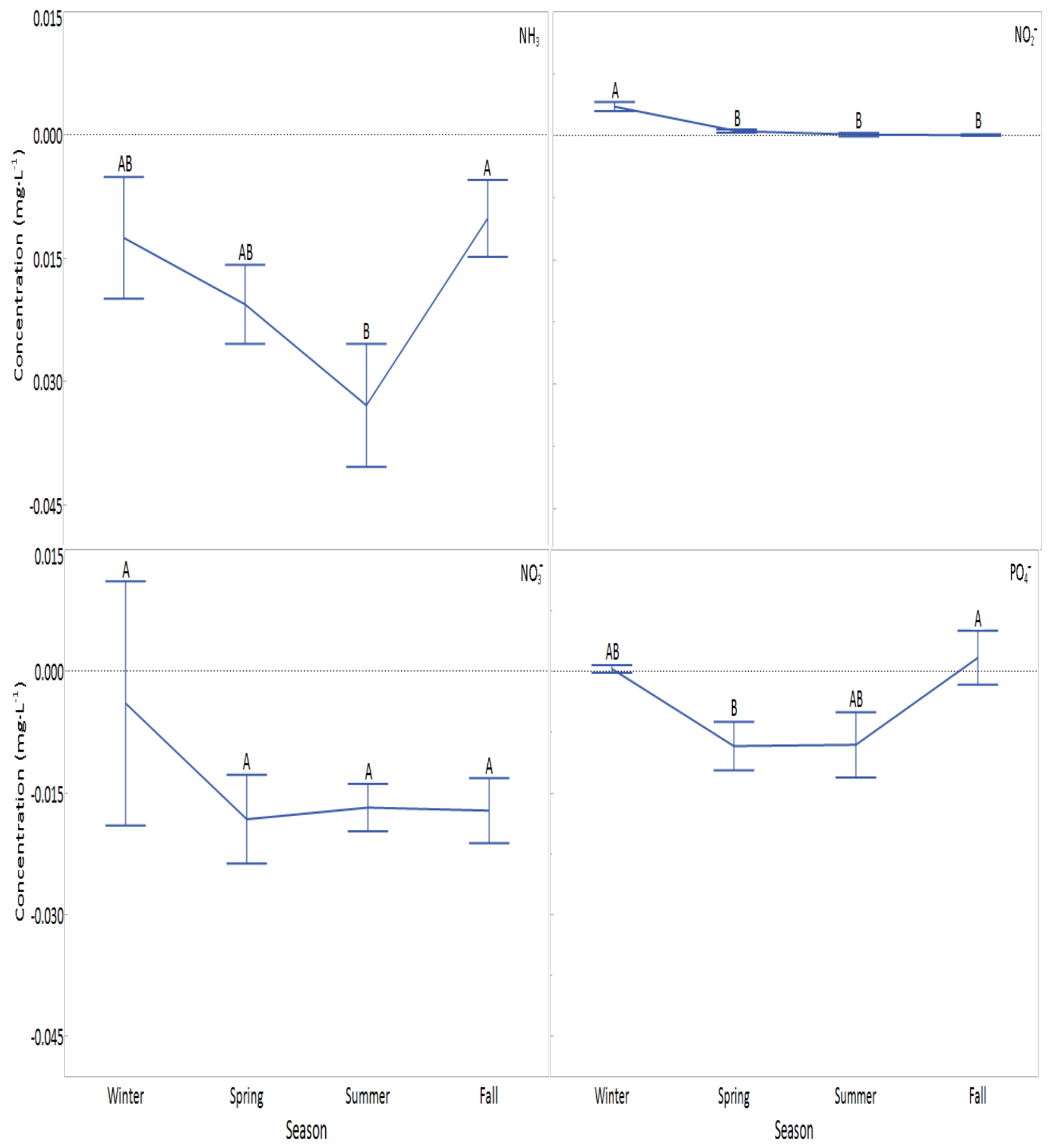

Figure 15. Average concentrations of ammonia $\left(\mathrm{NH}_{3}\right)$, nitrite $\left(\mathrm{NO}_{2}{ }^{-}\right)$, nitrate $\left(\mathrm{NO}_{3}{ }^{-}\right)$, and phosphate $\left(\mathrm{PO}_{4}^{-}\right)$removed from the flow-through system by Lactuca sativa 'Red Sais' across the seasons. Values below $0 \mathrm{mg} \cdot \mathrm{L}^{-1}$ indicate removal and values above $0 \mathrm{mg} \cdot \mathrm{L}^{-1}$ indicate $\mathrm{n}$ removal. Vertical bars represent standard error and means separation denoted by the same letter within a nutrient were not significantly different ( $P \leq 0.05$, Tukey HSD, $\mathrm{n}=3$ ) 
explain better yields during the spring. Conversely, not enough light intensity reduced yields during the summer season and consequently short day seasons, fall and winter.

\subsubsection{Nutrient Removal}

Ammonia $\left(\mathrm{NH}_{3}\right)$ and $\mathrm{NO}_{3}{ }^{-}$removal occurred during all seasons. While there was no difference observed in $\mathrm{NO}_{3}{ }^{-}$concentrations, removal differed in the $\mathrm{NH}_{3}$ concentrations in the summer (Fig. 15). Ammonia $\left(\mathrm{NH}_{3}\right)$ removal was expected to be lower during the fall and winter months where decreased temperatures and light intensities negatively impacted lettuce growth. However, $\mathrm{NH}_{3}$ removal was greatest during the summer, which had lower harvest yields compared to spring, then removal decreased going into the fall. Nitrite $\left(\mathrm{NO}_{2}{ }^{-}\right)$was the only nutrient with no removal in the system during all seasons. There was no difference among spring, summer, and fall. However, lower yields during may have resulted in the lack of $\mathrm{NO}_{2}{ }^{-}$ removal. If $\mathrm{NH} 3$ and $\mathrm{NO}_{3}{ }^{-}$are left, unused, in the system, nitrification occurs to form the $\mathrm{NO}_{2}{ }^{-}$ intermediate (Tyson et al., 2011). Winter harvests were characterized by lower yields, which would have no have needed as much nutrients compared to spring, summer, and fall.

\subsubsection{Economic Analysis}

Cost may be a determining factor for a grower wishing to produce lettuce year-round. Each sowing requires additional materials (seed and vermiculite), labor, and energy for harvesting, cleaning, and seeding. Table 17 shows a budget for harvesting lettuce year-round based on the 30 harvests obtained from this experiment. An $\$ 8.00$ per pound price premium was added to the lettuce to complement prices found at grocers and farmers markets. Bagged lettuce cost approximately $\$ 3.00$ for $8 \mathrm{oz}$ at the local Kroger grocery store; this is equivalent to 
$\$ 6.00$ per pound. Lettuce generally ranges from $\$ 6$ to $\$ 10$ per pound at the Morgantown Farmers' Market. Lettuce grown in the FTS was determined to not be profitable. Lettuce yields would need to consistently average $850 \mathrm{~g}$ per trays before reaching profitability. The highest lettuce yields were observed in spring, $715.2 \pm 302.0 \mathrm{~g}$. Individual yields reaching above $850 \mathrm{~g}$ per tray would have been profitable, but not enough harvests were available to offset the costs throughout the entire year. Profitability might be obtainable if yields per tray or amount of harvests are increased.

\subsection{Conclusion}

\subsubsection{Yield and Productivity}

Year-round, FTS lettuce production was successful in the high tunnel. Lettuce has an optimum temperature range for growth between 13 to $16^{\circ} \mathrm{C}$ and was suitable for the water temperatures in the FTS (Table 4; Table 13). An optimal light intensity for lettuce production ranges between 400 to $600 \mu$ moles $\mathrm{m}^{-2} \mathrm{~s}^{-1}$ (Weiguo et al., 2012). Harvests were made during each season. Yields were greatest during the spring, a time of high light intensity and cool temperatures. High light intensity enhances photosynthetic process (Liu and Yang, 2012) resulting in higher lettuce productivity within a shorter time. Ten harvests were made during the spring compared to only three harvests in the winter, a time characterized by low light intensity and air temperatures. However, lettuce production was unprofitable due to the reduced amount of harvests during colder seasons and low yields harvested per tray. Harvests and yields could be increased with either warmer temperatures or higher nutrient concentrations, conditions similar to RAQS. 


\subsubsection{Nutrient Removal}

Lettuce has been shown to be a poor nutrient remover in the FTS. Rate of nutrient removal is even less during the winter. Nutrient uptake would be lower during the winter because the nutrient demands of slow growing plants are low as a result of decreased light intensity and air temperatures. As light intensity increased, lettuce productivity increased. Increases in nutrient removal were observed as a result. The removal rate of nitrate was below $0 \mathrm{mg} \cdot \mathrm{L}^{-1}$ during all seasons suggesting that active uptake of nitrogen in the FTS by lettuce. Rate of nitrate removal was the same during all seasons. Nitrate has been the preferred source of nitrogen for plants in aquaponics (Lennard and Leonard, 2006) and hydroponic (Tyson et al., 2007) systems. Nitrate accumulation in the leaves was also observed in Blidariu et al. (2013). Differences were observed in ammonia removal rates. However, ammonia can be the preferred source of nitrogen if concentrations are low in combination with low water temperatures (Buzby and Lin, 2014), but can result in reduced lettuce growth (Savvas et al., 2006). Removal rate of ammonia was highest in the summer compared to other seasons indicating that ammonia concentrations were lowest in the summer. Access to increased levels of ammonia could have also contributed to the lower yields during the summer compared to yields during the spring. Phosphate uptake was also observed, but removal rates not to the extent as uptake of nitrogen. Phosphate is needed for root development and most phosphate uptake would have occurred when the plants were young and decrease as the plants aged (Buzby and Lin, 2014). Preliminary experiments in the FTS determined that this system is strongly $\mathrm{N}$ limited and that additions of ammonia increased phosphate removal rates. 
Table 17. An economic analysis of year-round lettuce (Lactuca sativa 'Red Sails') production in the experimental flow-through system at RMF

\begin{tabular}{|c|c|}
\hline \multicolumn{2}{|l|}{ Estimated Monthly Costs } \\
\hline $\begin{array}{l}\text { Part-time labor - } \$ 10 \text { per hour, } 20 \text { hours per week } \\
20 \mathrm{hrs} / \mathrm{wk} \times \$ 10 / \mathrm{hr} \times 52 \mathrm{wks} / \mathrm{yr}=\$ 10,400 / \mathrm{yr}\end{array}$ & $\$ 866.67$ \\
\hline $\begin{array}{c}\text { Electric - Average Cost: } \$ 0.09 / \mathrm{kWh} \\
\text { Estimated Usage: } 3,000 \mathrm{kWh} / \text { month } \\
3,000 \mathrm{kWh} / \text { month } \times \$ 0.09 / \mathrm{kWh} \\
\end{array}$ & $\$ 270.00$ \\
\hline \multicolumn{2}{|l|}{ Itemized Costs } \\
\hline $\begin{array}{r}\text { Vermiculite - } \$ 18.71 \text { per bag } \\
2.5 \text { bags fills } 36 \text { trays }\end{array}$ & $\$ 1.30 /$ tray \\
\hline $\begin{array}{l}\text { Seed - } \$ 100.00 \text { per pound } \\
11 \mathrm{lb}=400,000 \text { seeds }\end{array}$ & $\$ 0.00025 /$ seed \\
\hline $\begin{array}{l}\text { Styrofoam trays } \\
\qquad \$ 11.99 \text { per } 128 \text {-celled tray }\end{array}$ & $\$ 11.99 /$ tray \\
\hline \multicolumn{2}{|l|}{ Cost for Year-Round Production } \\
\hline $\begin{array}{l}\text { Vermiculite } \\
36 \text { trays (based on number of trays able to fill all } 4 \text { channels in HT 2) } \\
\text { Trays sown } 30 \text { times (or } 30 \text { harvests) } \\
75 \text { bags needed }\end{array}$ & $\begin{array}{l}\$ 1,403.25 / \text { year } \\
\$ 116.94 / \text { month }\end{array}$ \\
\hline $\begin{array}{l}\text { Seed } \\
\text { 9,216 seeds per 128-celled tray (if providing two seeds per cell) } \\
36 \text { trays }\end{array}$ & $\$ 2.30 /$ month \\
\hline Total (Materials + Labor + Electric $+40 \%$ shipping cost $(\$ 47.70)$ ) & $\$ 1,303.61 /$ month \\
\hline
\end{tabular}

\section{Lettuce Sales at Average Yield Rates}

$\$ 8.00 / \mathrm{lb}$ (200 g of lettuce/tray $=0.44 \mathrm{lbs} /$ tray) $\$ 8.00 / \mathrm{lb}$ (300 g of lettuce/tray $=0.66 \mathrm{lbs} /$ tray) $\$ 8.00 / \mathrm{lb}$ (400 g of lettuce/tray $=0.88 \mathrm{lbs} /$ tray) $\$ 8.00 / \mathrm{lb}$ (500 g of lettuce/tray $=1.10 \mathrm{lbs} /$ tray) $\$ 8.00 / \mathrm{lb}$ (600 g of lettuce/tray $=1.32 \mathrm{lbs} /$ tray) $\$ 8.00 / \mathrm{lb}$ (700 g of lettuce/tray $=1.54 \mathrm{lbs} /$ tray) $\$ 8.00 / \mathrm{lb}$ (800 g of lettuce/tray $=1.76 \mathrm{lbs} /$ tray)
Income (36 trays, 30 harvests per year)

$\$ 316.80 /$ month

$\$ 475.20 /$ month

$\$ 633.60 /$ month

$\$ 792.00 /$ month

$\$ 950.40 /$ month

$\$ 1,108.80 /$ month

$\$ 1,267.20 /$ month

Yield rates are listed to determine the amount of pounds needed per tray for sales. An $\$ 8.00$ per pound price premium on lettuce crops complement prices found at grocers and farmers markets. Bagged lettuce cost approximately $\$ 3.00$ for $8 \mathrm{oz}$ at local grocery stores; equivalent to $\$ 6.00$ per pound. Prices generally range from $\$ 6$ to $\$ 10$ per pound at the local farmers market. 


\section{Chapter 6: Conclusion}

The objectives of this aquaponic research project were to (1) evaluate various lettuce types and cultivars for performance in a FTS, (2) compare two harvesting methods for yield, nutrient removal, and quality in a FTS, and (3) evaluate year-round lettuce production in a pilot scale setting for yield and economic viability. Aquaponic lettuce production can be a viable option for producers to implement at aquaculture facilities.

Data collected from the lettuce variety experiment suggests that different types and cultivars can be grown in the FTS. Stand establishment and productivity of lettuce grown in the aquaponic treatment were comparable to the lettuce grown in the hydroponic treatment. Aquaponically grown lettuce crops can either be sold as whole heads or processed for the fresh-cut/ready-to-eat (RTE) market. Sales of RTE salad are increasing, with several billions of dollars sold every year in the United States (Kase et al., 2012). Although the RTE salads consist primarily of iceberg lettuce, consumers are demanding softer leaves with variations in taste, shape, and color (Martinez-Sanchez et al., 2012).

However, certain types and cultivars are suitable for aquaponic FTS production. Twenty cultivars, or $71 \%$, in the aquaponic treatment either had productivity per week that was higher or no different from the hydroponic treatment. Those cultivars included 'Winter Density', 'Rhazes', 'Speckled Amish', and 'Bambi (butterhead subtypes); 'Adriana', 'Red Cross', 'Rex', and 'Skyphos' (butterhead types); 'Vulcan' and 'Red Sails' (leaf type); 'Bionda' (a leaf subtype);

'Garrison', 'Sulu' and 'Red Saladbowl' (leaf subtypes); 'Green Forest', 'Outredgeous', and 'Jericho' (romaine types); and 'Concept', 'Magenta', and 'Teide' (crisphead subtypes) (Table 6). 
These types and cultivars can be harvested either as a cut-and-come-again (CC) or onceand-done (OD). Harvesting lettuce as a CC was more productive than lettuce harvested from the OD method. The initial lettuce crop for both harvesting methods took five weeks to until harvests. After the first harvest, lettuce grown in the OD method took another five weeks until it could be harvested again, while lettuce grown for the CC treatment was harvestable the next week. Two, salable harvests were gained in six weeks of growing time from one sowing in the CC treatment compared to two, salable harvests gained in 10 weeks of growing time from two sowings in the OD treatment. The productivity of lettuce harvested from the CC treatment started to decline following the second harvest as a result of decay and declines in visual ratings (Fig. 10; Table 13).

High quality ratings are essential to crop production for marketability to consumers. Market ratings were only significantly impacted lettuce harvests in the CC method after the second harvest. Although productivity was greater in the $\mathrm{CC}$ treatment compared to productivity in the OD treatment, it is recommended to stop production after the second harvest and resow a new lettuce crop. While some biomass was salvageable, it was time consuming to carefully harvest unaffected lettuce. Contact with decaying lettuce with tools and hands while harvesting can potentially spread the decay to other production areas. The lettuce must be handled carefully to prevent this situation. Decay can render a crop unsalable and affect profitability of the lettuce crop.

The FTS was found to be profitable when crops were harvested weekly in the harvest method comparison (Table 16) compared to the infrequent harvesting in the year-round production evaluation (Table 17). The limited harvests in winter means yields need to be higher 
during other seasons to compensate for the costs incurred during winter. A grower may increase winter harvests with grow lights to increase light intensity and photosynthetic activity. Simulating conditions in recirculating aquaponic systems (RAQS) such increased nutrient concentrations with heavier fish densities and warmer water temperatures are other methods of increasing yields. Conversely, a grower may wish to shut down an aquaponic operation during unproductive months instead of adding energy intensive equipment to the system.

Lettuce grows well in the FTS, but previous research has shown lettuce to be inefficient at nutrient removal (Buzby et al., 2009; Buzby and Lin, 2014). Overall, there was little to no removal of either nitrogen or phosphorus in most treatments. There was no difference in nutrient concentrations among influent and effluent in the type and cultivar or harvesting method objectives. Differences in removal rates was only observed in the type and cultivar experiment due to the extremely high nutrient concentrations of the hydroponic solution and significantly lower nitrogen concentrations in the spring water treatment (Table 12). When observed, removal was a single event, occurring on specific dates of each experiment. About $5 \%$ of nitrogen was removed from the aquaponic treatment in the variety trial, but it was no different than removal rates in the hydroponic and spring treatments (Table 12).

Nitrogen removal rates were greater than phosphate removal rates (Fig. 6; Fig. 11; Fig. 13). This was observed in Buzby and Lin (2014) in the same system. Phosphate is needed most for root development and most phosphate uptake would have occurred when the plants were young and decrease as the plants aged (Buzby and Lin, 2014). Preliminary experiments in the FTS determined that this system is strongly $\mathrm{N}$ limited and that additions of ammonia increased phosphate removal rates. 
Viable lettuce production can be achieved in large scale systems. However, further research is needed to quantify yields of different edible and ornamental crops and impacts on nutrient removal. Buzby et al. (2009) indicated that small-scale production of crops such as kohlrabi, nasturtium, and Swiss chard were more effective at nutrient removal than lettuce. Nutrient analysis of assimilation nutrients would be useful to determine nutrient concentration in the leaves and preferential uptake in the FTS. Development and execution of a marketing plan is also necessary to evaluate profitability and provide hard financial data to support projections. 


\section{Literature Cited}

Adediran, J.A., 2005. Growth of tomato and lettuce seedlings in soilless media. J. of Vegetable Sci. 11(1): 5-15

Adler, P.R., J.K. Harper, F. Takeda, E.M. Wade, and S.T. Summerfelt. 2000. Economic evaluation of hydroponics and other treatment options for phosphorus removal in aquaculture effluent. HortScience 35: 993-999

APHA (American Public Health Administration). 1995. Standard methods for the examination of water and wastewater, $19^{\text {th }}$ Ed. American Public Health Administration, Washington, D.C.

Blidariu, F. and A. Grozea. 2011. Increasing the economical efficiency and sustainability of indoor fish farming by means separation of aquaponics - review. Animal Sci. and Biotech 44(2): 1-8

Blidariu, F., I. Radulov, D. Lalescu, A. Drasovean, and A. Grozea. 2013. Evaluation of nitrate level in green lettuce conventional grown under natural conditions and aquaponic system. Animal Sci. Biotech. 46(1): 244-250.

Borrelli, K., R.T. Koenig, B.M. Jaeckel, and C.A. Miles. 2013. Yield of leafy greens in high tunnel winter production in the Northwest United States. HortScience 48(2): 183-188

Buzby, K.M., and L. Lin. 2014. Scaling aquaponic systems: Balancing plant uptake with fish output. Aquacultural Eng. 63: 39-44

Buzby, K.M., T.P. West, X. Wei, and K. Semmens. 2009. Nutrient removal by aquaponic crops.

Caliskan, S., H. Yetisir, S. Karanlik. 2014. Combined use of green manure and farmyard manure allows better nutrition of organic lettuce. Notulae Botanicae Horti Agrobotanici ClujNapoca. 42(1): 248-254

Castoldi, N., L. Bechini, and A. Ferrante. 2011. Fossil energy usage for the production of baby leaves. Energy 36: 86-93

Chon, S., H. Boo, B. Heo, S. Gorinstein. 2012. Anthocyanin content and the activities of polyphenol oxidase, peroxidase, and phenylalanine ammonia-lyase in lettuce cultivars. Intl. J. of Food Sci. and Nutr. 63(1): 45-48

Committee on Env. And Natural Resources (CENR) - National Science and Technology Council (NSTC). 2003. An assessment of coastal hypoxia and eutrophication in U.S. waters. NSTC, Washington, D.C. 
Diver, S. 2006. Aquaponics - Integration of hydroponics with aquaculture. ATTRA Horticulture Systems Guide, <http://attra.ncat.org/attra-pub/aquaponic.html>. 27 Oct. 2010

Dufault, R.J., B. Ward, R.L. Hassell. 2009. Dynamic relationships between field temperatures and romaine lettuce yield and head quality. Scientia Horticulturae 120(4): 452-459

Dyer, D.J. 2006. Effectiveness of aquatic phytoremediation of nutrients via watercress (Nasturtium officinale), basil (Ocimum basilicum), dill (Anethum graveolens) and lettuce (Lactuca sativa) from effluent of a flow-through aquaculture operation. MS Thesis. West Virginia University, Morgantown 2

Graber, A. and R. Junge. 2009. Aquaponic systems: Nutrient recycling from fish wastewater by vegetable production. Desalination 246: 147-156

Gilbert, P.M. 2007. Eutrophication and harmful algal blooms: A complex global issue, examples from the Arabian Seas including Kuwait Bay, and an introduction to the Global Ecology and Oceanography of Harmful Algal Blooms (GEOHAB) Programme. Intl. J. of Oceans and Oceanography 2(1): 157-169

Guadagnin, S.G., S. Rath, F.G.R. Reyes. 2005. Evaluation of the nitrate content in leaf vegetables produced through different agricultural systems. Food Additives and Contaminants 22(12): 1203-1208

Idaho Division of Environmental Quality (IDEQ). 1998. Idaho waste management guidelines for aquaculture operations. Idaho Department of Health and Welfare, Division of Envrionmentla Quality. Twin Falls, ID

Jones, J.B. 2005. Hydroponics: A practical guide for the soilless grower. $2^{\text {nd }}$ Ed. CRC Press, Boca Raton, Fla

Kader, A.A., W.J. Lipton, and L.L. Morris. 1973. Systems for scoring quality of harvested lettuce. HortScience 8(5): 408-409.

Kase, J.A., S. Borenstein, R.J. Blodgett, P.C.H. Feng. 2012. Microbial quality of bagged baby spinach and romaine lettuce effects of top versus bottom sampling. J. of Food Protection 75(1): 132-136

Kenny, O. and D. O'Beirne. 2009. The effects of washing treatment on antioxidant retention in ready-to-use iceberg lettuce. Int. J. of Food Sci. and Tech 44: 1146-1156

Kitsiou, D. and M. Karydis. 2011. Coastal marine eutrophication assessment: A review on data analysis. Env. Intl. 37: 778-801 
Lee, A., F. Liao, and H. Lo. 2012. 'Taoyuan No. 1': A high-yielding Batavia lettuce cultivar high in total phytochemicals and dietary fiber. HortScience 47(12): 1815-1816

Lennard, W.A. and B.V. Leonard. 2004. A comparison of reciprocating flow versus constant flow in an integrated, gravel bed, aquaponic test system. Aquaculture Intl. 12: 539-553

Lennard, W.A. and B.V. Leonard. 2006. A comparison of three different hydroponic subsystems (gravel bed, floating, and nutrient film technique) in an aquaponic test system. Aquacult. Intl. 14: 539-550

Liang, J., and Y. Chien. 2013. Effects of feeding frequency and photoperiod on water quality and crop production in tilapia-water spinach raft aquaponics system. Intl. Biodeterioration and Biodegradation 85: 693-700

Love, D.C., J.P. Fry, L. Genello, E.S. Hill, J.A. Frederick, X. Li, K. Semmens. 2014. An international survey of aquaponics practitioners. Plos One 9(7): e102662

Liu, W.K. and Q.C. Yang. 2012. Effects of short-term treatment with various light intensities and hydroponic solutions on nitrate concentration of lettuce. Acta Agriculturae Scandinavica Section B - Soil and Plant Science. 62: 109-113

Martinez-Sanchez, A., M.C. Luna, M.V. Selma, J.A. Tudela, J. Abad. 2011. Baby-leaf and multileaf of green and red lettuces are suitable raw materials for the spring-cut industry. Postharvest Biol. and Tech. 63:1-10

Martins, C.I.M., E.H. Eding, M.C.J. Verdegem, L.T.N. Heinsbroek, O. Schneider, J.P. Blancheton, E. Roque d'Orbcastel, J.A.J. Verreth. New developments in recirculating aquaculture systems in Europe: A perspective on environmental sustainability. Aquacult. Eng. 43(3): 83-93

Meade, J.W. 1989. Aquaculture Management. Van Nostrand Reinhold, New York, NY

Mikel, M.A., 2007. Genealogy of contemporary North American lettuce. HortScience 42(3): 489-493

Mou, B., 2008. Handbook of Plant Breeding - Vegetables I: Asteraceae, Bassicaceae, Chenopodicaceae, and Cuburbitaceae. p. 75-116. In: J. Prohens and F. Nuez (eds.). Lettuce. Springer, New York City, NY

Myung-Min, O., E.E. Carey, C.B. Rajashekar. 2009. Environmental stresses induce healthpromoting phytochemicals in lettuce. Plant Physiol. and Biochem. 47: 578-583 
Gomes Neto, N.J., R.M.L. Pessoa, I.M.B. Nunes Queiroga, M. Magnani, F.I. de Sousa Freitas, E.L. de Souza, J.F. Maciel. 2012. Bacterial counts and the occurrence of parasites in lettuce (Lactuca sativa) from different cropping systems in Brazil. Food Control 28: 47-51

Oziel, J., and T. Oziel. 2013. A basic overview of growing food in water along with fish. Water Garden J. 28(2): 6

Rakocy, J.E., M.P. Masser, and T.M. Losordo. 2006. Recirculating aquaculture tank production systems: Aquaponics - integrating fish and plant culture. Southern Regional Aquaculture Center 454: 1-16

Rakocy, J.E., D.S. Bailey, R.C. Shultz, and E.S. Thoman. 2004. Aquaponic production of tilapia and basil: Comparing a batch and staggered cropping system. Acta Hort. (ISHS) 648: 6369

Rakocy, J.E. 2007. Aquaponics: Vegetable hydroponics in recirculating systems. P. 631-672. In: M.B. Timmons and J.M. Ebeling (eds). Recirculating aquaculture systems. $2^{\text {nd }}$ Ed. Cayuga Aqua Ventures, Ithaca, NY

Rakocy, J.E., D.S. Bailey, K.A. Shultz, and W.M. Cole. 2007. Evaluation of a commercial-scale aquaponic unit for the production of tilapia and lettuce. P. 357-372. In: K. Fitzsimmons (eds). Tilapia aquaculture: proceedings of the fourth international symposium on tilapia in aquaculture, Orlando, FL

Rana, S., S.K. Bag, D. Golder, S. Mukherjee, C. Pradhan, and B.B. Jana. 2011. Reclamation of municipal domestic wastewater by aquaponics of tomato plants. Ecol. Eng. 37: 981 988

Roosta, H.R., and M. Hamidpour. 2011. Effects of foliar application of some macro- and micronutrients on tomato plants in aquaponic and hydroponic systems. Scientia Horticulturae 129: $329-402$

Saleh, M.M.S., A.M. Abu-Rayyan, and M.A. Suwwan. 2009. Planting date, mulching, lettuce type, and cultivar on lettuce productivity and quality. Intl. J. of Vegetable Sci. 15: 381401

Savvas, D., H.C. Passam, C. Olympios, E. Nasi, E. Moustaka, N. Mantzos, and P. Barouchas. 2006. Effects of ammonium nitrogen on lettuce grown on pumice in a closed hydroponic system. Hort Sci 41(7): 1667-1673

Savidov, N. 2004. Evaluation and development of aquaponic production and product market capabilities in Alberta. IDS Initiatives Fund Report 
Sheng, Z., L. Jinghong, W. Shiqiang, G. Jixi, W. Dingyong, Z. Ke. 2006. Impact of aquaculture on eutrophication in Changshou Reservoir. Chinese J. of Geochem. 25(1): 90-96

Sindilariu, P.-D., C. Schulz, R. Reiter. 2007. Treatment of flow-through trout aquaculture effluents in a constructed wetland. Aquaculture 280: 92-104

Snow, A., B. Anderson, and B. Wootton. 2012. Flow-through land-based aquaculture wastewater and its treatment in subsurface flow constructed wetlands. Environ. Rev. 20(1): 54-69

Timmns, M.B. and J.M. Ebeling. 2010. Recirculating Aquaculture Systems. $2^{\text {nd }}$. Cayuga Aqua Ventures. Ithaca, NY. NRAC Publication No. 401-2010

Tudela, J.A., A. Marin, A. Martinez-Sanchez, M.C. Luna, M.I. Gil. 2013. Pre-harvest and postharvest factors related to off-odors of spring-cut iceberg lettuce. Postharvest Biol. and Tech 86: 463-471

Tyson, R.V., E.H. Simmone, D.D. Treadwell, M. Davis, J.M. White. 2008. Effect of water pH on yield and nutritional status of greenhouse cucumber grown in recirculating hydroponics. J. of Plant Nutr. 31(11): 2018-2030

Tyson, R.V., D.D. Treadwell, and E.H. Simonne. 2011. Opportunities and challenges to sustainability in aquaponics systems. HortTech. 21(1): 6-13

U.S. Department of Agriculture, National Statistics Service. 2007. 2005 Census of Aquaculture: Summary of aquaculture products sold by species and size category. U.S. Dept. of Agr., Washington, D.C.

U.S. Department of Agriculture, National Statistics Service. 2014. 2012 Census of Aquaculture. U.S. Dept. of Agr., Washington, D.C.

U.S. Department of Agriculture, National Statistics Service. 2014. Trout production 2013. U.S. Dept. of Agr., Washington, D.C.

Weiguo, F., P. Li, Y. Wu, J. Tang. 2012. Effects of different light intensities on anti-oxidative enzyme activity, quality, and biomass in lettuce. Hort. Sci (Prague) 39: 129-134

Western Region SARE Research Innovations. 2013. Organic winter production scheduling in unheated high tunnels in Colorado. U.S. Dept. of Agr., Washington, D.C.

Wu, B.M., S.T. Koike, and K.V. Subbarao. 2011. Impact of consumer-driven changes to crop production practices on lettuce drop caused by Sclerotinia sclerotiorum and S. minor. Phytopathology 101: 340-348 
Vallance, J., F. Deniel, G. LeFloch, L. Guerin-Dubrana, D. Blanchard, P. Rey. 2011. Pathogenic and beneficial microorganisms in soilless cultures. Agron. Sustain. Dev. 31: 191-203

Viadero Jr., R.C., J.H. Cunningham, K.J. Semmens, A.E. Tierney. 2005. Effluent and production impacts of flow-through aquaculture operations in West Virginia. Aquacultural Eng. 33: 258-270

Zlotek, U., M. Swieca, A. Jakubczyk. 2014. Effect of abiotic elicitation on main healthpromoting compounds, antioxidant activity, and commercial quality of butter lettuce (Lactuca sativa L.). Food Chem. 148: 253-260 